\title{
Near-Infrared Dyes for Two-Photon Absorption in the Short-Wavelength Infrared: Strategies Towards Optical Power Limiting†
}

\author{
Simon Pascal, ${ }^{* a, b}$ Sylvain David, ${ }^{a}$ Chantal Andraud ${ }^{a}$ and Olivier Maury*a
}

a. Université de Lyon 1, ENS Lyon, Laboratoire de Chimie, CNRS UMR 5182, 46 allée d'Italie, 69364 Lyon, France.

b. Aix Marseille Univ, CNRS UMR 7325, Centre Interdisciplinaire de Nanoscience de Marseille (CINaM), Campus de Luminy, 13288

Marseille cedex 09, France.

† Dedicated to Prof. Joseph W. Perry, on the occasion of his retirement.

E-mail: pascal@cinam.univ-mrs.fr; olivier.maury@ens-lyon.fr

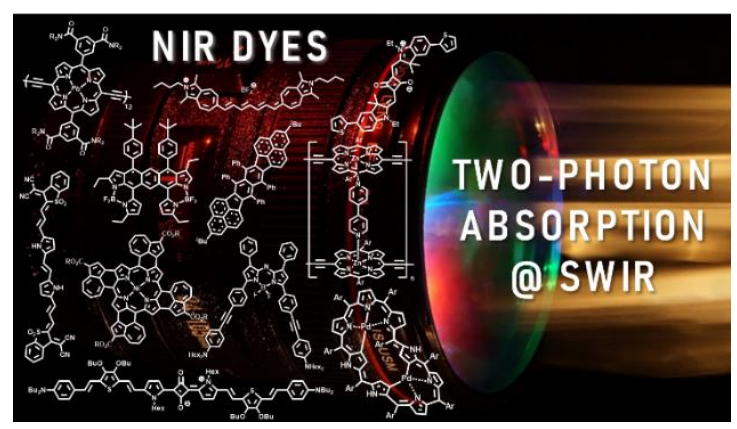

This work provides an overview of the recent advances in the field of two-photon absorbing chromophores active in the short-wavelength infrared (SWIR) spectral range. Herein the common strategies and main structure-properties relationships that lead to a near-infrared (NIR) electronic absorption of chromophores are described. A complete review of the molecules that feature two-photon absorption (2PA) beyond $1100 \mathrm{~nm}$ is presented for the purpose of further use in optical power limiting applications in the SWIR band. Recent progresses in the development of optical power limiting in this particular spectral region are reported with emphasis on the use of two-photon induced excited state absorption (ESA) process as optical power limiting enhancer.

\section{Introduction}

Sixty years ago, T. Maiman fired the first laser beam of history. ${ }^{1}$ Since then, thanks to continuous development of photonics and optronics, lasers are blooming in critical sectors such as aeronautics, defence, industry and medicine. Among the numerous discoveries that followed this event, Kaiser and Garrett used this newly available powerful coherent light to prove experimentally the existence of two-photon absorption (2PA), a third order nonlinear optic (NLO) phenomenon that consists in the simultaneous absorption of two photons of same frequency $\omega$ or different frequencies $\omega_{1}$ and $\omega_{2}$ via a virtual state (Figure 1) that was theoretically predicted in 1931 by Maria Göppert-Mayer (Figure 2). ${ }^{2}$

Since all nonlinear optical phenomena can be only observed under a very intense light irradiation, the experimental demonstration was only achieved in 1961 by observing the excited luminescence of $\mathrm{Eu}(\mathrm{II})$ ions in $\mathrm{CaF}_{2}$ :Eu using Maiman's ruby laser. ${ }^{3}$ Upon irradiation at $694 \mathrm{~nm}$, the blue emission of europium (II) at $425 \mathrm{~nm}$ is observed and its intensity is proportional to the square of the incident laser intensity, which is a characteristic signature of two-photon excited luminescence. Two years later in 1963, Peticolas and coworkers reported the TPEF of hydrocarbon crystals under ruby irradiation in a paper entitled "Double Photon Excitation in Organic Crystals" 4 which set the beginning of the design of organic chromophores for nonlinear optical applications, a currently wide and very active field of research.

Since these seminal reports, the development of NLO in general and 2PA in particular is closely related to the technical laser improvements and their availability for academic or industrial researchers. The 70's and the 80 's were dominated by the famous nanosecond pulsed Nd:YAG laser at $1064 \mathrm{~nm}$. During this period the two-photon spectroscopy remained confidential and was mainly focused on inorganic semiconducting materials, atoms or small molecules, the synthetic organic chemists community was mainly focused on the design of chromophores for second order NLO phenomenon like second harmonic generation, ${ }^{5-8}$ to which twophoton excited fluorescence (TPEF) could superimpose and was considered as a parasite effect.

The 1990's, with the increasing availability of femtosecondpulsed Ti:Sapphire tunable laser in the $700-900 \mathrm{~nm}$ spectral range (now extended to $700-1050 \mathrm{~nm}$ ), marked the explosion of TPEF organic dyes under the impulsion of several researchers

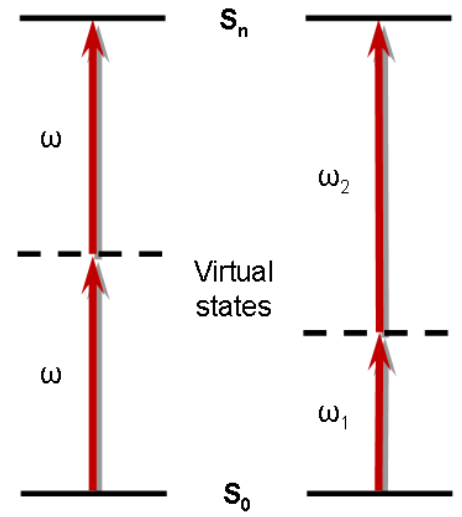

Figure 1. Degenerated (left) and non-degenerated (right) two-photon absorption processes. 


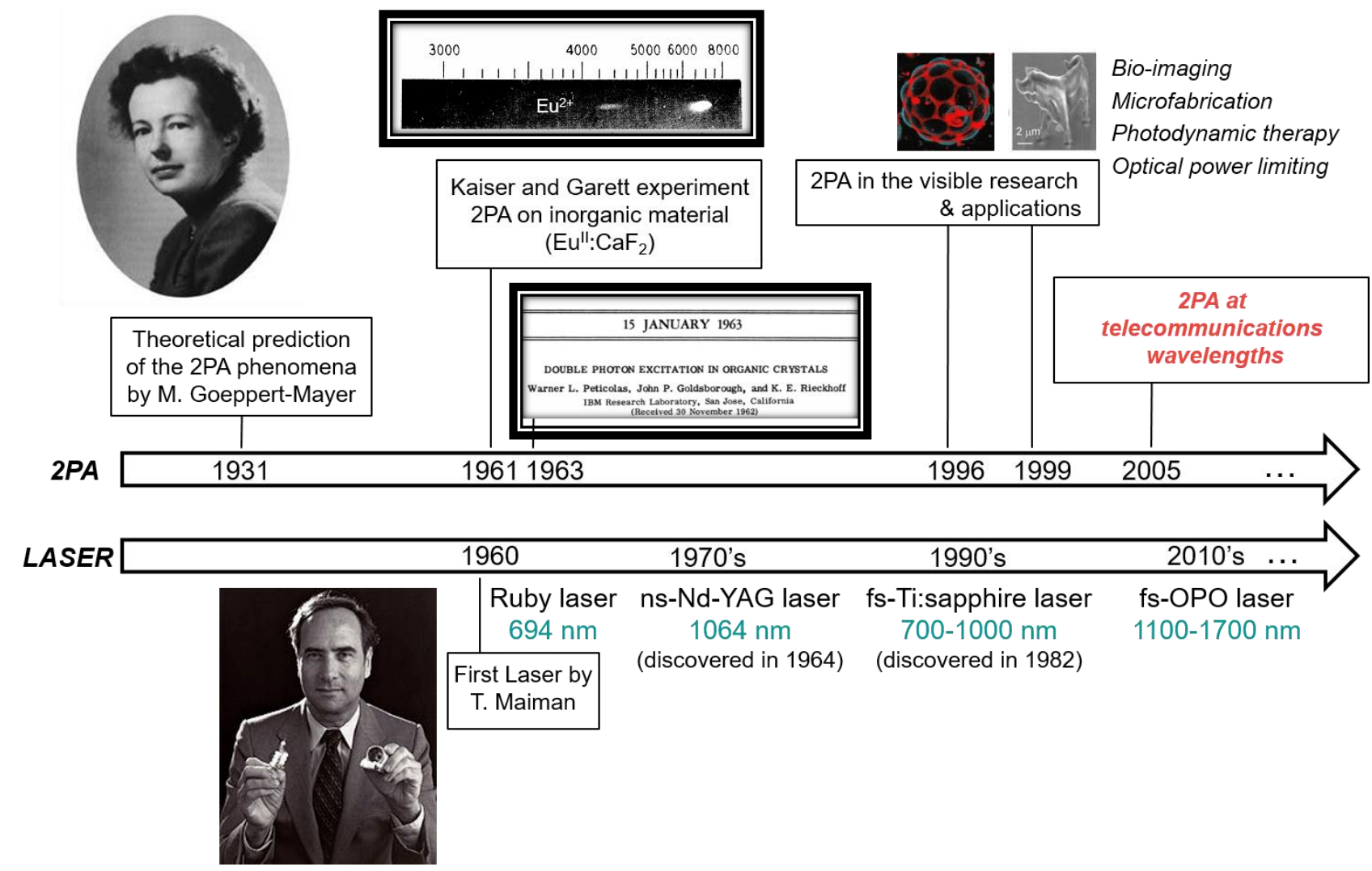

Figure 2. Parallel development of laser technologies and 2PA.

around the world among which the groups of Belfield, Blanchard-Desce, Marder, Prasad, Van Stryland, and our group (arbitrary list established according to SciFinder), who set the molecular engineering rules for 2PA optimization. ${ }^{9-14}$ This research area was strongly stimulated by the new applications that appeared during this period, taking benefit of the intrinsic advantages of two-photon excitation: (i) its confocal character giving rise to the 3D-resolution and (ii) the excitation at half energy localized in the near-infrared spectral range (NIR, ca. 700-1100 nm). In 1996, Webb and co-workers set the basis of two-photon microscopy for bio-imaging applications, a technique nowadays present in many universities and hospital imaging platforms. ${ }^{15-20}$ Several other important applications were developed during the same period among which 3D microfabrication ${ }^{21-25}$ and optical data storage, ${ }^{26-28}$ two-photon photodynamic therapy ${ }^{29-31}$ or anion sensing, ${ }^{32}$ and finally optical power limiting (OPL), ${ }^{33-35}$ which consists in the nonlinear absorption of high intensity light in order to protect optical detectors.

During the last decade, tunable fs-laser based on the optical parametric oscillator (OPO) technology became available, extending the excitation range in the short-wavelength infrared range (SWIR), from ca. $1100 \mathrm{~nm}$ up to $2500 \mathrm{~nm}$. This technological evolution triggered the design of new organic dyes featuring optimized 2PA in this emerging spectral range, which could be used for deep bio-imaging. Moreover, recent researches in aeronautics and civilian transportations explore the possibility for laser assisted guiding systems thanks to active imaging and LIDAR (light detection and ranging) technologies.
These new developments, in particular concerning autonomous vehicles, will be accessible in a close future to a large public audience and make one fear the temporary or permanent damaging of on-board optical devices by a high intensity light beam from hostile laser sources or just from parasite reflections on environmental elements. Since the beginning of the 2000 's, these security concerns stimulated the broad use of eye-safe lasers source working in the SWIR and the new search for OPL devices in this particular spectral range.

In this review, we summarized the research endeavours, mainly conducted these last two decades, to displace the 2PA of chromophores in the SWIR and to optimize their efficiency. In Section 1, the classical molecular engineering rules governing the 2PA optimization in the $700-900 \mathrm{~nm}$ range are reminded using selected relevant examples; in Section 2, the different strategies to shift the one-photon absorption (1PA) far into the red are illustrated and the classical NIR dye families are described. In Section 3, chromophores featuring 2PA in the $1100-1700 \mathrm{~nm}$ range are compiled in view of their potential use for 2PA-based optical power limiting, an emerging application in this spectral range at the centre of Section 4.

\section{Two-photon absorption: principle and molecular engineering rules}

A detailed description of all the physics describing twophoton absorption phenomenon is beyond the scope of this article and, since this aspect was already extensively reviewed, ${ }^{9-}$ 
$14,36,37$ only the broad outline is presented here. Basically, the attenuation of a light beam of irradiance / through an isotropic medium according to $z$ axis follows the propagation equation (1):

$$
\frac{d I}{d z}=-\alpha_{1} I-\alpha_{2} I^{2}-\alpha_{3} I^{3} \ldots
$$

where $\alpha_{1}, \alpha_{2}$ and $\alpha_{3}$ represent the linear (1PA), two-photon (2PA) and three photon (3PA) absorption coefficients, respectively. The linear absorption coefficient $\alpha_{1}$ is related to the molar extinction coefficient $\varepsilon$. Under very intense laser irradiation and assuming that no linear absorption occurs at the incident wavelength, the nonlinear contributions can be observed and equation (1) is generally approximated to its second term, underlining that the 2PA process is proportional to the square of the incident irradiance. At the molecular level, the 2PA cross-section, $\sigma_{2 P A}$ is related to the 2PA coefficient $\alpha_{2}$ according to relationship (2):

$$
\sigma_{2 P A}=\frac{h v}{N_{0}} \alpha_{2}=\frac{h v}{N_{a} C * 10^{-3}} \alpha_{2}
$$

where $h v$ is the incident photon energy (in J), $N_{0}$ the molecular density, $N_{a}$ the Avogadro constant and $C$ the concentration in mol L-1. $\sigma_{2 P A}$ is generally expressed in Göppert-Mayer (GM, 1 $\mathrm{GM}=10^{-50} \mathrm{~cm}^{4} \mathrm{~s}$ ) and can be measured by several techniques, including the most popular open-aperture z-scan and twophoton induced fluorescence ones (vide infra). The 2PA crosssection is linked to the $3^{\text {rd }}$ order polarizability tensor $v$ through the equation (3). ${ }^{38}$

$$
\sigma_{2 P A}=\frac{3 \hbar \omega^{2}}{2 \varepsilon_{0} n^{2} c^{2}} \operatorname{Im}[\gamma(-\omega ; \omega, \omega,-\omega)]
$$

Then, using a perturbative approach, it was shown that this expression can be expressed by the relationship approximated by the Orr and Ward ${ }^{39}$ sum-over states relationship (4) along all excited states, where $P(i, j, k, l ;-\omega ; \omega, \omega,-\omega)$ is a permutation operator, $|0\rangle$ is the ground state, and $|m\rangle,|n\rangle$ and $|p\rangle$ are excited states. $\left\langle 0\left|\mu_{i}\right| m\right\rangle$ and $\left\langle m\left|\bar{\mu}_{l}\right| n\right\rangle$ correspond respectively to the components $\mu_{0 m}^{i}$ and $\mu_{m n}^{i}$ of the transition dipole moment between $|0\rangle$ and $|m\rangle$ and between $|m\rangle$ and $|n\rangle$ along the axis $i$ of the molecule; $\left\langle n\left|\overline{\mu_{l}}\right| n\right\rangle$ is the the component of the static dipole moment difference $\mu_{n n}^{i}=\Delta \mu_{0 n}^{i}$ along the axis $\hbar \omega_{m 0}$ is the energy $E_{0 m}$ of the excited sate $|m\rangle$, while $\Gamma_{m 0}$ is the homogeneous width associated to the state $|m\rangle$.

$$
\begin{aligned}
& \gamma_{i j k l}(-\omega ; \omega, \omega,-\omega)=\frac{1}{6 \hbar^{3}} P(i, j, k, l ;-\omega ; \omega, \omega,-\omega) \times \\
& {\left[\begin{array}{l}
\sum_{m \neq 0} \sum_{n \neq 0} \sum_{p \neq 0} \frac{|0| \mu_{i}|m\langle\rangle| m\left|\bar{\mu}_{j}\right| n\langle\rangle n\left|\bar{\mu}_{k}\right| p\langle\rangle\left|\mu_{l}\right| 0<}{\left(\omega_{m 0}-\omega-i \Gamma_{m 0}\right)\left(\omega_{n 0}-2 \omega-i \Gamma_{n 0}\right)\left(\omega_{p 0}-\omega-i \Gamma_{p 0}\right)} \\
-\sum_{m \neq 0} \sum_{n \neq 0} \frac{\left.\gamma 0\left|\mu_{i}\right| m\langle\rangle m\left|\mu_{j}\right| 0\langle\rangle\left|\mu_{k}\right| n\langle\rangle\left|\mu_{l}\right| 0\right\rangle}{\left(\omega_{m 0}-\omega-i \Gamma_{m 0}\right)\left(\omega_{n 0}-\omega-i \Gamma_{n 0}\right)\left(\omega_{n 0}+\omega-i \Gamma_{n 0}\right)}
\end{array}\right]}
\end{aligned}
$$

The two-level or three level model ${ }^{40}$ allows to express (4) for the lowest 2PA states in the case of dipolar or symmetrical molecules respectively, according to (5):

$\operatorname{Im} \gamma(-\omega ; \omega, \omega,-\omega)=$

$$
\operatorname{Im} P\left[\begin{array}{c}
-\frac{\mu_{01}^{4}}{\left(E_{01}-\hbar \omega-i \Gamma_{01}\right)^{2}\left(E_{01}+\hbar \omega+i \Gamma_{01}\right)}(N) \\
+\frac{\mu_{01}^{2} \Delta \mu_{01}^{2}}{\left(E_{01}-\hbar \omega-i \Gamma_{01}\right)^{2}\left(E_{01}-2 \hbar \omega-i \Gamma_{01}\right)}(D i p) \\
+\frac{\mu_{01}^{2} \mu_{12}^{2}}{\left(E_{01}-\hbar \omega-i \Gamma_{01}\right)^{2}\left(E_{02}-2 \hbar \omega-i \Gamma_{01}\right)}(2 P)
\end{array}\right]
$$

where $\mu_{01}$ is the transition dipolar moment between the ground state and the lowest excited state $\mathrm{S}_{1}, \mathrm{E}_{01}$ the corresponding energy transition, $\Gamma_{01}$ the associated damping factor, fixed at a constant value, and $\Delta \mu_{01}$ the difference between the dipolar moment of the ground state $S_{0}$ and the excited state $S_{1}$.

The expression (5) consists of three terms : (i) the negative term $(N)$, contributing only for a one-photon resonance and being neglected for 2PA; (ii) the two-photon term (2P), related to a $2 \mathrm{PA}$ resonance with the excited state $|2\rangle$ and specific for centrosymmetric molecules (Figure 3, right); (iii) the dipolar term (Dip), which cancels for symmetrical systems and corresponds to a 2PA resonance with the lowest singlet excited state $|1\rangle$ (as shown on Figure 3 , left). This expression can rationalize the role of the molecular symmetry for most of the two-photon active non-centrosymmetric dyes. A spectral overlapping between the lowest linear transition and the 2PA with half scale is observed in most cases while, for centrosymmetric molecules, the 2PA selection rules differ from those of linear absorption and higher excited states are mostly involved (Figure 3).

Experimentally, the 2PA cross-section can be measured using various methods, the most common ones being nonlinear transmission, open aperture z-scan, two-photon induced fluorescence and non-degenerated 2PA. The nonlinear transmission (NLT) method enables the simple recording of the transmitted light intensity in function of the incident intensity. While this ratio is constant in the case of linear absorption, a deviation is observed for a nonlinear absorption. ${ }^{41}$ This method leads to the determination of $\alpha_{2}$ and hence $\sigma_{2 \mathrm{PA}}$ using the equation (2). The principal disadvantage of this method is the difficulty to differentiate the nonlinear absorption caused by 2PA from other nonlinear phenomena such as higher multiphonic absorption and second harmonic generation or, especially when long laser pulses are used (i.e. $>10^{-12} \mathrm{~s}$ ), the nonlinear absorption caused by excited state reabsorption at the incident laser wavelength; these competing processes can therefore lead to high overestimations of the 2PA crosssections. ${ }^{41,} 42$

The open-aperture z-scan method is a variation of the NLT technique. $9,43,44$ The transmitted intensity is measured as a function of the $z$ coordinates of a one-dimension axis from the

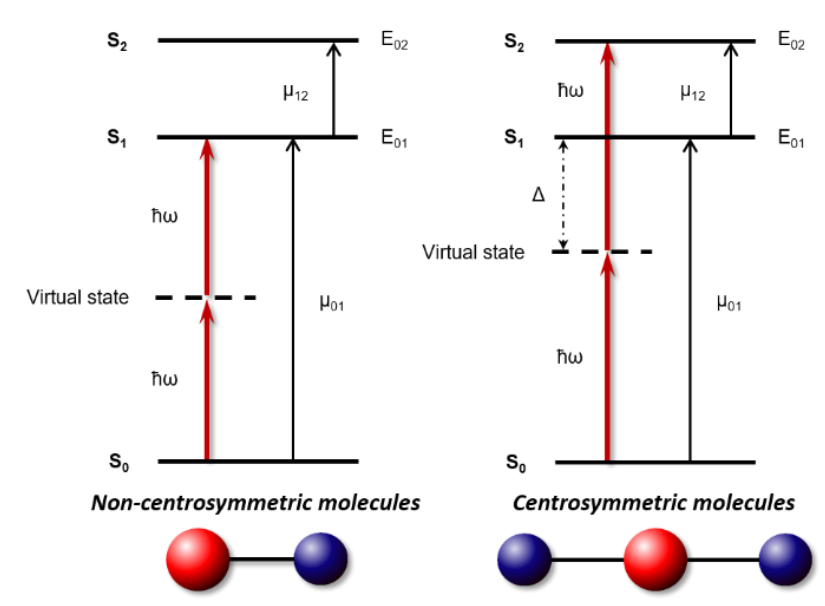


Figure 3. Symmetry effect on the two-photon absorption process. The blue and red spheres are schematic representations of donor and acceptor units.

focus point. The real and imaginary parts of the third order polarizability can be calculated separately and the $\sigma_{2 \mathrm{PA}}$ value is determined via equation (2). Again, much effort has to be made to differentiate 2PA from other phenomena when doing the measurement to avoid overestimated results.

Another common technique consists in measuring the twophoton excited fluorescence (TPEF). 45,46 The experiment requires the external calibration of the fluorescence excitation spectrum using a set of references with known cross-section over the studied spectral range. The measurement gives access to the product of fluorescence quantum yield and 2PA crosssection $\left(\Phi \times \sigma_{2 \mathrm{PA}}\right)$. The main disadvantage is that the method is limited to fluorescent molecules and requires a preliminary determination of the quantum yield $\Phi$. When this $\Phi$ value is low, which is generally the case for NIR dyes, the uncertainty of this measurement can have a dramatic influence in the global precision of the $\sigma_{2 \mathrm{PA}}$ determination process. ${ }^{47}$ Moreover, it cannot be applied in a region where 1PA also occurs and solvent overtone can have an influence on the measurement.

Finally, non-degenerated 2PA (ND-2PA) is measured using a pump-probe configuration with two beams. ${ }^{48}$ The pump consists in an intense and monochromatic infrared laser beam whereas the probe is a white-light continuum beam (WLC) of weaker intensity. This method allows the simultaneous absorption of two photons that differs in term of energy. Since the irradiation energy from the pump is known, the analysis of the probe spectral changes gives access to the relative ND-2PA spectrum of the sample. It is worth noting that due to the intrinsic error of the different methods used and the difficulty to differentiate all nonlinear phenomena, $\sigma_{2 \mathrm{PA}}$ values must be preferably compared when measurements methods and conditions are the same. Nevertheless, similar trends are generally observed between the different methods.

The basic structure-properties relationships in $2 \mathrm{P}$-absorbing organic dyes have been previously described in the literature, ${ }^{9}$, 12 thus only few key examples that are necessary for the general understanding of the concepts will be detailed in the following paragraphs. As all NLO effects, 2PA is highly related to intramolecular charge transfer (ICT) and the design of noncentrosymmetric dipolar molecules, i.e. an electron-donating (D) and an electron-withdrawing (A) extremities linked by a $\pi$ conjugated bridge, was explored in the first instance (Figure 4). ${ }^{33}$ The most common donor groups are tertiary amine, ether or thioether, whereas typical acceptors are nitro, aldehyde, cyano or trifluoromethanesulfonyl functions. ${ }^{12}$ As example, introduction of ICT via incorporation of a dibutylamino electrondonor and a nitro acceptor function on trans-stilbene 1 drastically enhances the nonlinear optical properties of the molecule. The 2PA cross-section is increased by one order of magnitude, from $8 \mathrm{GM}$ for 1 to $108 \mathrm{GM}$ for dimethylamino-4'stilbene $\mathbf{2}$, and the maximum of nonlinear absorption is shifted towards lower energies. ${ }^{49,} 50$

The series $\mathbf{3} \mathbf{a}-\mathbf{b}$ illustrates the influence of the electronwithdrawing strength of the acceptor moiety on the 2PA cross- section: replacement of a weak phosphonate acceptor with a stronger nitro function results in a significant increase of the $\sigma_{2 \mathrm{PA}}$ value from $650 \mathrm{GM}$ (3a) to $1300 \mathrm{GM}$ (3b), accompanied by

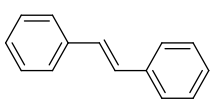

$\sigma_{2 \mathrm{PA}}=8 \mathrm{GM}$ at $514 \mathrm{~nm}$ (fs-TPEF)

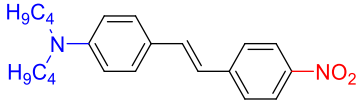

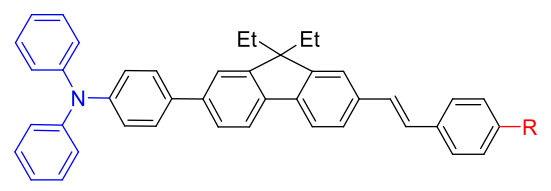

3a $\quad \mathrm{R}=\mathrm{PO}(\mathrm{OEt})_{2} \quad \sigma_{2 \mathrm{PA}}=650 \mathrm{GM}$ at $605 \mathrm{~nm}$ (fs-WLC) 3b $\mathrm{R}=\mathrm{NO}_{2} \quad \sigma_{2 \mathrm{PA}}=1300 \mathrm{GM}$ at $670 \mathrm{~nm}(\mathrm{fs}-\mathrm{WLC})$

$\mathrm{R}$

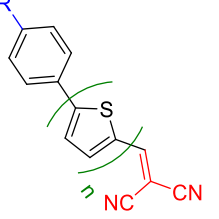

4a $\mathrm{n}=1, \mathrm{R}=\mathrm{H}$

$\sigma_{2 \mathrm{PA}}=28 \mathrm{GM}$ at $820 \mathrm{~nm}$ (fs-TPEF)

4b $\mathrm{n}=1, \mathrm{R}=\mathrm{OMe}$

$\sigma_{2 \mathrm{PA}}=95 \mathrm{GM}$ at $880 \mathrm{~nm}$ (fs-TPEF)

4c $\mathrm{n}=1, \mathrm{R}=\mathrm{OEt}$

$\sigma_{2 \mathrm{PA}}=108 \mathrm{GM}$ at $880 \mathrm{~nm}$ (fs-TPEF)

4d $\mathrm{n}=1, \mathrm{R}=\mathrm{NMe}_{2}$

$\sigma_{2 \mathrm{PA}}=176 \mathrm{GM}$ at $1050 \mathrm{~nm}$ (fs-TPEF)

4e $n=2, R=O E t$ (fs-TPEF)

$1^{\text {st }}$ band: $\sigma_{2 P A}=125 \mathrm{GM}$ at $1040 \mathrm{~nm}$

$2^{\text {nd }}$ band: $\sigma_{2 P A}=210 \mathrm{GM}$ at $930 \mathrm{~nm}$

4f $n=2, R=N_{2}$ (fs-TPEF)

$1^{\text {st }}$ band: $\sigma_{2 \mathrm{PA}}=600 \mathrm{GM}$ at $1190 \mathrm{~nm}$

$2^{\text {nd }}$ band: $\sigma_{2 P A}=570 \mathrm{GM}$ at $1100 \mathrm{~nm}$

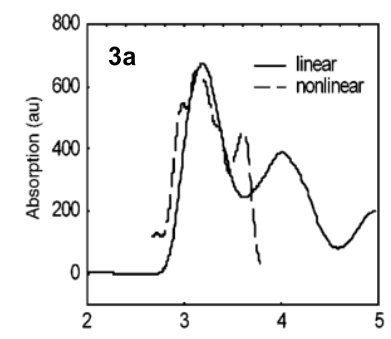

Photon energy (pump and probe) (eV)

Figure 4. Influence of intramolecular charge transfer on 2PA. Comparison of the linear absorption (plain line) and 2PA (dashed line) of dipole 3a in acetonitrile solution. Adapted with permission from reference ${ }^{48}$. Copyright 1999 American Chemical Society.

a red-shift of the 2PA maximum wavelength. ${ }^{48}$ In both cases, the main 2PA band can be superimposed to the lower energy 1PA band with half-energy scale, as a consequence of the noncentrosymmetry of the system. The nature of the electrondonating function also plays an important role: while compound 4b, incorporating a moderate electron-donor, exhibits a 2PA of $95 \mathrm{GM}$ at $880 \mathrm{~nm}$, the introduction of a tertiary amine in dye $\mathbf{4 d}$ leads to a noticeable red-shift of the nonlinear absorption and an enhancement of the cross-section (176 GM at $1050 \mathrm{~nm}$ ). ${ }^{51}$ Not surprisingly, the comparison between $\mathbf{4 a - d}$ and $\mathbf{4 e - f}$ shows that the lengthening of the $\pi$-conjugated backbone results in a red-shift of the electronic transitions, accompanied by a remarkable enhancement of the 2PA cross-section, up to 600 $\mathrm{GM}$ at $1190 \mathrm{~nm}$ for the extended dipole $\mathbf{4 f}$.

A quadrupole corresponds to a centrosymmetric molecule which possesses two identical donor or acceptor groups linked by a $\pi$-conjugated system (generally noted $A-\pi-A$ or $D-\pi-D$ ), as depicted in Figure 5 and illustrated in Figure 6. In this particular case, the (Dip) component of equation (5) is cancelled out. However, the possible resonance with an intermediary state 
close to half the energy of the final state, i.e. a low $\Delta$ value (see Figure 3$)$, leads to an enhanced value of the $(2 P)$ term and a strong improvement of the 2PA performances. ${ }^{52}$ The overall molecular polarizability can be intensified by the introduction of

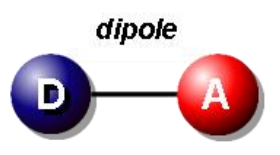

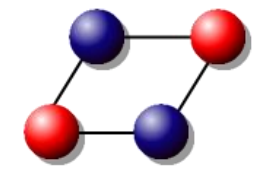

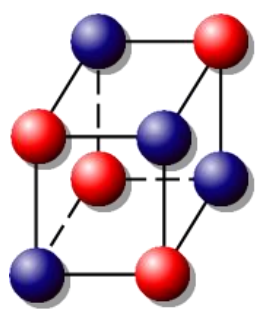

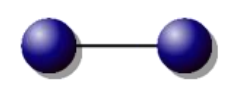

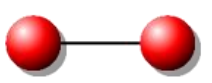

octupole

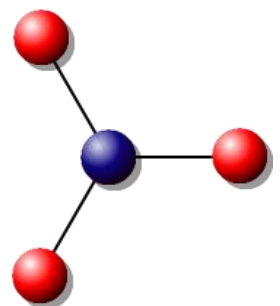

Figure 5. Schematic representation of dipolar, quadrupolar and octupolar molecules.

one or several auxiliary donor or acceptor moieties within the conjugated chain. If the incorporated $D$ or $A$ fragment has the same electronic influence that the extremities (i.e. structures like $A-\pi-A^{\prime}-\pi-A$ or $\left.D-\pi-D^{\prime}-\pi-D\right)$, the modulation of 2PA crosssection is weak, as illustrated in Figure 6 with quadrupoles 5 $(D-\pi-D)$ and $6 \mathbf{a}\left(D-\pi-D^{\prime}-\pi-D\right)$. For the latter compound, both central and distal moieties are electron-donating groups, which results in a weak increase of the cross-section compared to $\mathbf{5}$, from 635 to $900 \mathrm{GM} .{ }^{49}$ In contrast, the $2 \mathrm{PA}$ efficiency is strongly increased when the electronic influence of the central group differs from the peripheral ones due to the induction of ICT, as exemplified with compound $\mathbf{7 b}$, which displays a remarkably high 2PA cross-section of $1940 \mathrm{GM}$. In addition, Brédas, Marder and Perry have demonstrated that the position of the acceptor on the bridge strongly affects the linear and nonlinear absorption properties. ${ }^{53}$ Distyrylbenzene $7 c$, featuring cyano electron-withdrawing substituents on the vinyl bridge, exhibits a 2 PA cross-section about two times lower than $\mathbf{7 b}$, substituted on the central phenyl. According to quantum chemical calculations, the difference was attributed to a distortion from planarity in the ground state and a lower distance between donor and acceptor. ${ }^{53}$ Noteworthy, the multiplication of auxiliary fragments is a straightforward strategy for the optimization of the quadrupole 2PA cross-sections. For instance, 8 incorporates two highly electron-withdrawing extremities separated by three phenyl rings bearing auxiliary alkoxy donor functions and is characterized by an important $\sigma_{2 \mathrm{PA}}$ of $4400 \mathrm{GM}$ at $975 \mathrm{~nm}$.

The quadrupolar structures paved the way to the conception of branched molecules possessing no permanent dipolar moment and called octupoles (Figure 5). ${ }^{54,} 55$ These compounds initially developed for second order NLO because of their non-centrosymmetry ${ }^{54-56}$ present as well an interest for 2PA. Their structures are generally composed of an electrondonating (respectively electron-withdrawing) group branched out into three parts bearing acceptor (respectively donor) identical groups. A representative example was described by Prasad and co-workers who reported the elevation of the 2PA properties on the branched trigonal chromophore 11 (Figure 7). This octupole displays a cross-section six times higher than the related linear monomer 9 and almost three times higher than 10, which indicates that the 2PA cross-section increases faster than the number of branches. ${ }^{57}$ Such enhancement is due to a cooperative effect and is interpreted as an electronic coupling between the branches, called excitonic coupling. This strategy was widely used to enforce 2PA properties, ${ }^{58,59}$ in particular for fluorene oligomers ${ }^{60,61}$ and dendrimers. ${ }^{62}$

The nature and length of the conjugated backbone are also key parameters for the optimization of the 2PA cross-section of dipoles, quadrupoles and octupoles. In line with the previously described quadrupoles $\mathbf{6 a - b}$, Marder and co-workers proved that the $\sigma_{2 \mathrm{PA}}$ value of a family of quadrupolar diphenyl polyenes 12a-d (Figure 8) increases with the number vinylene units within the conjugated chain, from $240 \mathrm{GM}(\mathbf{1 2 a}, \mathrm{n}=1)$ to $410 \mathrm{GM}(\mathbf{1 2 d}$, $n=5) .63$ This phenomenon is enhanced when the additional
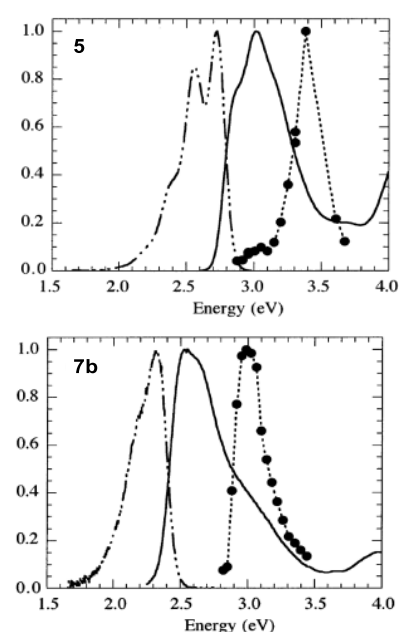

7a $\quad \mathrm{R}=\mathrm{Br}, \mathrm{R}^{\prime}=\mathrm{H}, \quad \sigma_{2 \mathrm{PA}}=450 \mathrm{GM}$ at $800 \mathrm{~nm}$ (ns-TPEF) 7b $\mathrm{R}=\mathrm{CN}, \mathrm{R}^{\prime}=\mathrm{H}, \quad \sigma_{2 \mathrm{PA}}=1940 \mathrm{GM}$ at $835 \mathrm{~nm}$ (ns-TPEF) 7c $R=H, R^{\prime}=C N, \quad \sigma_{2 P A}=730 \mathrm{GM}$ at $825 \mathrm{~nm}$ (ns-TPEF)

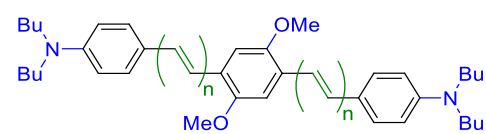

6a $\mathrm{n}=1, \quad \sigma_{2 \mathrm{PA}}=900 \mathrm{GM}$ at $730 \mathrm{~nm}$ (ns-TPEF) 6b $n=2, \quad \sigma_{2 P A}=1250 \mathrm{GM}$ at $775 \mathrm{~nm}$ (ns-TPEF)

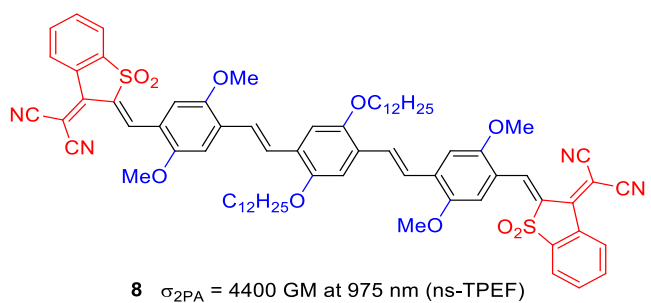


Figure 6. Influence of functionalization of quadrupolar structures on 2PA. Plots of the linear absorption (plain line), fluorescence (dashed line) and 2PA (dots) spectra of quadrupoles $\mathbf{5}$ and $\mathbf{7 b}$ in toluene. Reprinted with permission from reference ${ }^{53}$. Copyright 2002 American Chemical Society.
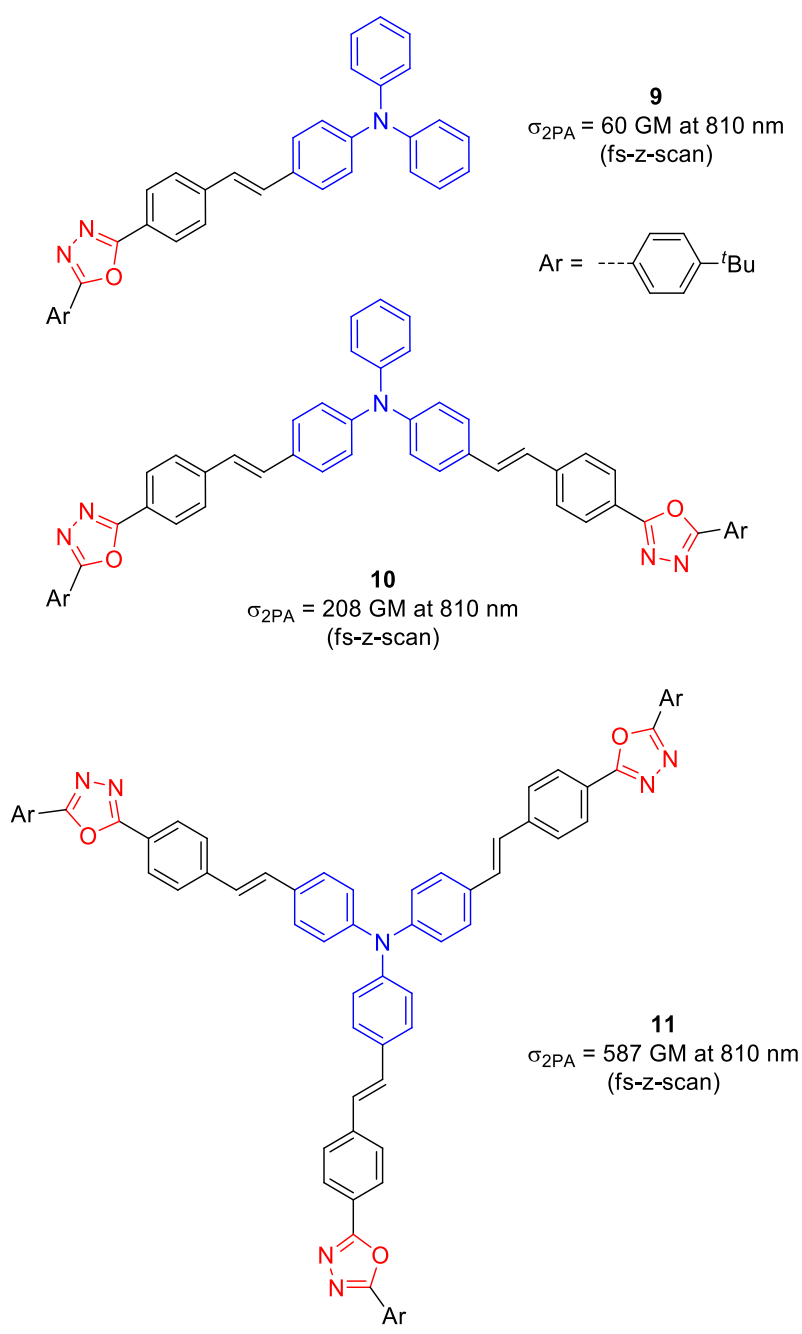

conjugated units involve auxiliary electron-donating (or withdrawing) units. ${ }^{64}$ In fact, the 2PA cross-sections reported for monomer 13a and trimer 13b increase from $240 \mathrm{GM}$ to 710 GM upon tripling the number of fluorene motifs, and a large enhancement is determined for tetradecamer 13c, which displays a cross-section of $6800 \mathrm{GM}$ at $600 \mathrm{~nm}$. However, in this last example, the angle introduced in the $\pi$ system by the geometry of the nitrogen atoms can be detrimental to the delocalization and this explains that the maximum 1PA and 2PA wavelengths are poorly red-shifted upon oligomerization. In fact, the position of the $\pi$-bridge connection is relevant within donor-acceptor chromophores. It was reported that metalinked electron-donating and electron-withdrawing groups result in a decrease of the electronic delocalization and less efficient ICT between the two moieties in the series of dipoles 14a-d. 65 In this series, $\sigma_{2 P A}$ vary from $15 \mathrm{GM}$ for $14 a$ (two metalinked units) to $120 \mathrm{GM}$ for $\mathbf{1 4 d}$ (two para-linked units).

It was reported that the replacement of triple bonds in quadrupole 15 with double bonds in compound 16 weakly influences the 2PA cross-section (Figure 9). ${ }^{66}$ This slight effect can be explained by the decrease of the conjugation in acetylenic derivative. The planarity of the chromophore plays an important role and can be optimized to enhance the conjugation along the $\pi$ system. This phenomenon is illustrated by comparison of molecule $\mathbf{1 6}$, for which free torsion is allowed between the two central phenyl rings, with compound 17, incorporating a central stiffened fluorenyl moiety, or molecule 18 that has two phenyl rings maintained in the same plan. Promoting the planarity of the dyes induces noticeable increases of 2PA cross-sections, going from $1040 \mathrm{GM}$ for $\mathbf{1 6}$ to 1260 and $1730 \mathrm{GM}$ for 17 and 18, respectively. ${ }^{66,67}$ 


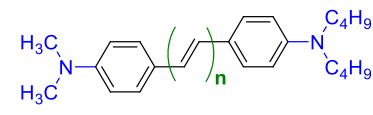

12a $n=2, \sigma_{2 P A}=240 \mathrm{GM}$ at $605 \mathrm{~nm}$ (ps-TPEF) 2b $\mathrm{n}=3, \sigma_{2 \mathrm{PA}}=230 \mathrm{GM}$ at $640 \mathrm{~nm}$ (ps-TPEF) 2c $n=4, \sigma_{2 P A}=340 \mathrm{GM}$ at $695 \mathrm{~nm}$ (ps-TPEF) 12d $n=5, \sigma_{2 P A}=410 \mathrm{GM}$ at $695 \mathrm{~nm}$ (ps-TPEF)

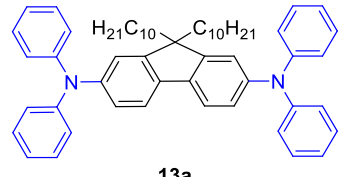

$\sigma_{2 \mathrm{PA}}=240 \mathrm{GM}$ at $600 \mathrm{~nm}$ (fs-TPEF)

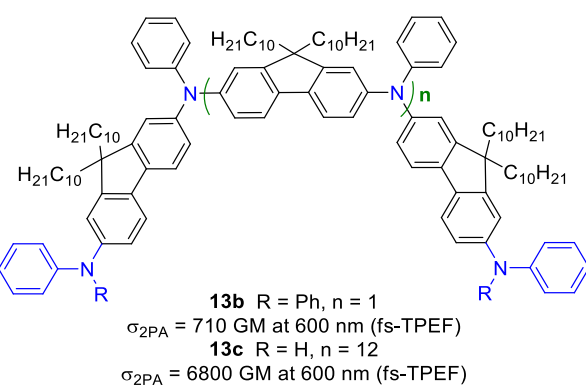

$\sigma_{2 P A}=6800 \mathrm{GM}$ at $600 \mathrm{~nm}$ (fs-TPEF)

Figure 8. Conjugated path lengthening and connection position effects on 2PA.
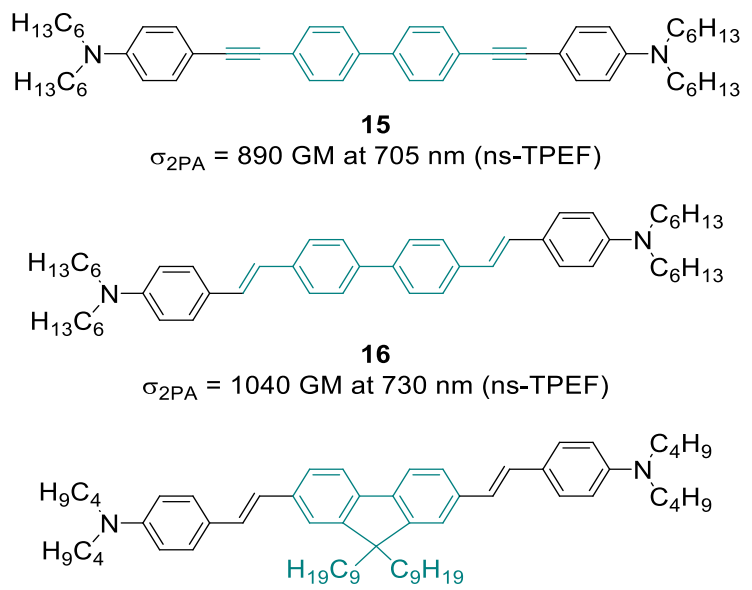

17

$\sigma_{2 \mathrm{PA}}=1260 \mathrm{GM}$ at $740 \mathrm{~nm}$ (ns-TPEF)

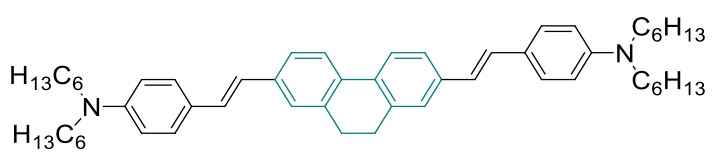

18

$\sigma_{2 \mathrm{PA}}=1730 \mathrm{GM}$ at $740 \mathrm{~nm}$ (ns-TPEF)

Figure 9. Influence of the structure planarity on 2PA.

Recently, Tian, Lu and co-workers synthesized chromophores 19a-c and showed that the use of a disilanyl linker is an efficient alternative to ethynyl bridges. ${ }^{68}$ The authors bring that the Si-Si $\sigma$ orbitals have higher energy than the $\mathrm{C}=\mathrm{C} \pi$ orbitals, which consequently leads to an improved delocalization and strongly enhanced ICT. This phenomenon is illustrated with compound 19c constituted of a tertiary amine extremity linked to an acceptor boron dipyrromethene core through disilanyl bridges yields impressive 2PA cross-sections ca. $4.2 \times 10^{5} \mathrm{GM}$ (Figure 10). As a comparison, the analogous chromophore 19a without electron-donating groups has a reported cross-section of only $1080 \mathrm{GM}$, proving the enhancement of ICT thanks to the disilanylene bridge. However, these promising 2PA results being the only ones reported for chromophores bearing disilanylene bridges, further study should be conducted to confirm them.

This section demonstrated the importance of molecular engineering for the optimization of 2PA wavelength range and

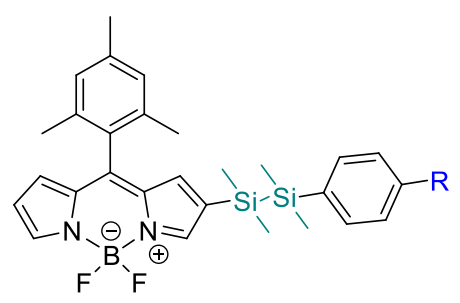

19a $\mathrm{R}=\mathrm{H}$

$\sigma_{2 \mathrm{PA}}=1080 \mathrm{GM}$ at $950 \mathrm{~nm}$ (fs-z-scan)

$19 b \mathrm{R}=\mathrm{OCH}_{3}$

$\sigma_{2 \mathrm{PA}}=82630 \mathrm{GM}$ at $850 \mathrm{~nm}$ (fs-z-scan)

$19 \mathrm{c} \mathrm{R}=\mathrm{N}\left(\mathrm{CH}_{3}\right)_{2}$

$\sigma_{2 \mathrm{PA}}=422990 \mathrm{GM}$ at $870 \mathrm{~nm}$ (fs-z-scan)

Figure 10. Use of disilanylene linkers to enhance 2PA in boron dipyrromethene dyes.

cross-section within the visible region. However, it is worthy to note that external parameters such as the solvent (see Section 3), ${ }^{69-71}$ the pressure ${ }^{72}$ or the temperature have also to be taken into account for the optimization of the 2PA cross-section. ${ }^{73}, 74$ Theoretical $^{38}$ and experimental ${ }^{11}$ structure-properties relationships are nowadays well established and are effective tools for the design of chromophores exhibiting large 2PA in the 700-1050 $\mathrm{nm}$ range, where Ti:Sapphire lasers operate. Since the last decade, the development of OPO lasers operating in the 
SWIR permits to shift the spectral range of interest beyond 1100 $\mathrm{nm}$. This perspective triggered the elaboration of new redshifted chromophores and gave an extra dimension to "old" NIR dyes exhibiting linear absorption beyond $650 \mathrm{~nm}$.

\section{Engineering of near-infrared chromophores}

Achieving 2PA in the NIR or SWIR necessarily requires a shift of the linear absorption towards the far-red and NIR regions (beyond $700 \mathrm{~nm}$ ). Thereby, this section aims to introduce and illustrate the classical strategies for the development of NIR absorbers. A particular attention will be focused on few specific families of dyes that will be further developed in the Section 3 of this review, dedicated to 2PA in the SWIR.

Historically, the design of chromophores featuring red-toNIR-absorbing properties was widely developed for applications as textile dyeing, photocopy and laser printing. ${ }^{75}$ During the last decades, NIR dyes were also introduced as molecular materials in organic lasers, ${ }^{76}$ as panchromatic photosensitizers or nonfullerene acceptors in solar cells, ${ }^{77-81}$ or as photoemissive, photoacoustic or PDT photosensitizer probes for bio-imaging and/or therapy. ${ }^{82-87}$ The energetic gap between the highest and lowest occupied molecular orbitals, generally referred as the HOMO-LUMO gap (HLG), governs the optical and electronic properties of conjugated organic molecules. Thus, the red-shift of the lowest energy transition can be tuned by molecular engineering playing on several parameters, for instance the extension of the conjugation length, the aromaticity or planarity of the system, the lowering of the bond length alternation (BLA), or the introduction of a charge transfer through push-pull functions (Figure 11). Two important reviews by Roncali 88 and Wang et al. $^{78}$ describe in depth these molecular engineering rules and the inescapable families of NIR dyes. Consequently, the following section aims to illustrate non-exhaustively the most common strategies to develop NIR dyes, which are also relevant for the design of efficient NIR $2 \mathrm{P}$-absorbers.

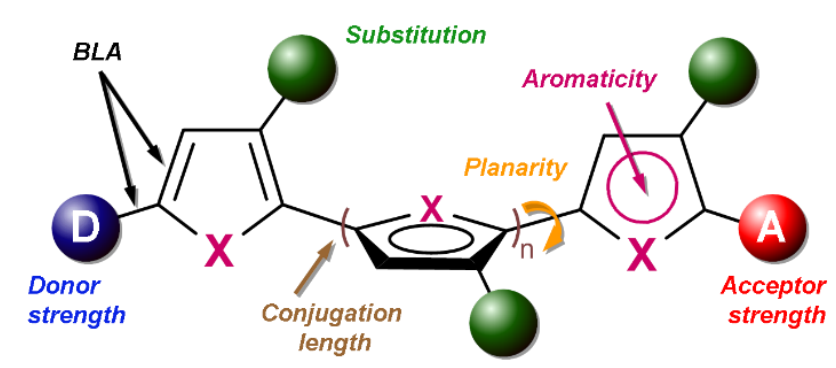

Figure 11. Illustration of important parameters to tune the electronic gap of organic dyes (graphical concept inspired from references ${ }^{78,88}$ ).

\section{Linear extension of the conjugation}

A seminal strategy used to decrease the HLG of an organic molecule consists in the extension its $\pi$-system length. A representative molecule to illustrate this approach is the transpolyacetylene for which a zero band gap is expected for infinite delocalization. ${ }^{89}$ When the chain length of $\mathbf{2 1}$ varies, the HLG $\left(E_{g}\right)$ can be tuned from 5.7 to $1.8 \mathrm{eV}$, corresponding to a redshift of the absorption band from 220 to $690 \mathrm{~nm}$ (Figure 12).

However, torsions of the chain inducing loss of planarity, together with isomerization and oxidation processes, prevent the polymer's electronic absorption from reaching higher wavelengths. To tackle these drawbacks, an alternative consists in the introduction of (hetero)aromatic units within the conjugated chain, a strategy that led to the development of conjugated polymers such as poly- $p$-phenylene, poly-pyrroles 22 and poly-thiophenes 23. ${ }^{90}$ Their (photo-)chemical stabilities are greatly enhanced but the absorption maximum rapidly reaches a plateau and the optical properties of an infinite polymer are most often comparable to those of oligomers containing $c a$. ten units. Meier and co-workers empirically rationalized this phenomenon on the poly- $p$ phenylenevinylenes $\mathbf{2 4}$ for which the plateau is reached for eleven repeated units (Figure 12). ${ }^{91}$ The absorption maximum is then governed by the effective conjugation length (ECL) which is influenced by the torsion phenomenon of the double bonds and the confinement of the electronic density on the aromatic units. The most red-shifted optical properties are reached using heterocycles that feature a low aromaticity and promote delocalization, such as thiophene units $\mathbf{2 3}$, which reaches an absorption maximum at $725 \mathrm{~nm}$ for an infinite polymer.

Fully planar architectures can be designed using fused aromatic moieties, exemplified in the acene series $\mathbf{2 5}$ or rylene series 26, widely used in organic electronics (Figure 13). ${ }^{92-94}$ On one hand, the acenes consist in a succession of linearly fused

$$
\gamma_{n}
$$

21

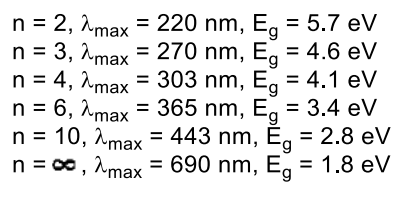

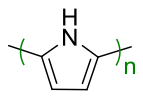

22

$\mathrm{n}=1, \lambda_{\max }=208 \mathrm{~nm}$ $\mathrm{n}=2, \lambda_{\max }=285 \mathrm{~nm}$ $\mathrm{n}=3, \lambda_{\max }=345 \mathrm{~nm}$ $\mathrm{n}=\infty, \lambda_{\max }=413 \mathrm{~nm}$

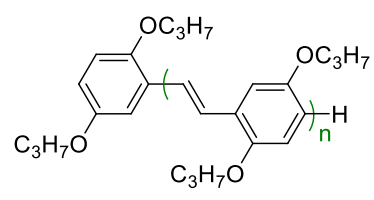

Figure 12. Examples of conjugated oligomers or polymers and associated spectroscopic data. 

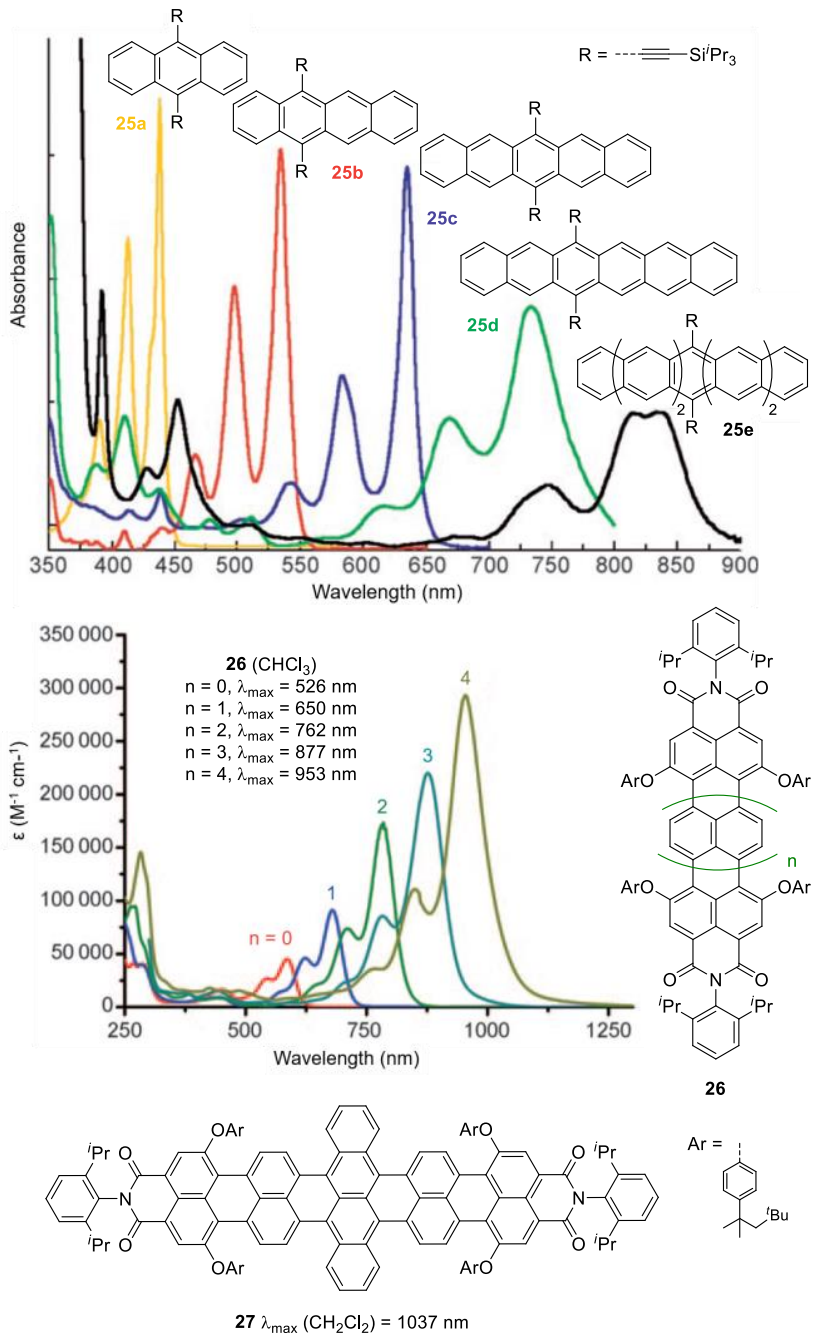

Figure 13. General structure of acene and rylene families. Evolution of the absorption spectra of acene $\mathbf{2 5}$ (arbitrary unit) and rylene $\mathbf{2 6}$ series with the conjugation length Adapted from references ${ }^{92}$ and ${ }^{95}$. Copyright 2008 \& 2010 WILEY-VCH Verlag GmbH \& Co. KGaA, Weinheim.

benzene rings starting from small naphthalene and anthracene derivatives to the famous pentacene, up to hepta and nonacene. ${ }^{96}$ Obviously, the longer compounds are the most difficult to synthesize and may exhibit weaker (photo)-stability but the absorption spectra are well structured and regularly red-shifted upon homologation, e.g. from $660 \mathrm{~nm}$ for pentacene 25a to about $850 \mathrm{~nm}$ for functionalized heptacene 25e. On the other hand, the general rylene structure consists in a succession of fused naphthalene units and can be named poly(peri-naphthalene), according to the polymer nomenclature. These molecules are highly stable and the introduction of amide extremities and lateral substituents ensure a good solubility in organic or aqueous solvents making them suitable for photonic or imaging applications. ${ }^{95}$ The very rigid structure of these compounds enables the extension of the conjugation while conserving the planarity, resulting in a 953 $\mathrm{nm}$ absorption maximum in the instance of four linked naphthalene units in chromophore 26. ${ }^{97,} 98$ This bathochromic shift is accompanied by a hyperchromic effect, i.e. the increase of the molar extinction coefficients up to $293000 \mathrm{M}^{-1} \mathrm{~cm}^{-1}$. The introduction of bulky electron-donating substituents allows additional tuning of the optical properties and the extension of the central naphthalene to tetracene moieties, as performed in molecule 27, shifts the maximum of absorption to $1050 \mathrm{~nm} .{ }^{99} \mathrm{~A}$ recent review by Freudenberg, Bunz and co-workers compiled the important works that were achieved in the development and properties screening of larger (hetero)acenes. ${ }^{100}$ It is also noteworthy that the conjugation can be extended in twodimensions within polycyclic (hetero)aromatic hydrocarbons. The molecular design of these systems and heterocyclic nanographenes was extensively reviewed by Stępień et al. in $2017,{ }^{101}$ and few examples of fused NIR dyes belonging to this family are shown in the section 3 .

\section{Intramolecular charge transfer}

For a given polyene chain, the HLG can be decreased by introduction of electron-donating and electron-withdrawing moieties, resulting in the hybridization of the frontier orbitals of the $\pi$-conjugated chain together with the donor and acceptor groups. Consequently, the HOMO is destabilized and the LUMO is lowered in energy. The establishment of a strong intramolecular charge transfer (ICT) thus implies a red-shift of the lower energy transition, generally characterized by a broad, intense and structureless absorption profile which is strongly affected by the solvent polarity. ${ }^{102}$ The magnitude of the bathochromic shift depends on the nature of the substituent as illustrated by the series $\mathbf{2 8}$ (Figure 14). For a given chromophore incorporating a dialkyl-amino donor group and a diphenylethylene $\pi$-conjugated bridge, the absorption is strongly red-shifted upon increasing the strength of the

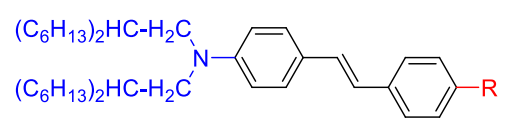

$$
\begin{gathered}
28\left(\mathrm{CHCl}_{3}\right) \\
\mathrm{R}=\mathrm{H}, \lambda_{\max }=366 \mathrm{~nm} \\
\mathrm{R}=\mathrm{CN}, \lambda_{\max }=401 \mathrm{~nm} \\
\mathrm{R}=\mathrm{CHO}, \lambda_{\max }=423 \mathrm{~nm} \\
\mathrm{R}=\mathrm{NO}_{2}, \lambda_{\max }=461 \mathrm{~nm} \\
\mathrm{R}=\mathrm{CH}=\mathrm{C}(\mathrm{CN})_{2}, \lambda_{\max }=525 \mathrm{~nm} \\
\mathrm{R}=\mathrm{C}(\mathrm{CN})=\mathrm{C}(\mathrm{CN})_{2}, \lambda_{\max }=670 \mathrm{~nm}
\end{gathered}
$$
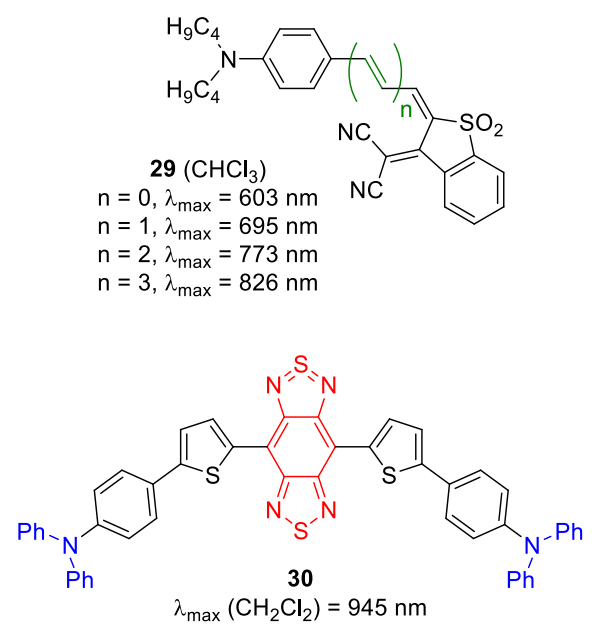

Figure 14. Effect of the acceptor strength and of the conjugated bridge length on the maximum wavelength of the ICT transition. 
acceptor function, starting from $366 \mathrm{~nm}$ for the molecule without terminal acceptor, up to $670 \mathrm{~nm}$ for the most electronwithdrawing tricyanoethylene moiety. ${ }^{103}$ Not surprisingly, the extension of the conjugated bridge will further red-shift the absorption towards the NIR as in series $\mathbf{2 9}$, reaching absorption beyond $800 \mathrm{~nm}$ upon elongation of the conjugation. ${ }^{104}$ It is noteworthy that the design of highly electron-withdrawing groups such as benzo-bis-thiadiazole allows to shift the absorption wavelengths towards the NIR within push-pull and quadrupolar derivatives such as $\mathbf{3 0 .}{ }^{105}$

\section{Polymethine approach}

Among the common strategies used two prepare NIR dyes, the polymethine approach is particularly powerful. It consists in linking two electron-donating (respectively electronwithdrawing) moieties via an odd number of $s p^{2}$-hybridized carbon atoms, allowing the cationic (respectively anionic) charge to be symmetrically delocalized between the two extremities. Note that polymethines can also exist as dissymmetrical structures incorporating distinct terminal groups. When the electronic contribution from each of the two terminal groups is equal, a key electronic structure called "cyanine state" is reached, corresponding to the ideal and symmetrical delocalization of the charge along the polymethine bridge (Figure 15). Polymethines under cyanine state present a degenerated ground state structure resulting in a fully delocalized charge over the $\pi$-conjugated skeleton, a BLA reaching zero, and consequently, a particularly sharp and exceptionally intense absorption band with a characteristic vibronic shoulder at higher energy. It is possible to further redshift this so-called cyanine-type absorption band upon increasing the strength of the donor or acceptor end groups (indolenine, benzothiazole, pyran, tricyanofuran...) and stiffening or lengthening of the conjugated bridge. ${ }^{106-108}$ However, although this ideal cyanine state is conserved until a certain $\pi$-conjugated length, the symmetry may be broken due to Peierls-type distortions for particularly long and unrigidified streptocyanines. ${ }^{109-112}$ Note that several parameters are also able to promote the stabilization of blue-shifted polyene-like

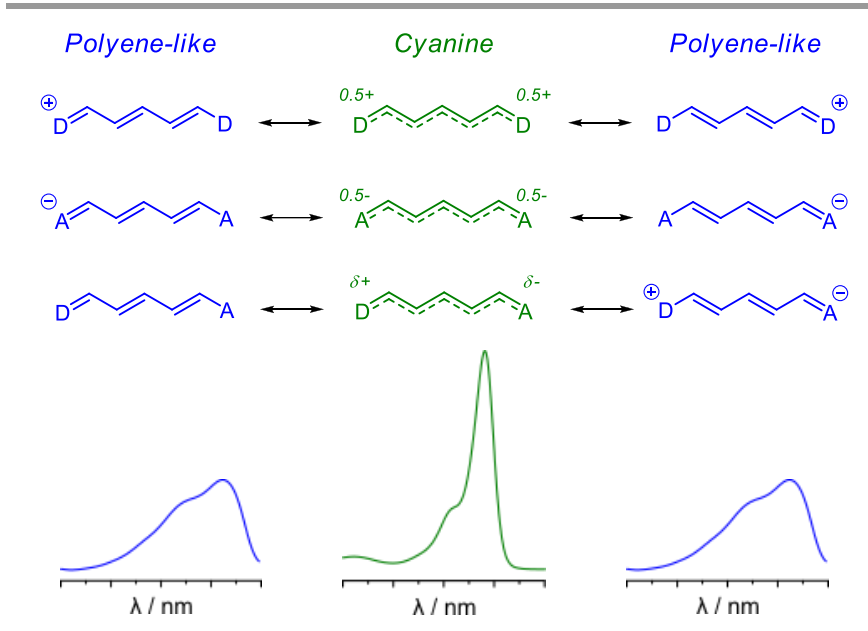

Figure 15. Resonant forms and corresponding linear absorption spectra shape of donor (D) and/or acceptor (A) substituted polymethines. (i.e. dipolar) structures, including the solvent polarity, ${ }^{113,114}$ ionpairing effects ${ }^{115-119}$ or substitution of electron-donating moieties at the centre of the polymethine chain. ${ }^{120-122}$

The design of polymethines is a foolproof strategy to reach NIR absorption with strong extinction coefficients, thus the chemistry and optical properties of polymethines has thrilled scientists for decades. ${ }^{106,} 123$ Polymethine structures are ubiquitous in the design of red to NIR dyes, as exemplified with the famous Indocyanine Green 31, an FDA-approved cationic heptamethine which features a strong absorption in the NIR, with molar extinction coefficient $\varepsilon_{\max } \sim 194000 \mathrm{M}^{-1} \mathrm{~cm}^{-1}$ (Figure 16). ${ }^{124}$ The polymethine family is extremely broad and also includes anionic structures (e.g. oxonols), ${ }^{125-127}$ neutral D-A merocyanines (e.g. 32), ${ }^{128-132}$ zwitterionic squaraine (e.g. 33) ${ }^{133-}$ 137 or croconaine (e.g. 34) dyes ${ }^{138,} 139$ featuring squaric or croconic acid cores, respectively. This family also encompasses the related polycyclic charged systems such as the well-known fluorescein, rhodamines ${ }^{140}$ and other xanthene dyes (eosin, erythrosine, rose Bengal...) like analogous 35 and 36, featuring a fused polycyclic skeleton. ${ }^{141-143}$

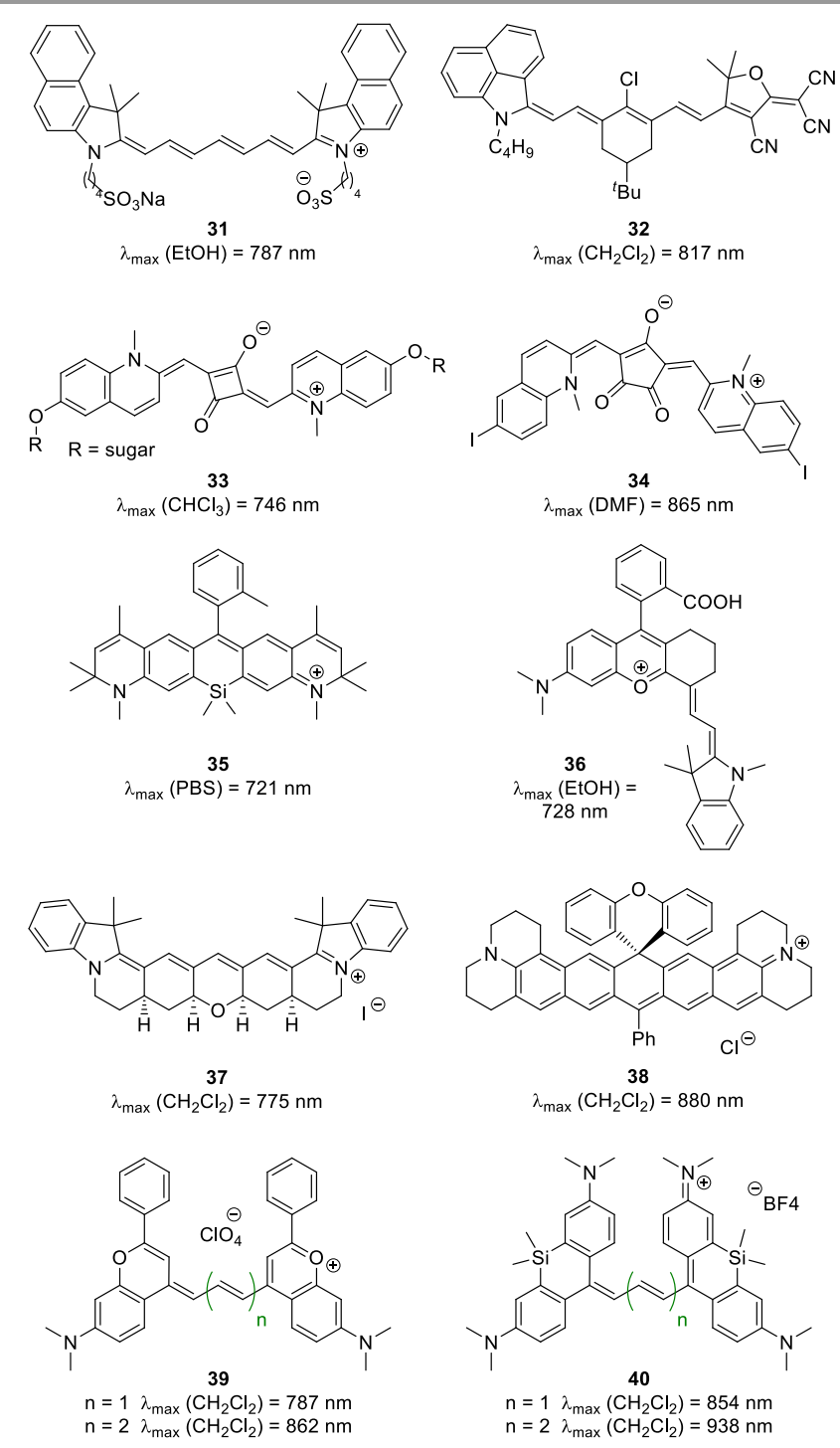

Figure 16. Examples of NIR-absorbing polymethine structures. 
The last decade has been prolific for the design of polymethines presenting original skeletons or efficient electron-rich extremities. For instance, it was shown that the conformational restraint within polymethines is helpful to slightly red-shift the absorption while significantly improving the radiative deexcitation rate in heptamethine $\mathbf{3 7}$ or julolidine-

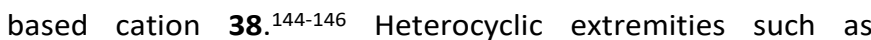
azaazulene, ${ }^{147,} 148$ indolizine, ${ }^{149}$ flavylium ${ }^{150-152}$ or xanthylium ${ }^{153}$ were also developed and demonstrated stronger abilities to red-shift the absorption compared to classical indolenium or pyridinium moieties. The flavylium and xanthylium series 39 and $\mathbf{4 0}$ show that NIR wavelengths are straightforwardly reached with only a trimethine-long bridge.

Boron dipyrromethene ${ }^{154,} 155$ (bodipy, e.g. 4156) and azaboron dipyrromethene ${ }^{157}, 158$ (aza-bodipy, e.g. 42 ${ }^{159}$ ) are rigidified monomethines incorporating a boron difluoride bridge (Figure 17); they exhibit very similar cyanine-like absorption profiles and therefore belong to the classification of polymethine dyes. Within these two families, it is possible to induce significant bathochromic shift up to the NIR using several approaches such as introduction of electron-donating substituents, 160,161 creation of a six-membered ring by $B-O$ chelation (e.g. 43), extension of conjugation or fusion of the core (e.g. 44), 156, 159, 162-165 rigidification of the conjugated backbone by annelation, 166167 or replacement the boron centre by a carbon atom, in recently disclosed cardipy dyes. ${ }^{168}$ According to theoretical predictions, the combination of these approaches would lead to highly red-shifted absorptions, up to ca. $1000 \mathrm{~nm}$ for the most optimized structures. ${ }^{169}$

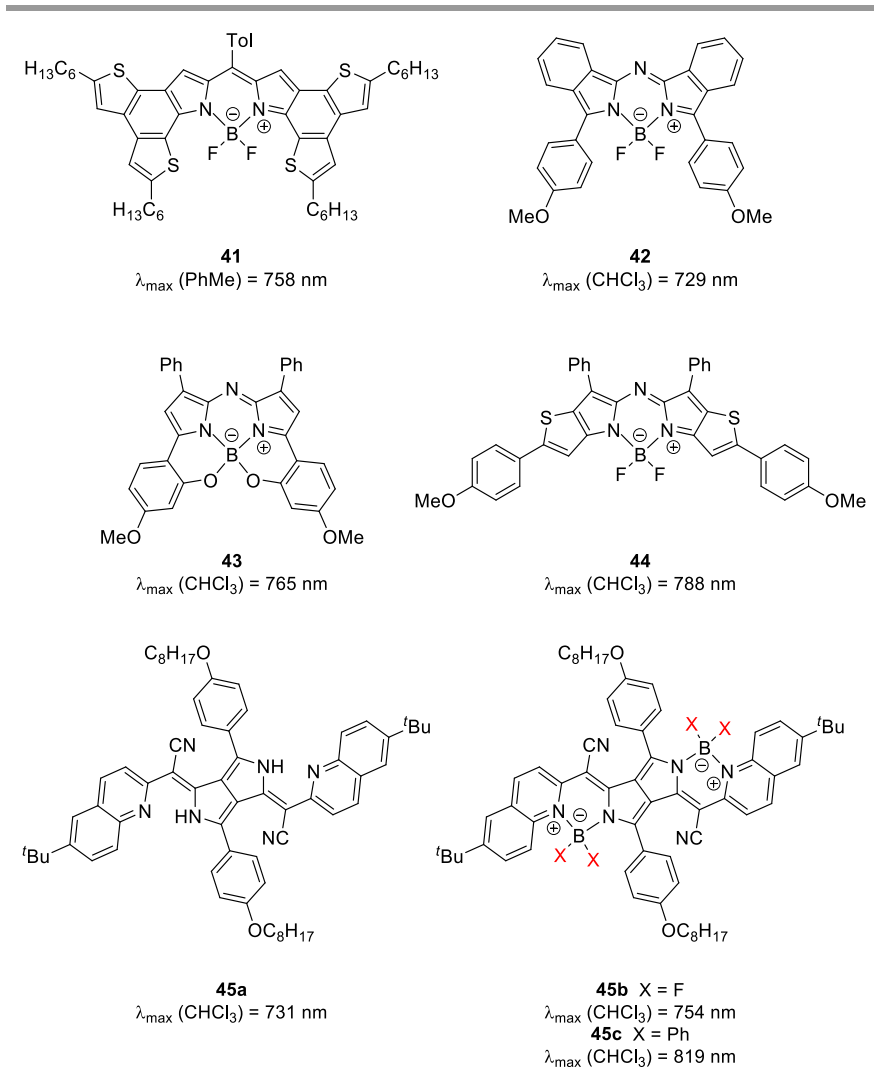

Figure 17. Examples of NIR-absorbing bodipy, aza-bodipy and pyrrolopyrrole derivatives.
In 2007, the original boron complexes of a pyrrolopyrrole dye 45a was prepared, showing NIR absorption and a marked redshift when replacing the fluorine ligands (45b) with phenyls on the boron atoms (45c) that is due to the steric hindrance of the $\mathrm{BPh}_{2}$ groups causing a twist of the chromophore. ${ }^{170,171}$ Later, A-D-A triads constituted of two analogues of $45 \mathrm{~b}$ linked through a bisbenzothiazole or a cyclopentadithiophene unit showed that the absorption could be pushed further in the NIR, beyond $900 \mathrm{~nm} .{ }^{172,173}$

Linear oligomerization strategies were reported for bodipy arrays 46, prepared via successive cross-coupling reactions and with tunable absorption depending on the number of units, up to the NIR-II domain for the hexamer (Figure 18). ${ }^{174}$ In contrast, the rigidified oligomers 47 , conveniently obtained in only two consecutive oxidative steps (i.e. oligomerization and fusion) show that the ECL is limited, an absorption plateau being almost reached ca. $950 \mathrm{~nm}$ for the arc-shaped octamer. ${ }^{175}$

Chromophores where a cationic charge is delocalized through an extended bidimensional structure, such as historical Malachite Green or Crystal Violet (48) (Figure 19) can be considered as distant members of the polymethine family. ${ }^{176} \mathrm{~A}$ significant red-shift towards the NIR is achieved upon planarization of the phenyl moieties as illustrated by the
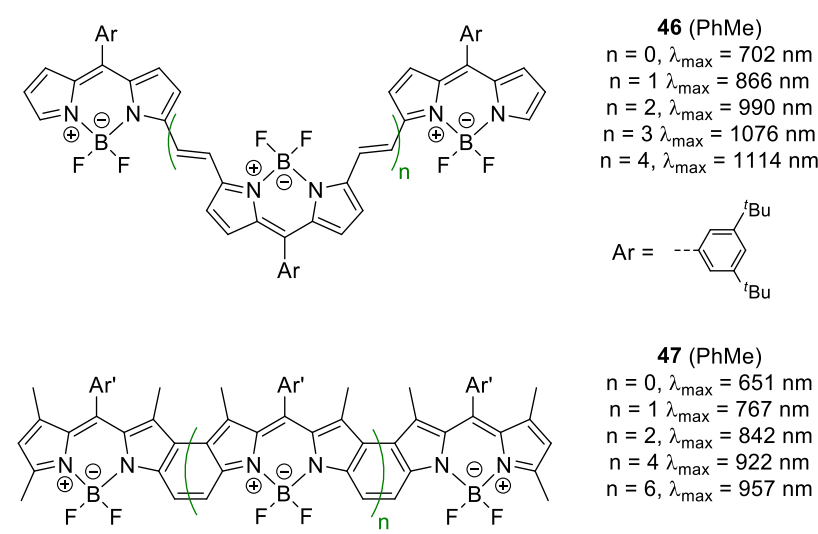

47 (PhMe)

$\mathrm{n}=0, \lambda_{\max }=651 \mathrm{~nm}$ $\mathrm{n}=1 \lambda_{\max }=767 \mathrm{~nm}$ $\mathrm{n}=2, \lambda_{\max }=842 \mathrm{~nm}$ $\mathrm{n}=4 \lambda_{\max }=922 \mathrm{~nm}$ $\mathrm{n}=6, \lambda_{\max }=957 \mathrm{~nm}$

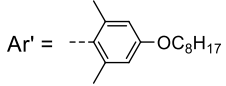

Figure 18. NIR ribbons based on indole- or pyrrole-containing dyes.

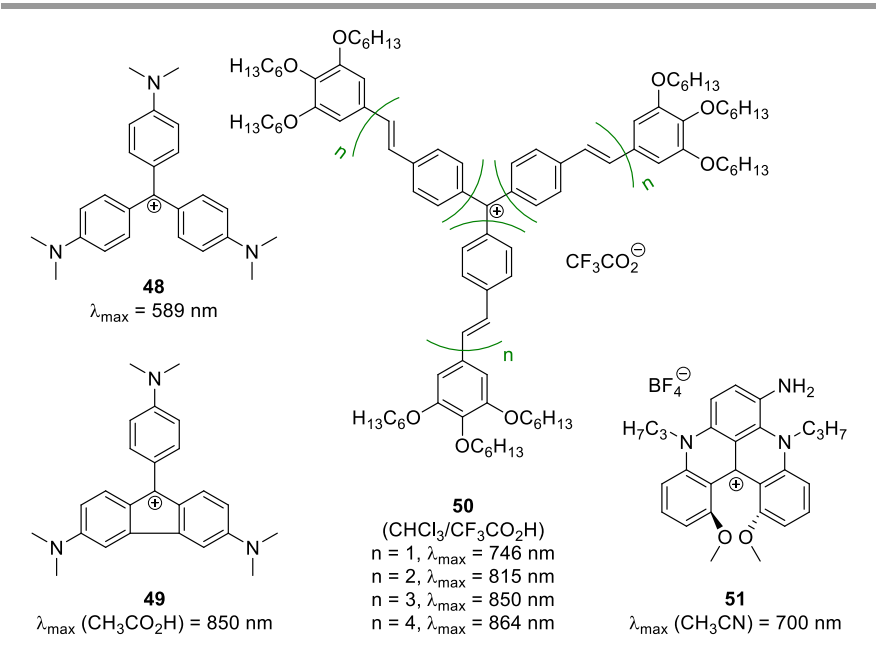

Figure 19. Cationic structures derived from Crystal Violet. 
fluorene derivative $49 .{ }^{177}$ In addition, the extended methylium salt series $\mathbf{5 0}$ exhibit absorption maxima up to $864 \mathrm{~nm}$, depending on the chains length ${ }^{178}$ and additional bathochromic shift up to $1068 \mathrm{~nm}$ can be obtained using stronger electrondonating groups like ferrocenyl or dialkylamine. ${ }^{179,180}$ Note that structures analogous to Crystal Violet can be identified in dimethoxyquinacridinium cations, such as $\mathbf{5 1}$, which are helicenium dyes that commonly display far-red to NIR absorptions. ${ }^{181,182}$

\section{Macrocyclic approach}

The elaboration of cyclic $\pi$-conjugated architectures enables reaching aromatic macrocycles with low HLG. For instance, the annulene derivatives, ${ }^{183}$ composed of $s p^{2}$-hybridized carbon atoms, can easily reach the NIR range, as illustrated in the case of compounds $\mathbf{5 2}$ and $\mathbf{5 3}$ which possess eighteen delocalized $\pi$ electrons and present absorption properties around $800 \mathrm{~nm}$ (Figure 20). ${ }^{184}$ To gain in stability, the most efficient strategy is to introduce various heterocycles within cyclic $\pi$-conjugated systems. Porphyrinoids, including porphyrins, phtalocyanines and other related macrocycles, are widely studied chromophores that possess eighteen $\pi$ electrons delocalized through four pyrrolic units linked by (aza-)methine bridges.
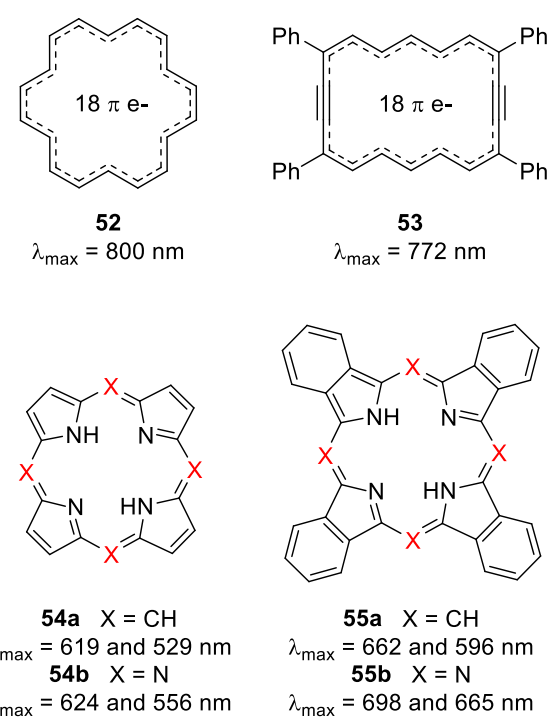

$55 \mathrm{a} \quad \mathrm{X}=\mathrm{CH}$

$\lambda_{\max }=662$ and $596 \mathrm{~nm}$

$55 b \quad X=N$ $\lambda_{\max }=698$ and $665 \mathrm{~nm}$

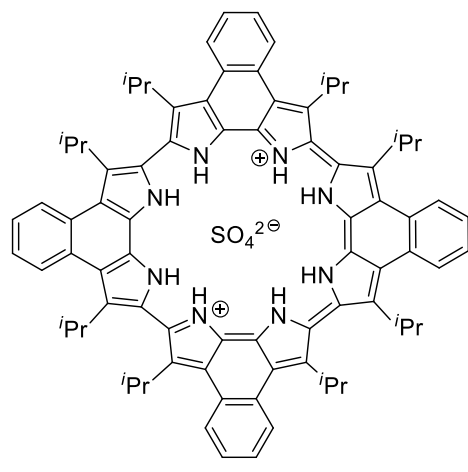

56

$\lambda_{\max }\left(\mathrm{CH}_{2} \mathrm{Cl}_{2}\right)=1334 \mathrm{~nm}$

Figure 20. Annulene rings and porphyrinoid systems.
They are characterized by multiple absorption transitions: the intense Soret band generally found around $400 \mathrm{~nm}$ and $Q$ bands in the $600-800 \mathrm{~nm}$ range, responsible for the far-red absorption found for series $\mathbf{5 4}$ and $\mathbf{5 5 . 7 5}$

Starting from these archetypal architectures, it is possible to shift the absorption towards the NIR in various ways, unexhaustively listed here and deeply illustrated in the Section 3 of this review. First, the periphery functionalization in meso or pyrrolic positions, together with the insertion of a metal in the cavity allow to tune the photophysical properties and shift the absorption to lower energies. Second, increasing the number of delocalized $\pi$ electrons by incorporating a higher number of pyrrolic heterocycles efficiently lowers the HLG, such as in sapphyrin (5 units), amethirine (6 units), NIR-absorbing cyclo[8]pyrrole, ${ }^{185}$ or SWIR-absorbing cyclo[10]pyrrole. ${ }^{186}$ Third, the further annellation of these extended porphyrin derivatives stiffens the structure and induces an additional bathochromic shift, as illustrated by cyclo[4]naphtoindole $\mathbf{5 6}$ absorbing $c a$. $1300 \mathrm{~nm} .{ }^{187}$ Eventually, the design of planar porphyrin tapes remarkably shifts the $Q$ bands far into the NIR and SWIR regions. Nevertheless, when the oligomers are linked together by only one carbon-carbon bond in meso-meso position, the conformation is twisted, nearly perpendicular between the consecutive porphyrin units. This phenomenon is illustrated by the series $\mathbf{5 7}$ where the $Q$ band absorption maximum remains around $600 \mathrm{~nm}$, even for a dodecamer (Figure 21). However, if the planarity is forced by fusion of two consecutive units via intramolecular oxidative coupling, ${ }^{188}$ a spectacular bathochromic shift is obtained, up to $2800 \mathrm{~nm}$ for the dodecamer of the series 58 (Figure 14). ${ }^{189,} 190$ These exceptional researches initiated by Osuka and co-workers have triggered the exploration of fused porphyrinoids and
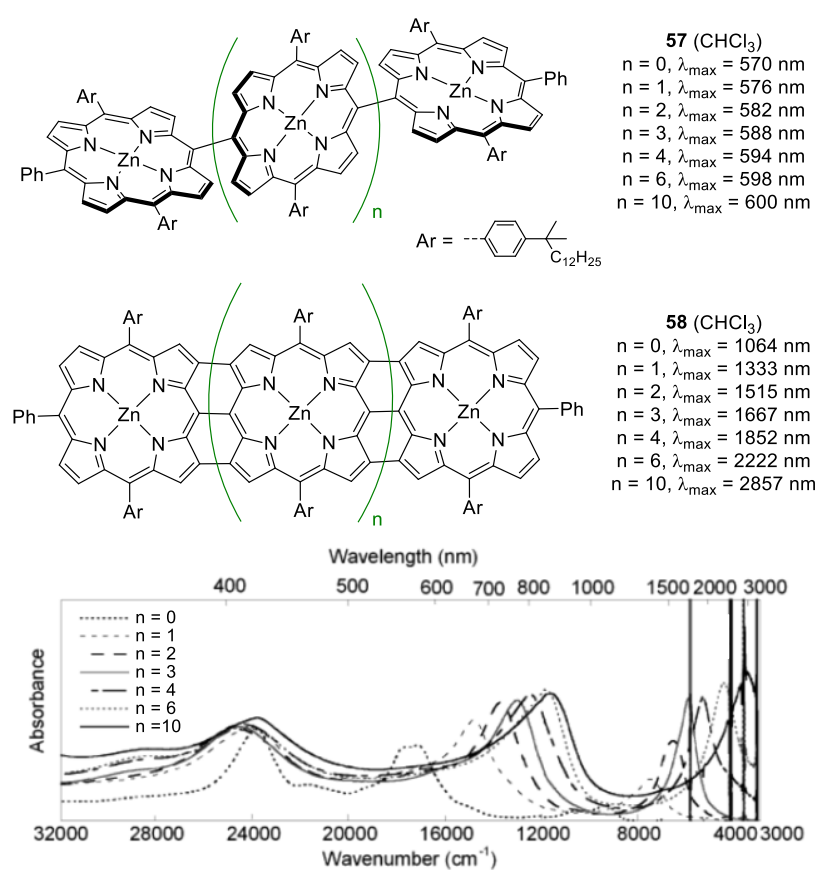

Figure 21. Porphyrin oligomers and arrays, and absorption spectra of the series $\mathbf{5 8}$ in $\mathrm{CHCl}_{3}$. Adapted with permission from reference ${ }^{190}$. Copyright 2002 American Chemical Society. 
conjugated porphyrin arrays, notably for NLO and as molecular wires, and the many designed imagined by the community were reviewed in-depth in 2013 and 2015. ${ }^{191,192}$

The chemistry of porphyrinoids and related macrocycles is extremely rich and it is out of the scope of this review to list exhaustively the countless approaches employed to access the many NIR-absorbing candidates. The interested reader is invited to consult the relevant reviews on the topics of $\mathrm{N}$ confused porphyrins, ${ }^{193}$ heteroporphyrins, ${ }^{194}$ carbaporphyrins, $195, \quad 196$ expanded and contracted porphyrins, ${ }^{185,} \quad{ }^{197-199}$ porphycenes, ${ }^{200}$ subporphyrins, ${ }^{201}$ bacteriochlorins ${ }^{202}$ and exotic bodipy-based macrocycles. ${ }^{203}$

\section{Diradicals}

Importantly, it was shown that radical transfer within a conjugated molecule can be as efficient as the delocalization of a charge to shift the absorption properties towards NIR wavelengths. The hydrocarbon 59, reported in 2005, presents a 1PA maximum at $746 \mathrm{~nm}$ due to two unpaired electrons delocalized in each extremities of the resonant aromatic centre (Figure 22). This open-shell ground state electronic structure was evidenced through single crystal analysis and theoretical calculations that estimated a singlet diradical character $\gamma=0.75$ for 59.204 The lengthening of the molecule with a central naphtoquinoid unit induces a bathochromic shift towards 865 $\mathrm{nm}$ and an increase of the 2PA, attributed to a larger diradical character $(\gamma=0.83)$ and a more spin-localized system in the case of phenalenyl 60 (see Section 3 for details). ${ }^{205,} 206$ The many strategies developed to design diradicaloids were extensively reviewed in 2015 and 2018 by Wu and co-workers. ${ }^{207,} 208$ Recently, original radicaloid NIR-absorbers were reported using fluorene, ${ }^{209,} 210$ carbazole, ${ }^{211}, 212$ bisanthene, ${ }^{213}$ diketopyrrolopyrole 214,215 or diindenopyrene ${ }^{216}$ units.

\section{Coordination complexes}

Coordination complexes of nickel, palladium or platinum (II) incorporating non-innocent dithiolene ligands can adopt a square planar molecular geometry that allows the electron delocalization through the whole structure. ${ }^{217,} 218$ Thus, metal and ligands frontier orbitals contribute to the optical transitions and the linear maximum absorption is localized in the NIR. The dithiolene complexes 61 (Figure 23) can be compared to polymethines: the second oxidation degree of these complexes presents a bond length alternation close to zero and the
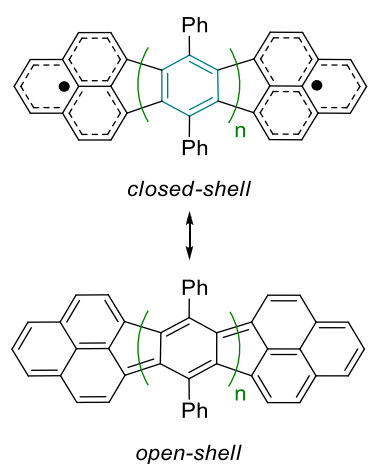

$59 \mathrm{n}=1(\gamma=0.75)$

$\lambda_{\max }\left(\mathrm{CHCl}_{3}\right)=746 \mathrm{~nm}$

$60 \mathrm{n}=2(\gamma=0.83)$

$\lambda_{\max }\left(\mathrm{CHCl}_{3}\right)=875 \mathrm{~nm}$
Figure 22. Polycyclic aromatic hydrocarbon diradicals.

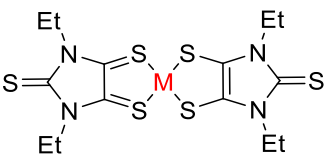

$61\left(\mathrm{CHCl}_{3}\right)$

$\mathrm{M}=\mathrm{Ni}, \lambda_{\max }=996 \mathrm{~nm}$

$\mathrm{M}=\mathrm{Pt}, \lambda_{\max }=998 \mathrm{~nm}$

$M=P d, \lambda_{\max }=1010 \mathrm{~nm}$

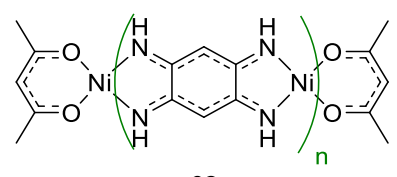

62

$\mathrm{n}=1, \lambda_{\max }\left(\mathrm{CH}_{2} \mathrm{Cl}_{2}\right)=576 \mathrm{~nm}$

$\mathrm{n}=2, \lambda_{\max }(\mathrm{THF})=627 \mathrm{~nm}$

$\mathrm{n}=3, \lambda_{\max }(\mathrm{DMSO})=693 \mathrm{~nm}$

$\mathrm{n}=4, \lambda_{\max }(\mathrm{DMSO})=757 \mathrm{~nm}$
Figure 23. NIR-absorbing coordination complexes

presence of the metal in the central position induces a delocalization through an odd number of atoms. The functionalization of the ligands, the variation of the metal centre and the exchange of the sulphur atom with heavier selenium atom ${ }^{219}$ provide possibilities of fine tuning of the optical properties between 700 and $1100 \mathrm{~nm} .^{220,} 221$ Another example of highly delocalized complexes includes the 2,5diaminobenzoquinonediimine, a non-innocent ligand that was used to prepare $\mathrm{Ni}(\mathrm{II})$ coordination tapes $\mathbf{6 2}$, featuring absorption spanning over the NIR region for the tetrameric complex.222, 223 Recently, a mononuclear Pt(II) complex featuring two di-substituted quinoidal ligands showed absorption ca. $900 \mathrm{~nm}$ due to a unique delocalization pathway in trans fashion across the metal centre. ${ }^{224}$

In the light of these selected examples, we illustrated that few families of dyes absorbing in the NIR exist and that their designs rely on established strategies comparable to the one used for the enhancement of 2PA. In fact, it appears that the most used techniques to shift the optical properties are the optimization of the ICT, the stiffening of the structure and the extension of the $\pi$-conjugation, possibly through (macrocyclic) oligomerization. This section also highlighted that the electronic absorption in the NIR emerges from other particular transitions, such as $Q$ bands in porphyrins, cyanine state in polymethines, or delocalized radicals.

\section{Dyes for two-photon absorption in the SWIR region}

During the last two decades, more than a hundred examples of organic molecules possessing their 2PA maximum beyond $1100 \mathrm{~nm}$ were reported in the literature, to the best of our knowledge. This third section aims to provide an exhaustive compilation of these dyes, including their linear and nonlinear absorption maxima in a given solvent, the corresponding 2PA cross-sections and the measurement methods used (data compiled in Table 1, at the end of the Section 3).

\section{Dipoles and quadrupoles}

The first example of 2PA in the NIR using a dipolar chromophore was reported in 2004: a photorefractive polymer composite doped with the chromophore 63 was excited at 1550 $\mathrm{nm}$ by a 2PA process but no molecular cross-section was recorded (Figure 24). ${ }^{225}$ In the following year, the groups of 
Marder and Van Stryland have developed a family of D- $D^{\prime}-A^{\prime}-A$ dipoles incorporating electron-rich pyrrole rings and moderately electron-poor thiazoles, respectively as auxiliary donor and acceptor units along the conjugated backbone and reported the first molecular $\sigma_{2 \mathrm{PA}}$ of $1500 \mathrm{GM}$ at $1440 \mathrm{~nm}$ for 64 (Figure 24).226 This new dye settled the benchmark level of activity for this whole emerging field of research. The same group also published in 2007 a series of quadrupolar A-D-A dyes incorporating central thiophene (65) or pyrrole rings (66). ${ }^{227}$
Such chromophores present strong electron-withdrawing extremities and an extended $\pi$ system rigidified by weakly aromatic intermediary groups, these factors being known to highly optimize the ICT. The pyrrole-containing molecule 66 exhibits a narrow and intense 1PA in the $600-800 \mathrm{~nm}$ range; however, because of the centrosymmetry of the quadrupole, the 2PA is blue-shifted and shows a maximum cross-section of $5900 \mathrm{GM}$ at $1240 \mathrm{~nm}$. Moderate 2PA beyond $1100 \mathrm{~nm}$ was also<smiles>CCCCNc1ccc(/C=C/C=C/C=C2/C(=C(C#N)C#N)c3ccccc3S2(=O)=O)cc1</smiles>

63
at $1550 \mathrm{~nm}$<smiles></smiles>

64 (fs-WLC) $\sigma_{2 \mathrm{PA}}=1500 \mathrm{GM}$ at $1440 \mathrm{~nm}$

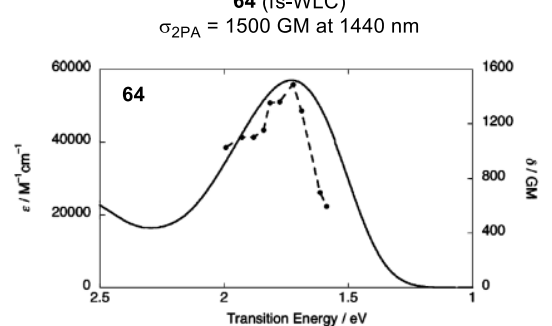

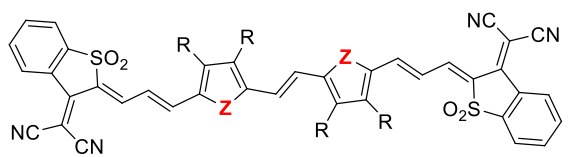

$65 \mathrm{Z}=\mathrm{S}, \mathrm{R}=\mathrm{OBu}$ $\sigma_{2 \mathrm{PA}}=3800 \mathrm{GM}$ at $1040 \mathrm{~nm}$ (fs-z-scan) $\sigma_{2 \mathrm{PA}}=5900 \mathrm{GM}$ at $1240 \mathrm{~nm}$ (fs-z-scan)
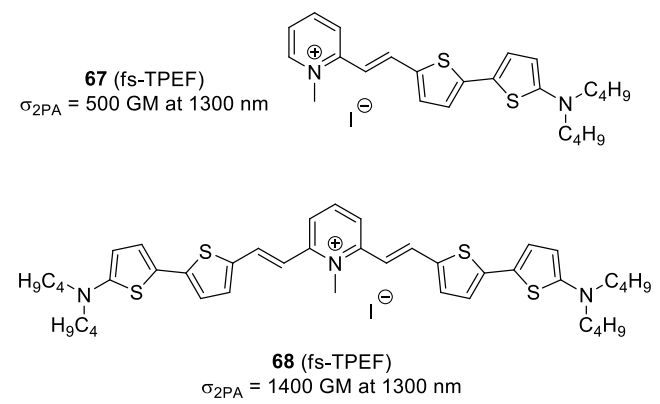

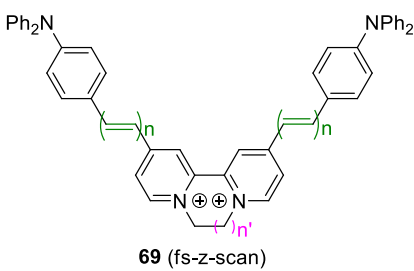

a $\mathrm{n}=1, \mathrm{n}^{\prime}=1, \sigma_{2 \mathrm{PA}}=280 \mathrm{GM}$ at $1130 \mathrm{~nm}$ b $\mathrm{n}=2, \mathrm{n}^{\prime}=1, \sigma_{2 \mathrm{PA}}=550 \mathrm{GM}$ at $1130 \mathrm{~nm}$ c $n=1, n^{\prime}=2, \sigma_{2 P A}=165 \mathrm{GM}$ at $1130 \mathrm{~nm}$ d $n=2, n^{\prime}=2, \sigma_{2 P A}=135 \mathrm{GM}$ at $900 \mathrm{~nm}$

$\mathrm{Ph}_{2}$

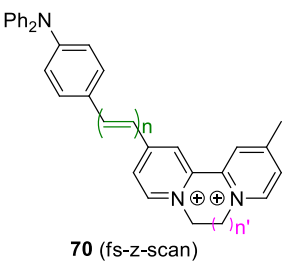

a $\mathrm{n}=1, \mathrm{n}^{\prime}=1, \sigma_{2 \mathrm{PA}}=260 \mathrm{GM}$ at $1190 \mathrm{~nm}$ b $\mathrm{n}=2, \mathrm{n}^{\prime}=1, \sigma_{2 \mathrm{PA}}=670 \mathrm{GM}$ at $1190 \mathrm{~nm}$ c $\mathrm{n}=1, \mathrm{n}^{\prime}=2, \sigma_{2 \mathrm{PA}}=310 \mathrm{GM}$ at $1130 \mathrm{~nm}$ d $n=2, n^{\prime}=2, \sigma_{2 P A}=340 \mathrm{GM}$ at $1130 \mathrm{~nm}$

Figure 24. Dipoles and quadrupoles featuring 2PA beyond $1100 \mathrm{~nm}$. Linear absorption (plain line) and 2PA (dashed line, half wavelength) spectra of 64 in THF. Reprinted with permission from reference ${ }^{226}$. Copyright 2005 American Chemical Society.

reported for several other thiophene-containing polyenes that feature dicyanovinyl (see $\mathbf{4 f}$ in Figure 4), ${ }^{51}$ pyridinium ${ }^{228}$ or quinolinium ${ }^{229}$ acceptors. Interestingly, the methylpyridiniumterminated compounds $\mathbf{6 7}$ and $\mathbf{6 8}$ depicted Figure 24, illustrate well the strong 2PA enhancement (three-fold increase in this example) that occurs going from dipolar to quadrupolar structures.

In 2010, Coe and co-workers developed two series of dipolar and bis-dipolar salts incorporating diphenylamino(phenyl) electron-donor group(s) and a strong electron-withdrawing diquaternized bipyridyl core (69 and 70) which feature 2PA in the $1000-1200 \mathrm{~nm}$ range. ${ }^{230}$ Elongation of the conjugated path leads to higher $\sigma_{2 \mathrm{PA}}$ values when going from $69 \mathrm{a}$ to $69 \mathrm{~b}$ and $70 \mathrm{a}$ to $\mathbf{7 0 b}$, whereas the lengthening of the diquaternized bridge results in a dramatic decrease of the 2PA efficiency due to the possible torsion between the two pyridinium units. Importantly, the mono-functionalized analogues 70a-d exhibit higher $\sigma_{2 \mathrm{PA}}$ values at lower energy, certainly due to the stronger electronwithdrawing character of the mono-functionalized diquat moieties compared to the bis-dipolar structures.

Several studies of the 2PA of perylene-bisdicarboximides are present in the literature, however, since these chromophores generally absorb in the green-yellow region, their nonlinear absorption is located ca. 700-800 nm. Nevertheless, Wasielewski and co-workers synthesized donor-substituted dyes and showed that the substitution in positions 1 and 7 using dialkylamino (71) of $p$-aminophenyl-ethynyl (72) moieties is efficient to red-shift the 1PA absorption beyond $700 \mathrm{~nm}$ and thus record 2PA in the NIR (Figure 25). ${ }^{231}$ The compound 72 exhibits a cross-section of $700 \mathrm{GM}$ ca. $1350 \mathrm{~nm}$, which is significantly lower than ones of the previously presented D-A-D oligophenylenevinylenes. According to 2PA selection rules for centrosymmetric molecules, the 2PA maximum is blue-shifted compared to the $S_{0} \rightarrow S_{1}$ transition.

New generations of quadrupolar chromophores were more recently developed and introduce nitrogen- or sulphurcontaining fused heterocyclic electron-donor cores. In 2017, a highly electron-rich pyrrolo[3,2-b]pyrrole was attached to two azulenyl polyaromatic hydrocarbons to form the quadrupolar A-D-A chromophores 73 and $\mathbf{7 4}$ (Figure 26). ${ }^{232}$ In contrast with 


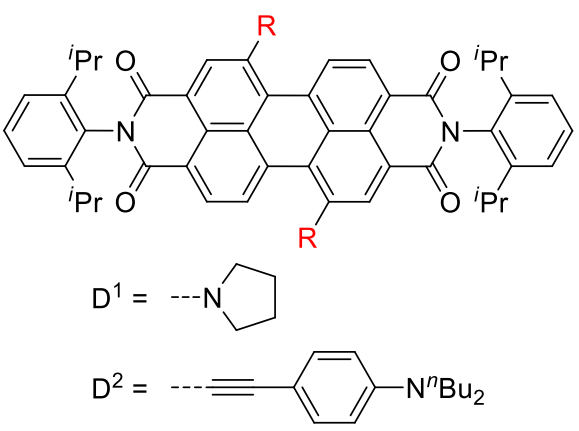

$71 \mathrm{R}=\mathrm{D}^{1}$

$\sigma_{2 \mathrm{PA}}=200 \mathrm{GM}$ ca. $1150 \mathrm{~nm}$ (fs-z-scan)

$72 R=D^{2}$

$\sigma_{2 \mathrm{PA}}=700 \mathrm{GM}$ ca. $1350 \mathrm{~nm}$ (fs-z-scan)

Figure 25. Perylene-bisdicarboximides D-A-D structures.

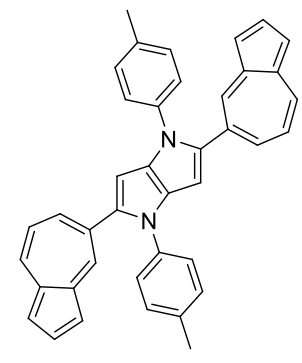

73 (fs-z-scan) $\sigma_{2 \mathrm{PA}}=100 \mathrm{GM}$ at $1550 \mathrm{~nm}$, $200 \mathrm{GM}$ at 1350 and $1250 \mathrm{~nm}$

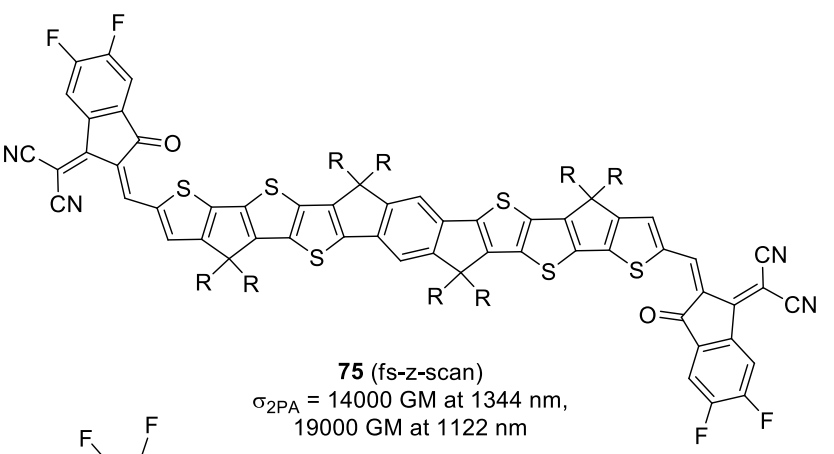

Figure 26. Quadrupoles featuring fused heterocyclic cores.

previously reported 2PA properties of pyrrolopyrroles, ${ }^{233}$ these two examples show nonlinear absorption in the SWIR due to a strong ICT, with however modest 2PA cross-sections varying between $100-200 \mathrm{GM}$ in the $1200-1600 \mathrm{~nm}$ range for 73 . In 2020, the latest works by Perry and Marder were dedicated to fused-ring quadrupoles introducing indacene and thieno[3,2$b$ ]thiophene electron-rich cores that show exceptionally strong 2PA due to the particularly efficient ICT. ${ }^{234}$ Consequently, while cross-sections higher than $6000 \mathrm{GM}$ are measured for the smallest compounds, the most extended quadrupoles $\mathbf{7 5}$ and $\mathbf{7 6}$ present huge values reaching 14000 and $27000 \mathrm{GM}$ around $1345 \mathrm{~nm}$.

This subsection shows that it is possible to reach impressive 2PA cross-sections with quadrupolar structures, especially if they incorporate electron-rich (fused) thiophene units. However, this approach appears to be limited by the intrinsic 2PA selection rules for centrosymmetric molecules and requires particularly extended structures, thus synthetic efforts, to locate the 2PA maximum wavelength around $1500 \mathrm{~nm}$. It is worthy to mention here that several dipolar and quadrupolar dyes incorporating benzo-bis-thiadiazole moieties show NIR absorptions and are widely used for the development of several NIR-II imaging agents (with fluorescence beyond $1000 \mathrm{~nm}$ ), 87 however their NLO properties are still to be investigated and are expected to present 2PA in the SWIR. As an example, a series of polyenes incorporating thiophene rings, strong benzothiadiazole acceptors and chiral non-conjugated decorations was theoretically found to exhibit two-photon circular dichroism (2PCD) in the $1200-1300 \mathrm{~nm}$ range. ${ }^{235}$

\section{Polymethine dyes}

The polymethine dyes rapidly appeared to be attractive candidates for 2PA in the SWIR due to the optimal delocalization of their $\pi$ electrons along an odd number of carbon atoms. In 2008, Rebane proposed to use Styryl 9M (77, Figure 27) as a standard for the 2PA cross-section determination using TPEF method in the NIR. This fluorescent merocyanine exhibits a maximum 2PA cross-section of $780 \mathrm{GM}$ at $1240 \mathrm{~nm}$, which however drops to $8.4 \mathrm{GM}$ at $1550 \mathrm{~nm} \cdot{ }^{46}$

The 2PA of a series of symmetrical polymethine dyes were then systematically investigated by Van Stryland and coworkers (Figure 28). ${ }^{236-239}$ Their comprehensive studies highlighted that all polymethines exhibit analogous 2PA profiles with two bands that were rationalized as followed: the lower energy 2PA bands is generally weak and can be superimposed of the $S_{0} \rightarrow S_{1}$ one photon transition. ${ }^{240}$ This indicates that the transition towards the first excited state is forbidden using a two-photon excitation for symmetry reason but becomes partially allowed due to vibronic coupling that induce a symmetry breaking of the ground state electronic structure. ${ }^{240}$ The second 2PA transition is intense and blue-shifted and is assigned to a dark state, inactive in one-photon excitation but that is fully allowed using a two-photon one. This behaviour is well illustrated with trimethine 78a (Figure 28) displaying two 2PA bands with cross-sections equal to 50 and $280 \mathrm{GM}$ at 1030 and $664 \mathrm{~nm}$, respectively. In this series, the 2PA maximum is red-shifted by about $140 \mathrm{~nm}$ for every two carbon atoms elongation of the polymethine chain. This bathochromic shift is accompanied by a strong increase of the 2PA cross-section that reaches $200 \mathrm{GM}$ at $1310 \mathrm{~nm}$ for the heptamethine $\mathbf{7 8 c}$. 
<smiles>CN(C)c1ccc(/C=C/C2=C/C(=C/c3sc4ccccc4[n+]3C)CC(C)(C)C2)cc1</smiles>

77

$\sigma_{2 P A}=780 \mathrm{GM}$ at $1240 \mathrm{~nm}$ (fs-TPEF)

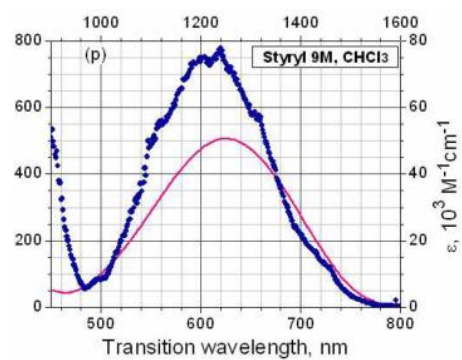

Figure 27. Structure of Styryl 9M (77) and plot of its 1PA (line) vs 2PA (dots) (bottom: $\lambda_{1 \mathrm{PA} ;}$ top: $\lambda_{2 \mathrm{PA}}$ ) spectra in $\mathrm{CHCl}_{3}$ on a doubled wavelength scale. Reprinted with permission from reference ${ }^{46} \odot$ The Optical Society.

The best result of the series is measured in the case of heptamethine $79 \mathrm{c}$ incorporating indolenium extremities $\left(\sigma_{2 \mathrm{PA}}=\right.$ $600 \mathrm{GM}$ at $1330 \mathrm{~nm}$ ). Quite surprisingly, the stiffening of the conjugated skeleton in $\mathbf{8 0}$ leads to a blue-shift of 2PA and a reduced cross-section compared to $\mathbf{7 8 b}$. This observation is possibly explained by the reduction of the vibronic phenomena due to partial cyclization of the bridge. Heptamethines 79c and 81 confirmed this tendency, with a $600 \mathrm{GM}$ cross-section for the non-rigidified dye and $60 \mathrm{GM}$ for the stiffened analogue. Finally, the nonamethine $\mathbf{8 2}$ presents the most intense and red-shifted 2PA of the series, with $600 \mathrm{GM}$ around $1500 \mathrm{~nm}$.
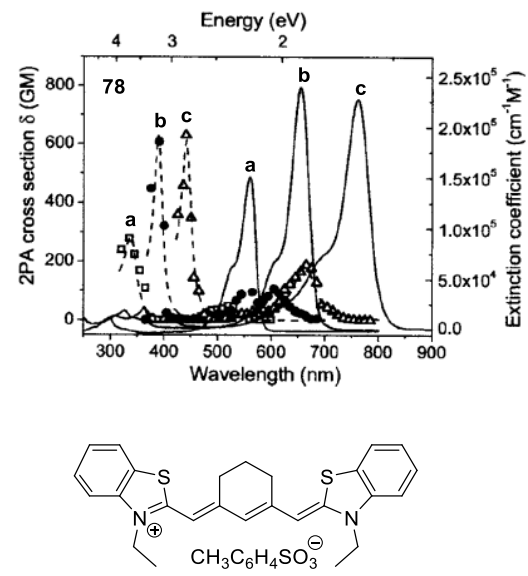

80

$1^{\text {st }}$ band: $\sigma_{2 \mathrm{PA}}=55 \mathrm{GM}$ at $1160 \mathrm{~nm}$ (fs-TPEF) $2^{\text {nd }}$ band: $\sigma_{2 P A}=700 \mathrm{GM}$ at $780 \mathrm{~nm}$ (fs-z-scan)

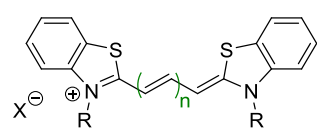

78a $\mathrm{n}=1, \mathrm{R}=\mathrm{Et}, \mathrm{X}=\mathrm{CH}_{3} \mathrm{C}_{6} \mathrm{H}_{4} \mathrm{SO}_{3}^{-}$ $1^{\text {st }}$ band: $\sigma_{2 \mathrm{PA}}=50 \mathrm{GM}$ at $1030 \mathrm{~nm}$ (fs-TPEF) $2^{\text {nd }}$ band: $\sigma_{2 \mathrm{PA}}=280 \mathrm{GM}$ at $664 \mathrm{~nm}$ (fs-z-scan)

78b $\mathrm{n}=2, \mathrm{R}=\mathrm{Me}, \mathrm{X}=\mathrm{CH}_{3} \mathrm{C}_{6} \mathrm{H}_{4} \mathrm{SO}_{3}$ $1^{\text {st }}$ band: $\sigma_{2 \mathrm{PA}}=100 \mathrm{GM}$ at $1170 \mathrm{~nm}$ (fs-TPEF) $2^{\text {nd }}$ band: $\sigma_{2 P A}=600 \mathrm{GM}$ at $770 \mathrm{~nm}$ (fs-z-scan)

$78 \mathrm{c} n=3, \mathrm{R}=\mathrm{Me}, \mathrm{X}=\mathrm{I}^{-}$

$1^{\text {st }}$ band: $\sigma_{2 \mathrm{PA}}=200 \mathrm{GM}$ at $1310 \mathrm{~nm}$ (fs-TPEF) $2^{\text {nd }}$ band: $\sigma_{2 P A}=880 \mathrm{GM}$ at $880 \mathrm{~nm}$ (fs-z-scan)

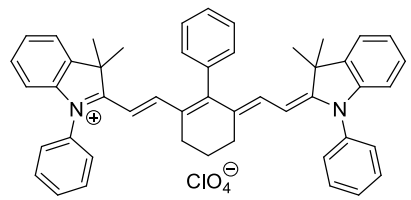

81

$1^{\text {st }}$ band: $\sigma_{2 \mathrm{PA}}=60 \mathrm{GM}$ at $1340 \mathrm{~nm}$ (fs-TPEF) $2^{\text {nd }}$ band: $\sigma_{2 P A}=1200 \mathrm{GM}$ at $920 \mathrm{~nm}$ (fs-z-scan)

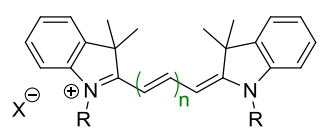

79a $\mathrm{n}=1, \mathrm{R}=\mathrm{Me}, \mathrm{X}=\mathrm{BF}_{4}^{-}$

$1^{\text {st }}$ band: $\sigma_{2 P A}=10 \mathrm{GM}$ at $980 \mathrm{~nm}$ (fs-TPEF)

$2^{\text {nd }}$ band: $\sigma_{2 P A}=470 \mathrm{GM}$ at $710 \mathrm{~nm}$ (fs-z-scan)

$79 b \mathrm{n}=2, \mathrm{R}=\mathrm{C}_{3} \mathrm{H}_{7}, \mathrm{X}=\mathrm{I}^{-}$

$1^{\text {st }}$ band: $\sigma_{2 \mathrm{PA}}=140 \mathrm{GM}$ at $1180 \mathrm{~nm}$ (fs-TPEF)

$2^{\text {nd }}$ band: $\sigma_{2 P A}=720 \mathrm{GM}$ at $780 \mathrm{~nm}$ (fs-z-scan)

$79 \mathrm{c} n=3, \mathrm{R}=\mathrm{C}_{6} \mathrm{H}_{5}, \mathrm{X}=\mathrm{ClO}_{4}^{-}$

$1^{\text {st }}$ band: $\sigma_{2 \mathrm{PA}}=600 \mathrm{GM}$ at $1330 \mathrm{~nm}$ (fs-TPEF)

$2^{\text {nd }}$ band: $\sigma_{2 P A}=2550 \mathrm{GM}$ at $906 \mathrm{~nm}$ (fs-z-scan)

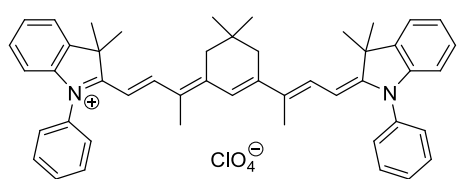

82

$1^{\text {st }}$ band: $\sigma_{2 P A}=600 \mathrm{GM}$ at $1480 \mathrm{~nm}$ (fs-TPEF) $2^{\text {nd }}$ band: $\sigma_{2 \mathrm{PA}}=2550 \mathrm{GM}$ at $1040 \mathrm{~nm}$ (fs-z-scan)

Figure 28. 2PA properties of selected cationic polymethines. Linear absorption (plain line) and 2PA (dashed line) spectra of series 78 in ethanol. Adapted with permission from reference 236 (c) The Optical Society.<smiles>CC1(C)CC(/C=C/C2=C(Cl)/C(=C/C=C3/N(Cc4ccccc4)c4ccccc4C3(C)C)CC([R18]Br)C2)C(C)(C)c2ccccc21</smiles>

83

$\sigma_{2 \mathrm{PA}}=731 \mathrm{GM}$ at $1437 \mathrm{~nm}$ (fs-z-scan)

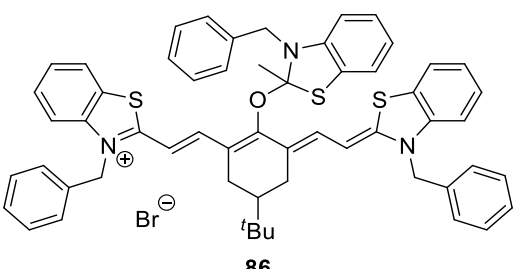

$\sigma_{2 \mathrm{PA}}=544 \mathrm{GM}$ at $1495 \mathrm{~nm}$ (fs-z-scan)<smiles>CC1(C)OC(=C(CN)CN)C(N)=C1C=CC1=C(Cl)C(=CC=C2N(Cc3ccccc3)c3ccccc3C2(C)C)CC(Br)C1</smiles>

84

$\sigma_{2 \mathrm{PA}}=792 \mathrm{GM}$ at $1445 \mathrm{~nm}$ (fs-z-scan)

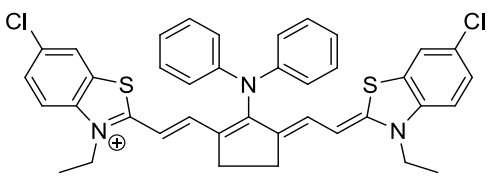

87

$\sigma_{2 \mathrm{PA}}=950 \mathrm{GM}$ at $1552 \mathrm{~nm}(\mathrm{fs}-\mathrm{TPEF})$

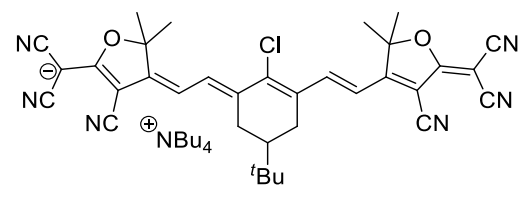

85 $\sigma_{2 \mathrm{PA}}=890 \mathrm{GM}$ at $1592 \mathrm{~nm}$ (fs-z-scan)

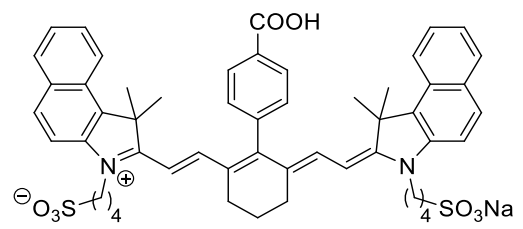

88

$\sigma_{2 \mathrm{PA}}=900 \mathrm{GM}$ at $1552 \mathrm{~nm}(\mathrm{fs}-\mathrm{TPEF})$

Figure 29. 2PA of selected heptamethines and influence of central substitution. 
The heptamethines 83-86 depicted in Figure 29 were developed by our group for optical limiting applications at around $1500 \mathrm{~nm}$ (see Section 4). ${ }^{241,} 242$ Surprisingly, within this series of polymethines rigidified using a tert-butylcyclohexenyl framework, no detrimental effect of the stiffening is observed, in contrast with compounds $\mathbf{8 0}$ and $\mathbf{8 1}$. The symmetrical indolenium-heptamethine $\mathbf{8 3}$ presents a significant 2PA crosssection of $544 \mathrm{GM}$ ca. $1500 \mathrm{~nm}$. The impact of ion-pairing occurring in nonpolar solvent (toluene) between a polymethine analogue of $\mathbf{8 3}$ and a small bromine anion was recently investigated and reveals a slight blue-shift of the 2PA maximum and a lower $\sigma_{2 \mathrm{PA}}$ value with $310 \mathrm{GM}$ at $1400 \mathrm{~nm}$, mainly due to the loss of the cyanine electronic structure for a dipolar polyene-like one. ${ }^{119}$ Dissymmetrical heptamethine 84 exhibits a profound modification of its electronic structure from cyanine to dipole upon decreasing the solvent polarity. This equilibrium implies a broadening of the 1PA spectrum, thus this merocyanine shows a broad 2PA from 1200 to $1700 \mathrm{~nm}$ with a maximum of $790 \mathrm{GM}$ at $1445 \mathrm{~nm}$. Of particular interest, the rare example of anionic polymethine $\mathbf{8 5}$, featuring strongly electronwithdrawing tricyanofuran end groups, displays a red-shifted $1 \mathrm{PA}$ at $900 \mathrm{~nm}$ and thus an important 2PA with a maximum cross-section of $890 \mathrm{GM}$ at $1600 \mathrm{~nm}$. $^{126,242}$ Noteworthy, various salts of anionic polymethine $\mathbf{8 5}$ were used as dopant in polycarbonate-based thin films for all-optical signal processing applications and demonstrated enhanced third order nonlinearities at $1550 \mathrm{~nm}$ in silicon-organic hybrid waveguides, compared to inorganic blends. ${ }^{243}$

A positive effect of the substitution of the polymethine bridge at the central position is observed for compound 87, studied by Achilefu, Berezin and co-workers for its potential use as molecular probe in two-photon bio-imaging experiments. ${ }^{244}$ Indeed, the 2PA cross-section around $1550 \mathrm{~nm}$ is nearly doubled upon introduction of a central diphenylamine substituent, by comparison with the substitution with an oxygen atom in $\mathbf{8 6}$. It is worthy to note that this study also reports the 2PA of the Indocyanine Green 31 (see Figure 16), with $\sigma_{2 \mathrm{PA}}=590 \mathrm{GM}$ at $1552 \mathrm{~nm}$, and a decorated analogue 88, which also features a substantial increase of the 2PA cross-section (900 GM at the same wavelength) upon central substitution with a phenyl moiety.

Marks and Prasad reported that tictoid twisted systems such as 89a can be coupled to polymethine structures at the central position to enhance the third order nonlinear response (Figure 30). ${ }^{245-247}$ The 2PA of cationic 91 shows a cross-section of $c a .45$ $\mathrm{GM}$ at $1305 \mathrm{~nm}$ and an additional weak band at $1410 \mathrm{~nm}$, which highlight a cooperative coupling effect that occurs in the dyad compared to the corresponding thiopyrylium-based heptamethine 90. It is worthy to underline that the latter compound has a linear absorption peaking at $c a .1040 \mathrm{~nm}$, thus it is reasonable to expect that its 2PA maximum should be located beyond $1600 \mathrm{~nm}$.

The first studies of the third order nonlinear optical properties of bis-dioxaborine-containing polymethines, among which 93 and 94, were reported in 2006 by Marder, Perry and co-workers for all-optical signal processing applications (Figure 31). ${ }^{248}$ In this context, Padilha and colleagues described in 2009 the D-A polymethine $\mathbf{9 2} \mathbf{b}$ that shows strong solvent-dependent absorption spectra, like merocyanine 85 (Figure 29), which confers to the compound a dipolar polyene-like absorption in

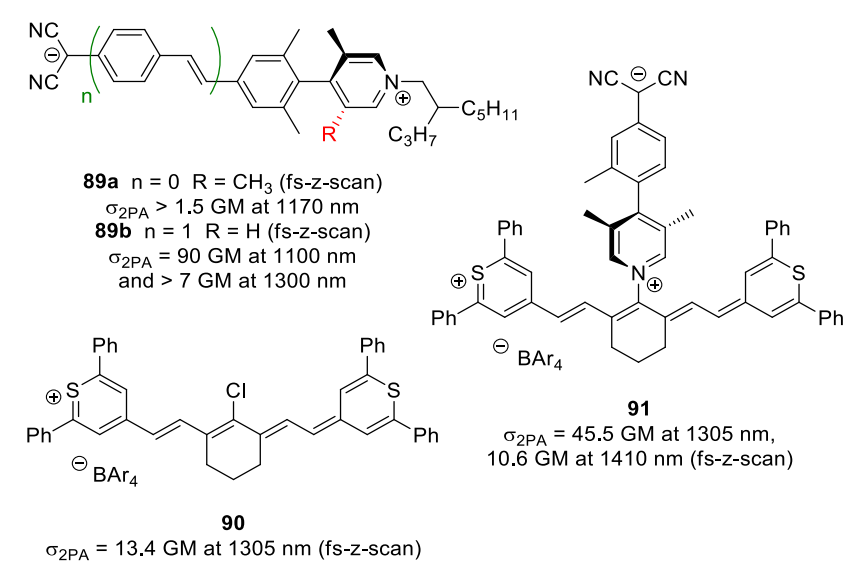

Figure 30 . Combination of cationic polymethine and tictoid zwitterion. 
<smiles>CCNc1ccc2c3c(c(=O)oc2c1)OP(F)(F)=[W]3=N</smiles>

$1^{\text {st }}$ band: $\sigma_{2 \mathrm{PA}} \mathrm{ca} .800 \mathrm{GM}$ at $1250 \mathrm{~nm}$ $2^{\text {nd }}$ band: $\sigma_{2 \mathrm{PA}}=5000 \mathrm{GM}$ at $900 \mathrm{~nm}$

92b $\mathrm{n}=2$, (fs-z-scan) in MeCN $1^{\text {st }}$ band: $\sigma_{2 \mathrm{PA}}$ ca. $1000 \mathrm{GM}$ at $1450 \mathrm{~nm}$ $2^{\text {nd }}$ band: $\sigma_{2 \mathrm{PA}}=10000 \mathrm{GM}$ at $980 \mathrm{~nm}$

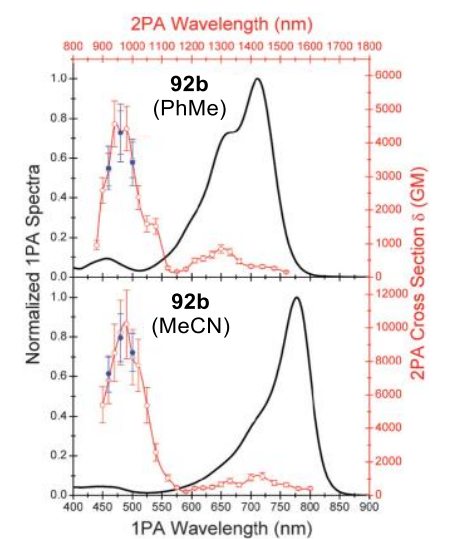<smiles>[Y]Oc1c(/C(=C/C=C/C(=O)c2c(O[B-](F)(F)F)oc3ccc(NCC)cc3c2=O)O[B-](F)(F)F)c(=O)oc2cc(N=CC)ccc12</smiles>

93a $\mathrm{n}=1, \mathrm{X}=\mathrm{HNBu}_{3}{ }^{+}$(fs-z-scan) $1^{\text {st }}$ band: $\sigma_{2 \mathrm{PA}}=140 \mathrm{GM}$ at $1120 \mathrm{~nm}$ $2^{\text {nd }}$ band: $\sigma_{2 \mathrm{PA}}=2900 \mathrm{GM}$ at $860 \mathrm{~nm}$

93b $\mathrm{n}=2, \mathrm{X}=\mathrm{HNBu}_{3}{ }^{+}$(fs-z-scan) $1^{\text {st }}$ band: $\sigma_{2 \mathrm{PA}}=710 \mathrm{GM}$ at $1300 \mathrm{~nm}$ $2^{\text {nd }}$ band: $\sigma_{2 P A}=8800 \mathrm{GM}$ at $940 \mathrm{~nm}$

93c $\mathrm{n}=3, \mathrm{X}=\mathrm{HN}\left({ }^{i} \mathrm{Pr}\right)_{2} \mathrm{Bu}^{+}$(fs-z-scan) $1^{\text {st }}$ band: $\sigma_{2 \mathrm{PA}}=1100 \mathrm{GM}$ at $1450 \mathrm{~nm}$ $2^{\text {nd }}$ band: $\sigma_{2 \mathrm{PA}}=15000 \mathrm{GM}$ at $960 \mathrm{~nm}$

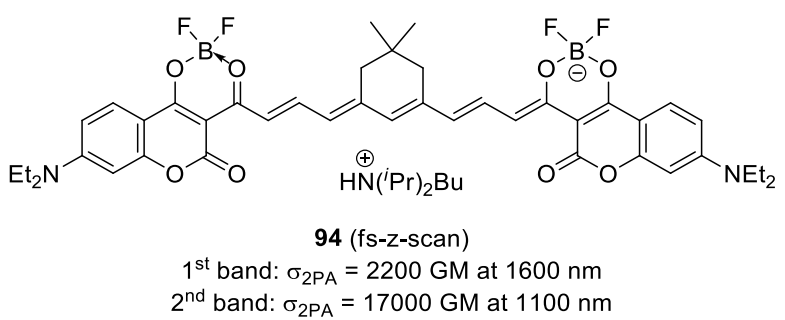

Figure 31. Dioxaborine polymethines incorporating coumarin end groups. Linear absorption (black) and 2PA (red) spectra of 92b in toluene (top) and acetonitrile (bottom). Reproduced from reference ${ }^{249}$ with permission from The Royal Society of Chemistry.

toluene $\left(\varepsilon \sim 124000 \mathrm{M}^{-1} \mathrm{~cm}^{-1}\right.$ at $\left.712 \mathrm{~nm}\right)$ and a cyanine-like one in acetonitrile $\left(\varepsilon \sim 232000 \mathrm{M}^{-1} \mathrm{~cm}^{-1}\right.$ at $\left.777 \mathrm{~nm}\right) .{ }^{249}$ Consequently, a strong ten-fold modulation of the cross-section is observed when measuring 2PA in toluene (4700 GM at $960 \mathrm{~nm}$ ) or acetonitrile ( $10000 \mathrm{GM}$ at $980 \mathrm{~nm}$ ). However, the impact of this electronic reorganization is less pronounced for $2 \mathrm{P}$ transitions measured ca. $1300 \mathrm{~nm}$. In 2010, Padilha, Van Stryland and coworkers extended the scope of anionic polymethines using coumarin-dioxaborine extremities in 93a-c. ${ }^{250}$ The lengthening of the conjugated path allows reaching large cross-sections with $1100 \mathrm{GM}$ at $1450 \mathrm{~nm}$ for 93c and $2200 \mathrm{GM}$ at $1600 \mathrm{~nm}$ for the nonamethine analogue 94. Impressively, the second twophoton band reaches impressive values, with 15000 to 17000 $\mathrm{GM}$ around $1100 \mathrm{~nm}$ within this series. The elevation of the 2PA cross-section is probably due to the extension of the end group conjugation brought by the coumarin-dioxaborine extremities, as well as the ICT enforcement afforded by the terminal diethylamine donors. ${ }^{251,252}$

Van Stryland and colleagues prepared a cationic 2azaazulene 95 featuring a strepto (i.e. unrigidified) polymethine bridge with a $2250 \mathrm{GM}$ cross-section at $1800 \mathrm{~nm}$ in dichloromethane (Figure 32). ${ }^{253}$ The optical measurements in acetonitrile solution show the presence of symmetric and asymmetric forms of the dye due to the symmetry breaking that occurs in polar solvent for this unstiffened polymethine chain. ${ }^{110,112,240}$ This equilibrium results in the broadening of the 1PA spectrum and a blue-shift of the lower energy transition. The authors demonstrate that for the symmetric form, the 2PA band has a purely vibronic origin and appears at higher energy

compared to the $\mathrm{S}_{0} \rightarrow \mathrm{S}_{1}$ transition. In the asymmetric form, 2PA becomes coincident with the main one-photon transition due to a lowered symmetry related to the variation of permanent dipole moment upon excitation.

The influence of the nature of the $\pi$-conjugated bridge was explored in the alkyne-pentamethine $\mathbf{9 6}$, which was compared to its alkene-pentamethine analogue 97 (Figure 33). ${ }^{254}$ Despite exhibiting a large bond-length alternation, the alkyne carbocation shows characteristics analogous to cyanines, such

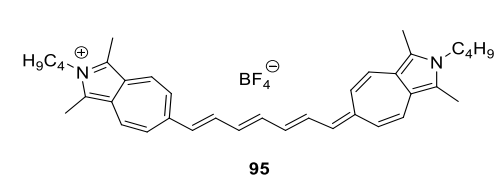

$\sigma_{2 \mathrm{PA}}=2250 \mathrm{GM}$ at $1800 \mathrm{~nm}$ (fs-z-scan)

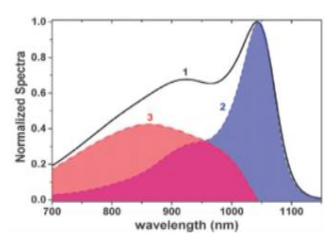

Figure 32. Aza-azulene-containing polymethine 95 (left) and its linear absorption in acetonitrile (right) with contributions of the symmetric form (blue area, ca. $42 \%$ ) and of the asymmetric form (red area, $c a .58 \%$ ). Reproduced from reference ${ }^{253}$ with permission from the PCCP Owner Societies.

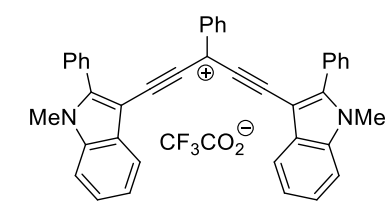

96

$\sigma_{2 \mathrm{PA}}<50 \mathrm{GM}$ ca. $1600 \mathrm{~nm}$, $150 \mathrm{GM}$ ca. $1350 \mathrm{~nm}$ (fs-ND-TPA)

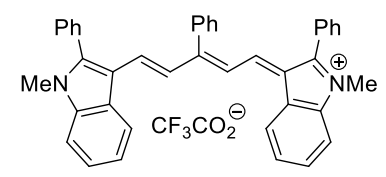

97 $\sigma_{2 \mathrm{PA}}=200 \mathrm{GM}$ at $1300 \mathrm{~nm}$ (fs-ND-TPA)
Figure 33. Influence of alkene vs alkyne polymethine bridge on the 2PA properties. 
as an intense and sharp near-infrared absorption $(\varepsilon \sim 76000$ $\mathrm{M}^{-1} \mathrm{~cm}^{-1}$ at $785 \mathrm{~nm}$ ). However, the low-energy 2PA transition of 96 found ca. $1600 \mathrm{~nm}\left(\sigma_{2 \mathrm{PA}}<50 \mathrm{GM}\right.$ ) is superimposed to the one-photon allowed transition. This behaviour is closer to the one of octupolar triarylmethyl cations such as Crystal Violet (see 48, Figure 19) and Brilliant Green. ${ }^{60}$ In contrast, the alkene polymethine analogue $97\left(\varepsilon \sim 69000 \mathrm{M}^{-1} \mathrm{~cm}^{-1}\right.$ at $\left.704 \mathrm{~nm}\right)$ has a weaker 2PA transition localized above the lowest energy 1PA band and shows $200 \mathrm{GM}$ at $1300 \mathrm{~nm}$.

The nonlinear absorption band of the classical pentamethine 98 is compared to the related squaraine (99) and tetraone (100) dyes featuring identical conjugated length in Figure 34. ${ }^{237}, 255$ These three structures exhibit characteristic cyanine-type absorption spectra and, consequently, the lower energy 2PA band can be superimposed with the vibronic shoulder of the one-photon main transition. Both squaraine $\mathbf{9 9}$ and tetraone 100 have a $650 \mathrm{GM}$ cross-section, but respectively localized at 1250 and $1150 \mathrm{~nm}$. The 2PA of zwitterionic squaraines can be enhanced by structural modifications, as illustrated below.

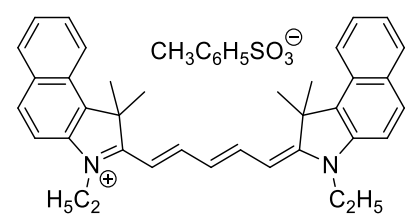

$\sigma_{2 \mathrm{PA}}=700 \mathrm{GM}$ ca. $1250 \mathrm{~nm}$ (fs-z-scan)

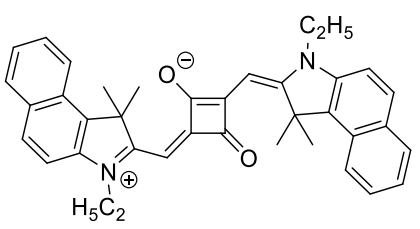

99

$\sigma_{2 \mathrm{PA}}=650 \mathrm{GM}$ ca. $1250 \mathrm{~nm}$ (fs-z-scan)

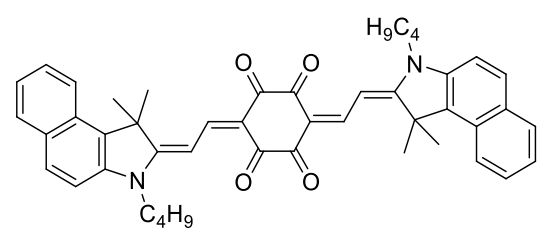

100

$\sigma_{2 \mathrm{PA}}=650 \mathrm{GM}$ ca. $1150 \mathrm{~nm}$ (fs-z-scan)

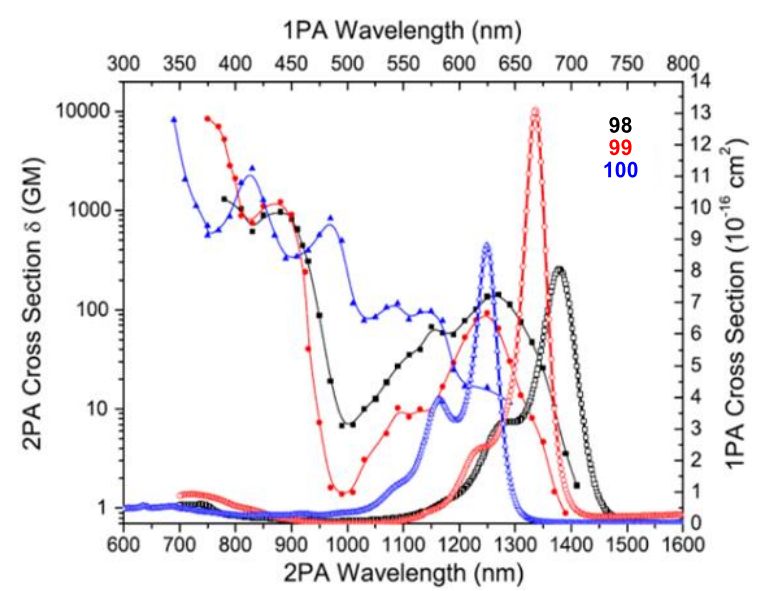

Figure 34. Comparison between 1PA and 2PA spectra of non-rigidified polymethine 98 (black), squaraine 99 (red) and tetraone 100 (blue). Adapted from reference ${ }^{237}$. Copyright 2008 Elsevier Science B.V. All rights reserved.

The first study of the 2PA properties of polymethine squaraines beyond $1100 \mathrm{~nm}$ was realized in 2002 by Scherer and co-workers. ${ }^{256}$ The monomer 101 displays two 2PA bands in the NIR region: a first long wavelength and low intensity band, noted $E_{2}$ on Figure $35\left(\sigma_{2 \mathrm{PA}}=483 \mathrm{GM}\right.$ at $\left.1240 \mathrm{~nm}\right)$ that matches well with the shoulder of the linear maximum absorption and a second blue-shifted band with higher crosssection, noted $E_{3}\left(\sigma_{2 \mathrm{PA}}=5065 \mathrm{GM}\right.$ at $\left.898 \mathrm{~nm}\right)$. In 2012, the structure of squaraine $\mathbf{1 0 1}$ was modified to introduce terminal indole rings substituted by ethylhexyl chains. ${ }^{257}$ The study reports a lower energy 2PA band at $1160 \mathrm{~nm}$ exhibiting a 1490 $\mathrm{GM}$ cross-section, and the high stability of this dye allowed the elaboration of an organic glass that holds promises for insertion in devices operating in the SWIR. The 2PA spectra of squaraine oligomers 102a-d show an important increase of the 2PA crosssection with the unexpected disappearance of the lower energy band $\left(E_{2}\right)$, accompanied by the intensification, red-shift and broadening of the second band $\left(E_{3}\right)$, presumably due to the multiplication of vibronic side bands (Figure 35). In 2016, the groups of Belfield and Van Stryland reported the synthesis of a star-shaped molecule $\mathbf{1 0 3}$ incorporating three squaraine units that show weak interactions together. ${ }^{258}$ Such design results in the measurement of a high 2PA cross-section of $1000 \mathrm{GM}$ at $1200 \mathrm{~nm}$, which shows a three-fold enhancement of 2PA per squaraine $\operatorname{arm}\left(\sigma_{2 \mathrm{PA}} / \mathrm{n} \sim 333 \mathrm{GM}\right)$ compared to the centrosymmetric unit 104 that features $100 \mathrm{GM}$ at the same wavelength. ${ }^{259}$
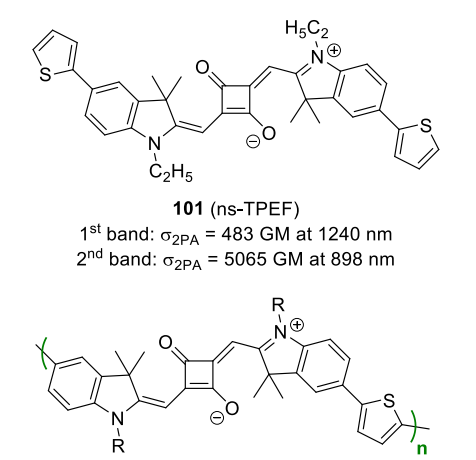

102a $n=2, \sigma_{2 P A}=4755 \mathrm{GM}$ at $1038 \mathrm{~nm}$

$102 \mathrm{~b} \mathrm{n}=3, \sigma_{2 \mathrm{PA}}=12945 \mathrm{GM}$ at $1064 \mathrm{~nm}$ $102 \mathrm{c} n=4, \sigma_{2 \mathrm{PA}}=17718 \mathrm{GM}$ at $1073 \mathrm{~nm}$ 102d $n=5, \sigma_{2 P A}=24760 \mathrm{GM}$ at $1078 \mathrm{~nm}$ $\sigma_{2 P A} / n=4952 \mathrm{GM}$
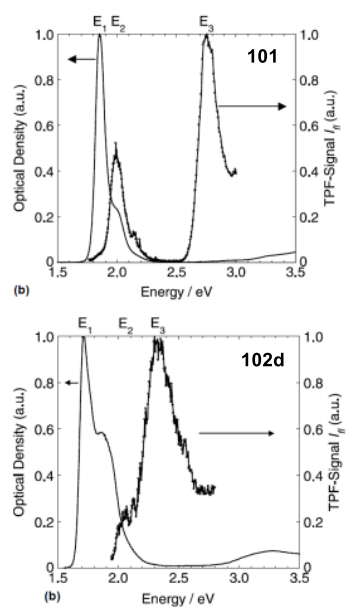

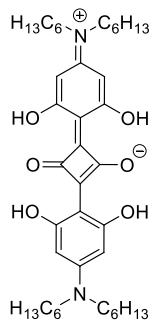

103 (fs-z-scan)

$1^{\text {st }}$ band: $\sigma_{2 \mathrm{PA}}=100 \mathrm{GM}$ at $1200 \mathrm{~nm}$ $2^{\text {nd }}$ band: $\sigma_{2 P A}=1000 \mathrm{GM}$ at $820 \mathrm{~nm}$

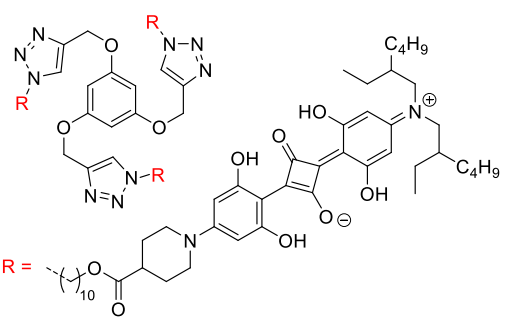

104 (fs-z-scan)

$1^{\text {st }}$ band: $\sigma_{2 \mathrm{PA}}=1000 \mathrm{GM}$ at $1200 \mathrm{~nm}$ $2^{\text {nd }}$ band: $\sigma_{2 \mathrm{PA}}=8000 \mathrm{GM}$ at $820 \mathrm{~nm}$
Figure 35. Squaraines and related oligomers. Linear absorption (plain line) and 2PA (dotted line) of compounds $\mathbf{1 0 1}$ and $\mathbf{1 0 2 d}$ in $\mathrm{CHCl}_{3}$. Adapted from reference ${ }^{256}$. Copyright 2002 Elsevier Science B.V. All rights reserved. 
In 2006, Brédas, Marder, Perry and co-workers optimized the squaraine structure through the elaboration of the extended compound 105, featuring auxiliary heterocycles and electron-donating dibutylaniline end groups (Figure 36). ${ }^{52}$ This chromophore presents a cyanine-shaped linear absorption $(\varepsilon$ $300000 \mathrm{M}^{-1} \mathrm{~cm}^{-1}$ at $832 \mathrm{~nm}$ ), a first 2PA band at $1500 \mathrm{~nm}$ with a $800 \mathrm{GM}$ cross-section and a second more intense transition at $1100 \mathrm{~nm}$ (18000 GM). Following the idea of mixing high ICT and extended conjugation, Duan, Zhan and co-workers prepared a low band-gap polymer based on the squaraine and pyridopyrazine units. ${ }^{260}$ Copolymer 106 exhibits a 2PA crosssection of $2300 \mathrm{GM}$ per repeated unit along a spectral range spanning from $1400 \mathrm{~nm}$ to $1650 \mathrm{~nm}$, which is more than three times higher than the constitutive unit $\mathbf{1 0 7}$. The authors justify these results by the high degree of conjugation and the strong delocalisation within the copolymer.

The octupolar cyclohexane-1,3,5-trione 108 (Figure 37), which is someway reminiscent of the quadrupolar tetraone structure $\mathbf{1 0 0}$ (Figure 34), can be seen as a tris-merocyanine dye and also displays several 2PA bands. ${ }^{261}$ The less intense 2PA transition lies at $1200 \mathrm{~nm}$ and is attributed to the lower energy transition $S_{0} \rightarrow S_{1}$, while the second band is blue-shifted, has a ten times higher intensity and is correlated to the $S_{0} \rightarrow S_{2}$ transition. ${ }^{60}$ The introduction of stronger electron-donor extremities such as benzothiazoles shifts the first band to lower energies but no 2PA cross-section was determined because of the limited spectral range related to the recording method.

In 2016, Lambert, Vauthey and co-workers reported the effect of exciton coupling on the 2PA of linear and branched indolenine-squaraine oligomers. ${ }^{262}$ In this series of squaraines, 109 and 110 show a batchochromic shift of the nonlinear absorption band from ca. 1200 to $1300 \mathrm{~nm}$ upon replacement
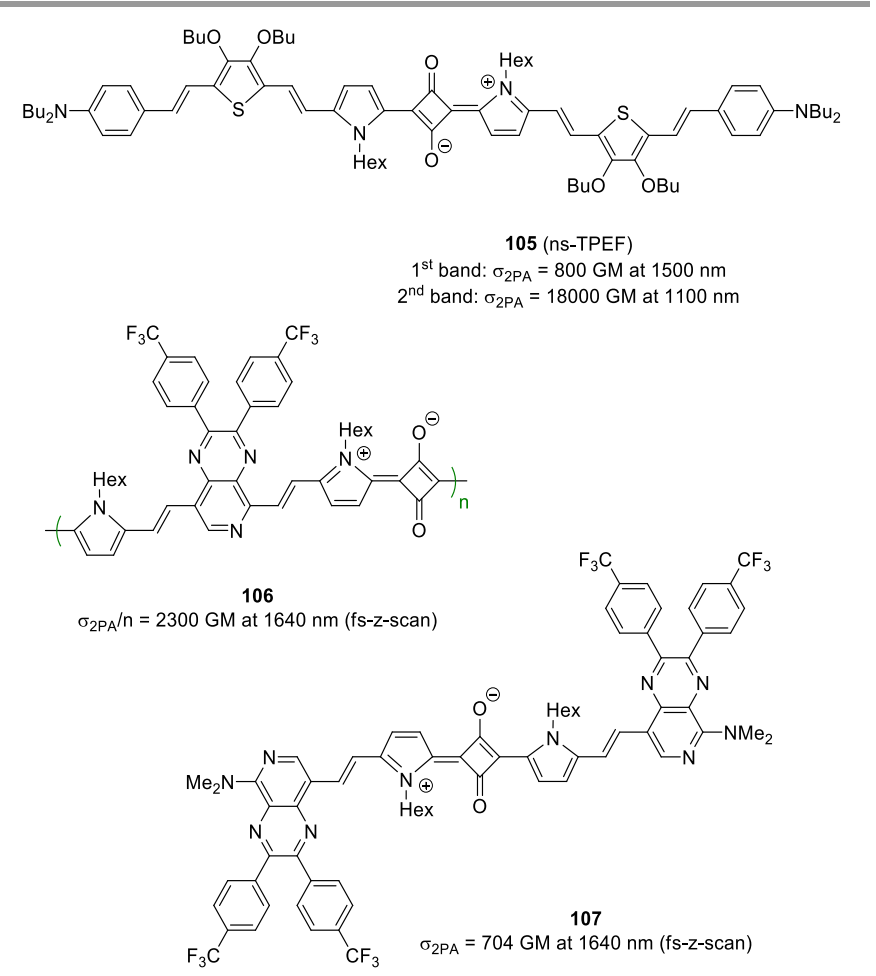

Figure 36. Extended squaraine derivatives.

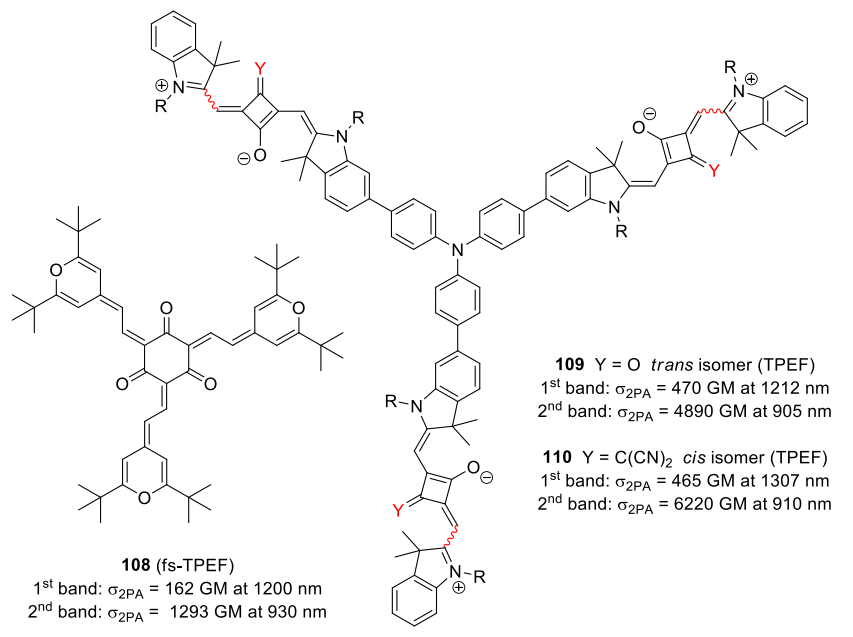

Figure 37. Octupolar merocyanine and branched squaraine derivatives.

of the oxygen atom of the squaric acid units with dicyanovinylene moieties. However, the 2PA cross-sections are estimated lower than for the squaraine trimer 104 (Figure 35), branched via a tri-substituted phenyl ring.

As mentioned in Section 2, (aza-)bodipy dyes can be considered as rigidified monomethine analogues and their structure can be tuned to reach absorption in the 700-800 $\mathrm{nm}$ range. Thus, they are attractive candidates for $2 \mathrm{PA}$ in the 1.3$1.5 \mu \mathrm{m}$ range and the first examples were reported simultaneously ca. 2009 by Prasad 263,264 and our group 265 (Figure 38). Molecules 111, 112 and 113 exhibit strong ICT from the electron-donor extremities towards the central electronwithdrawing (aza-)bodipy core via an extended conjugation pathway. The lower energy absorption band becomes broader compared to unsubstituted (aza-)bodipy dyes as a result of the mixing between charge transfer and cyanine-like transitions. ${ }^{169}$, 266 The 2PA recorded for $\mathbf{1 1 3}$ presents a relatively similar profile than that of cyanines with two transitions: a broad one spreading over the whole $1200-1600 \mathrm{~nm}$ range with a $600 \mathrm{GM}$ cross-section at $1500 \mathrm{~nm}$ and a very intense one at higher energy. Due to its high solubility in organic solvents and excellent chemical and photo-stability, this compound is particularly attractive for further use in optical power limiting devices (see Section 4). As expected, reducing the strength of

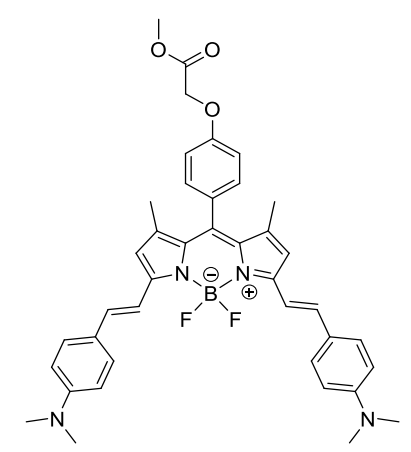

111

$\sigma_{2 \mathrm{PA}}=101 \mathrm{GM}$ at $1310 \mathrm{~nm}$ (fs-NLT)

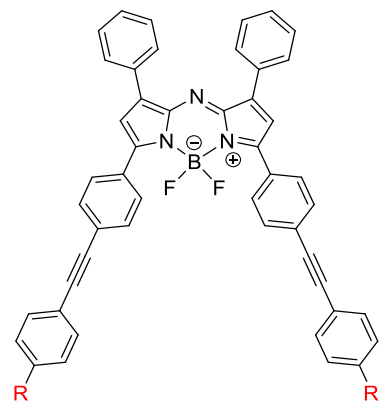

$112 \mathrm{R}=\mathrm{OMe}$ $113 \mathrm{R}=\mathrm{NHex}_{2}$ $\sigma_{2 \mathrm{PA}}=1070 \mathrm{GM}$ at $1220 \mathrm{~nm}$ (fs-z-scan) $\sigma_{2 \mathrm{PA}}=80 \mathrm{GM}$ at $1440 \mathrm{~nm}$ (fs-z-scan)

Figure 38. Bodipy and aza-bodipy derivatives with 2PA in the SWIR. 
the donor end group in $\mathbf{1 1 2}$ results in a dramatic decrease of the 2PA efficiency. Further investigations on dissymmetric and methoxy- or carbazole-substituted (aza)-bodipys report weaker cross-sections between $1200 \mathrm{~nm}$ and $1450 \mathrm{~nm}$, proving once again the need for a strong ICT to generate a consequent 2PA within this family. ${ }^{267-269}$ In 2013, comparative ZINDO and DFT calculations supported the importance of aza-bodipy core functionalization to achieve fine tuning of linear and nonlinear optical properties. ${ }^{270}$ This theoretical study predicted that introduction of thiophene and fluorene linkers, as well as the elaboration of aza-bodipy dimers, could allow reaching crosssections maxima up to $5000 \mathrm{GM}$.

In 2019, the introduction of different electron-withdrawing and electron-donating substituents on the aza-bodipy core was investigated at different positions to rationalize the effect of ICT on the 2PA properties. ${ }^{271}$ On Figure 39 , it can be seen that the substitution with nitrofluorenyl moieties on positions 3,5 of the aza-bodipy centre (114) results in a weak 2PA corresponding to the lowest energy linear absorption. This band is attributed to a cyanine-type transition, which is two-photon forbidden. In contrast, substitution on the same position with highly electrondonating dihexylamino(dihexylfluorenyl)ethynyl moieties in 115 enables a strong ICT towards the aza-bodipy core which results in a broadened and red-shifted linear absorption. The ICT is responsible for the high 2PA cross-sections measured at $1490 \mathrm{~nm}(1125 \mathrm{GM})$ and $1210 \mathrm{~nm}$ (3000 GM). It has been shown very recently that combination of electron-donating dihexylaminophenylethynyl groups and strongly electronwithdrawing benzothiadiazole moieties further increase ICT with a maximum cross section of $4520 \mathrm{GM}$ recorded at 1300 $\mathrm{nm} .{ }^{272}$ Theoretical calculations unravel that the increase of the $2 \mathrm{PA}$ cross-section in the SWIR is due to a mixed ICT and cyanine character of the lower energy transition, while the NIR band features the strongest $\sigma_{2 P A}$ and shows a pure ICT character. Upon substitution in positions 2,6 of the aza-bodipy core (116), a noticeable red-shift of the linear absorption is recorded, however the pseudo-quadrupolar structure of the dye results in a blue-shift of the unique 2PA band compared to the corresponding 1PA transition.
This overview of polymethine derivatives points out that it is not trivial to retain an important 2PA in the SWIR using such structures. The major reason is that the cyanine transition is not two-photon allowed for symmetry reason; it is necessary to play with various parameters to achieve a high 2PA cross-section: (i) increase vibration phenomena by increasing the length of the conjugated chain (see 79a-c, Figure 28), (ii) induce a symmetry breaking (see 95, Figure 32), (iii) increase the number of chromophore units (see Figure 35 and Figure 36), or (iv) introduce a strong ICT (see 115 in Figure 39).

\section{Porphyrinoids}

The wide family of porphyrinoids and related aromatic macrocycles was extensively studied for several aspects of nonlinear optics including second harmonic generation, twophoton absorption in the visible or nonlinear microscopy for bio-imaging. ${ }^{273-277}$ Naturally, the first 2PA studies were performed in the classical $700-900 \mathrm{~nm}$ region to take benefit from the exceptionally intense Soret band. However, the $Q$ bands localized in the far-red region also offer a great opportunity to carry out 2PA studies in the NIR spectral range. In 2003, Rebane et al. recorded the 2PA of tetraphenylporphyrin 117 between $1100 \mathrm{~nm}$ and $1400 \mathrm{~nm}$ but only a very low cross-section was measured (Figure 40). ${ }^{278}$ Interestingly, in spite of the centrosymmetric character of the porphyrins, the 2PA band is coincident with the vibronic structure of the $Q$ bands. Following these preliminary results, the 2PA of porphycenes 118a, a constitution isomer of porphyrin 117, was recorded at $1100 \mathrm{~nm} .{ }^{279}$ The 2PA crosssection of free base 118a and chelated compound 118b are comparable, with a slight increase for the Pd(II) derivative (19 $\mathrm{GM}$ at $1100 \mathrm{~nm}$ ) underlining the minor effect of the metalation for this macrocycle. In 2008, Gryko and Rebane investigated corrole free-bases, which are contracted porphyrinoids, and estimated their nonlinear absorption corresponding to the $Q$ bands within the 1040-1360 nm range, with cross-sections lower than 5 GM. ${ }^{280}$ Reports of the 2PA properties of phtalocyanines are scarce in the literature, and only few of them were measured as standards in the NIR range, with

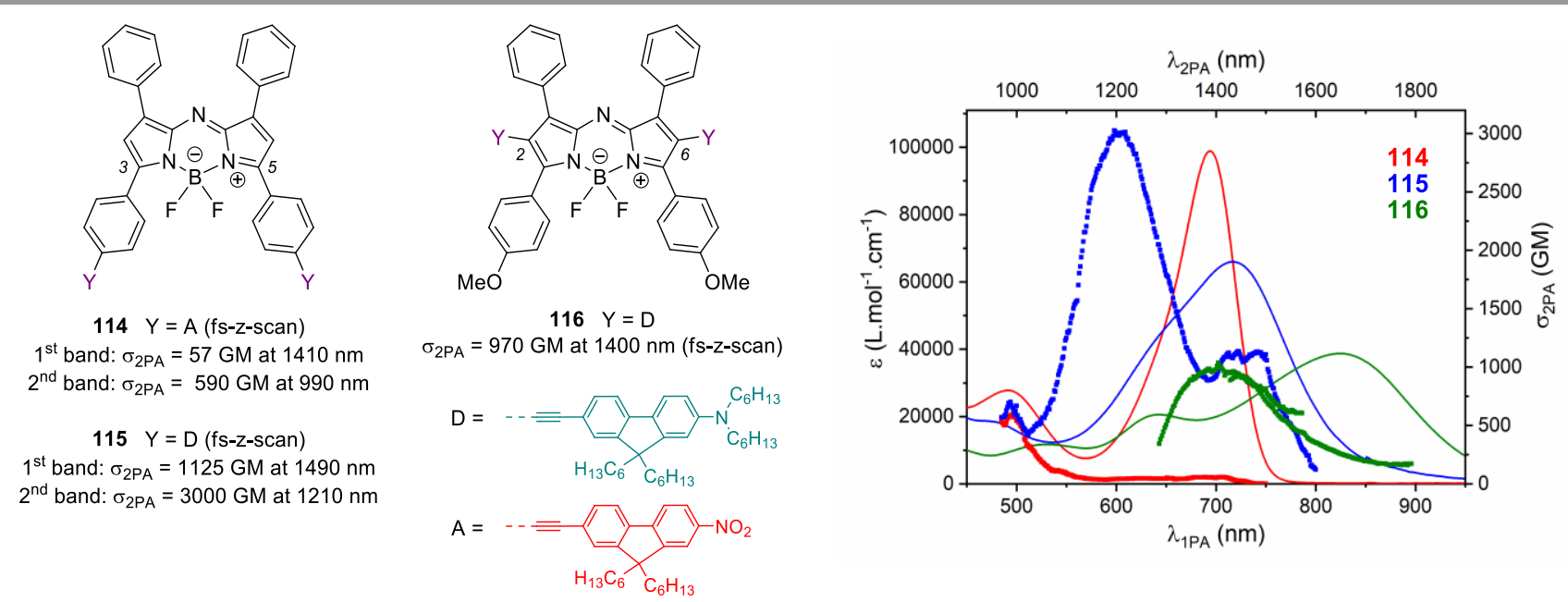

Figure 39. Influence of auxochromes nature and position on the 2PA of aza-bodipys 114, 115 and $\mathbf{1 1 6}$. Linear (plain lines) and 2PA (squares) spectra in chlorinated solvents. 

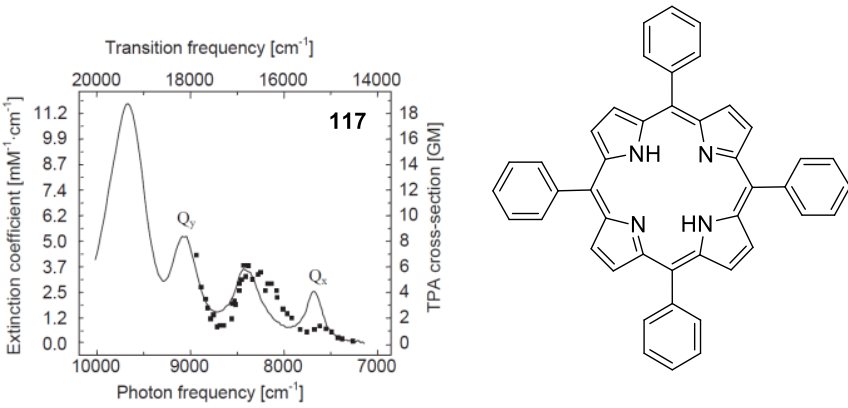

117

$\sigma_{2 \mathrm{PA}}=6 \mathrm{GM}$ ca. $1200 \mathrm{~nm}$ (fs-TPEF)

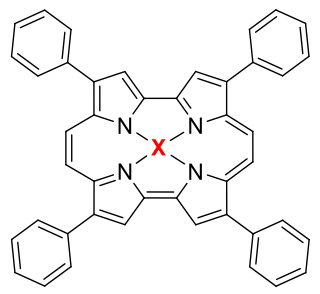

118a $X=2 \mathrm{H}$

$\sigma_{2 \mathrm{PA}}=14 \mathrm{GM}$ at $1100 \mathrm{~nm}$ (fs-TPEF)

$118 b \quad X=P d$

$\sigma_{2 \mathrm{PA}}=19 \mathrm{GM}$ at $1100 \mathrm{~nm}$ (fs-TPEF)

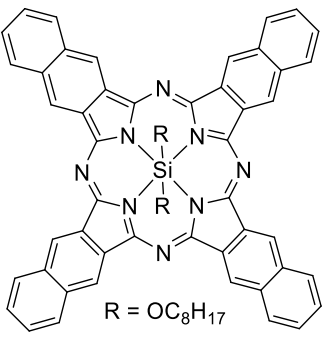

119

$\sigma_{2 \mathrm{PA}}=35 \mathrm{GM}$ at $1400 \mathrm{~nm}$, $48 \mathrm{GM}$ to 1280 (fs-TPEF)

Figure 40. Porphyrinoids structures with NIR/SWIR 2PA and linear absorption (plain line) and 2PA (squares) spectra of $\mathbf{1 1 7}$ in the spectral region of Q bands. Adapted from reference 278. Copyright 2003 Elsevier Science B.V. All rights reserved.

notably a zinc tetrakis(phenylthio)phthalocyanine (13 GM at $1270 \mathrm{~nm}$ ) and the silicium naphthalocyaninedioctyloxide 119, which shows 2PA peaking at 1400 and $1280 \mathrm{~nm}$ with crosssections of 35 and $48 \mathrm{GM}$, respectively. ${ }^{46}$ Note that the presence of a nonlinear optical response of dysprosium (III) and lutetium (III) bisphtalocyanines was recently observed at 1550 $\mathrm{nm} .{ }^{281}$

In 2006, Kuciauskas and Humphrey reported that the charge transfer from tetraphenylporphyrin ligand to the metal centre increases the nonlinear absorption. ${ }^{282}$ While no cross-section enhancement was measured for the electropolymerized film of the Co(II) complex, a one order of magnitude elevation was observed for the $\mathrm{Fe}$ (III) and $\mathrm{Mn}$ (III) ones compared to the free base. Wen and his group reported in 2003 the 2PA at $1300 \mathrm{~nm}$ of a solid matrix doped with $\mathrm{Ga}(\mathrm{III}), \mathrm{In}(\mathrm{III}), \mathrm{TI}(\mathrm{III}), \mathrm{Sn}$ (II) or $\mathrm{Pb}$ (II) metalloporphyrins. ${ }^{283}$ This study pointed out that the influence of the nature of the central metal/metalloid ion is negligible with modest 2PA cross-sections comprised between 26-77 GM at $1200 \mathrm{~nm}$ and $25-36 \mathrm{GM}$ at $1350 \mathrm{~nm}$, as exemplified with symmetrical indium porphyrin 120 (Figure 41). The slight increase of nonlinear absorption compared to $\mathbf{1 1 7}$ is explained by the presence of methoxy donor groups, however the angle between the porphyrin core and the peripheral groups limits the establishment of an effective ICT. A similar assumption can be drawn in the case of the $\mathrm{Fe}$ (III) tetrahydroxyphenylporphyrin derivative that was reported to exhibit a 2PA crosssection of $82 \mathrm{GM}$ at $1150 \mathrm{~nm} .^{284}$ In the same period, Drobizhev and co-workers published a complete 2PA investigation of a series of porphyrinoids, ranging from benzoporphyrins to chlorin. ${ }^{285}$ In this study, the characteristic low 2PA cross-section of the Q-band region, about 1-10 GM, was attributed to a partial symmetry breaking of the excited state. Afterwards, theoretical

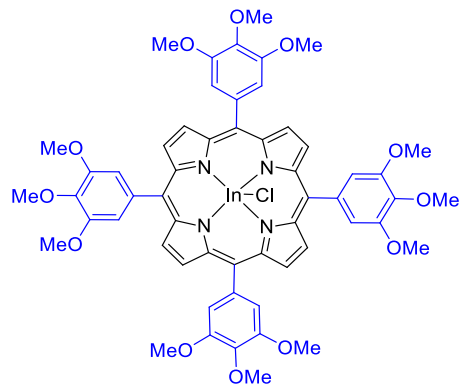

120

120

$\sigma_{2 \mathrm{PA}}=36 \mathrm{GM}$ at $1350 \mathrm{~nm}$, $47 \mathrm{GM}$ at $1200 \mathrm{~nm}$ (ns-z-scan)

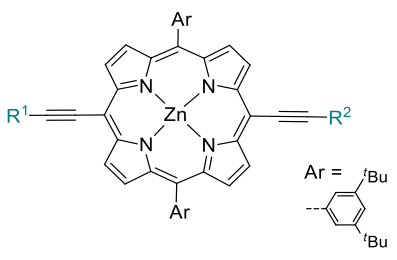

$122 \mathrm{R}^{1}=\mathrm{R}^{2}=\mathrm{Ph}$ $\sigma_{2 \mathrm{PA}}=1890 \mathrm{GM}$ at $1260 \mathrm{~nm}$ (fs-z-scan) $123 R^{1}=R^{2}=D$

$\sigma_{2 \mathrm{PA}}=3520 \mathrm{GM}$ at $1360 \mathrm{~nm}$ (fs-z-scan) $124 R^{1}=R^{2}=A$

$\sigma_{2 \mathrm{PA}}=5490 \mathrm{GM}$ at $1430 \mathrm{~nm}$ (fs-z-scan) $125 R^{1}=D, R^{2}=A$

$\sigma_{2 \mathrm{PA}}=8030 \mathrm{GM}$ at $1400 \mathrm{~nm}$ (fs-z-scan)
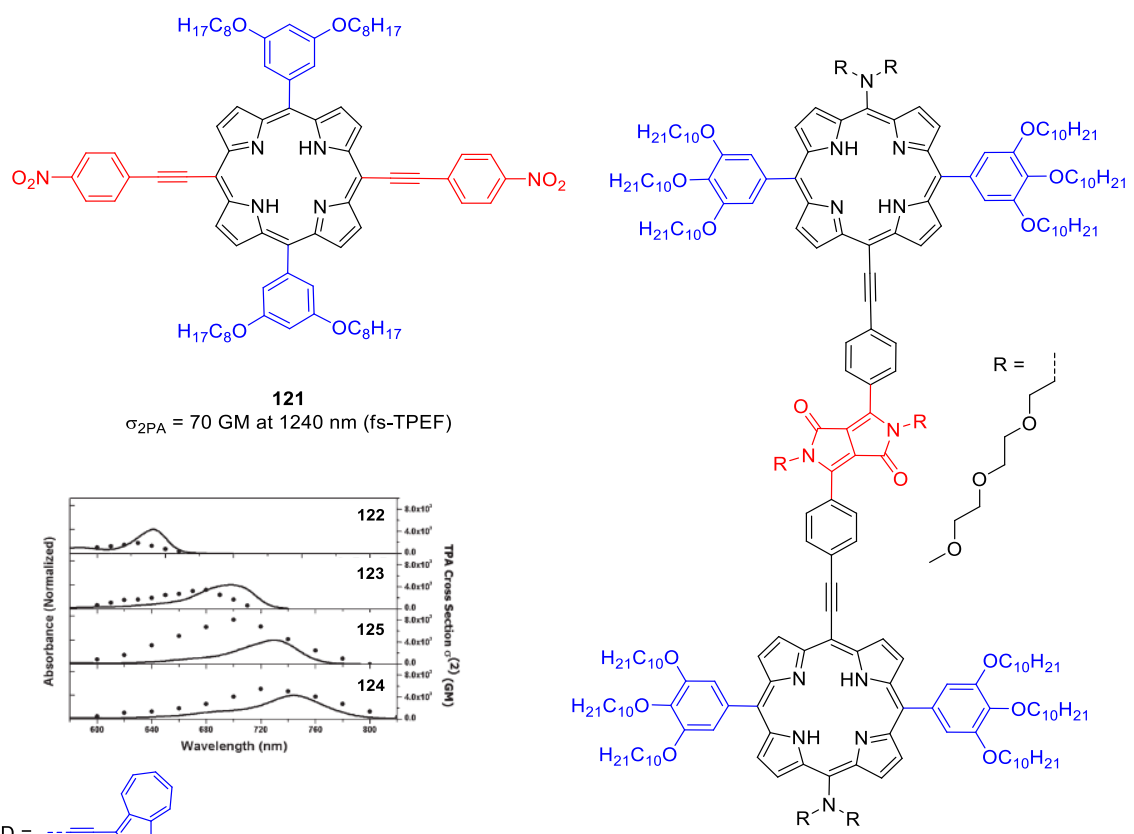

126

$\sigma_{2 \mathrm{PA}}$ ca. $1500 \mathrm{GM}$ at $1360 \mathrm{~nm}$ (TPEF)

Figure 41. Introduction of ICT in porphyrin architectures. 1PA (plain lines) and 2PA (closed circles) of compounds $122-125$ in toluene. Reproduced from reference 286 with permission from The Royal Society of Chemistry. 
simulations clearly underlined that introduction of electrondonating or electron-withdrawing moieties via extended conjugated linkers, in particular at the meso-position, results in the establishment of ICT and strongly increases the NIR 2PA efficiency. ${ }^{287-290}$ These concepts are illustrated by the tetrasubstituted porphyrin base $\mathbf{1 2 1}$ incorporating ethynyl-linked peripheral nitrophenyl moieties as acceptors and mild alkoxy donors, which exhibits a 2PA cross-section of $70 \mathrm{GM}$ at 1240 nm. ${ }^{291-293}$ Following this approach, Osuka and co-workers developed a series of azulene-based porphyrins 122-125 enabling a strong ICT between donor and acceptor extremities. ${ }^{286}$ The most efficient chromophore was the dipolar $\mathrm{Zn}$ (II) porphyrin 125 with a 2PA cross-section of $8030 \mathrm{GM}$ at $1400 \mathrm{~nm}$. Nevertheless, the A- $\pi-A$ chromophore 124 show the most red-shifted 1PA the series and consequently a 2PA peaking at $1430 \mathrm{~nm}$ (5490 GM). In addition, it was shown by Gryko et al. that the coupling of two porphyrins to an electron-withdrawing diketopyrrolopyrrole core in $\mathbf{1 2 6}$ results in the strong increase of the 2PA cross-section in this D-A-D architecture, with $\sigma_{2 \mathrm{PA}} c a$. $1500 \mathrm{GM}$ beyond $1300 \mathrm{~nm} .^{294}$

The decoration of porphyrin with fused azulene rings proved to be useful to enrich and extend the conjugated system as shown in $\mathrm{Ni}(\mathrm{II})$ fused porphyrinoid 127, presenting an impressive bathochromic shift of 1PA ( $\lambda_{\max }$ reaching $1200 \mathrm{~nm}$ ) for a monomeric structure and with a $\sigma_{2 \mathrm{PA}}$ of $7170 \mathrm{GM}$ at 1310 $\mathrm{nm}$ (Figure 42).295 This high $\sigma_{2 \mathrm{PA}}$ value can be explained by the NIR 2PA originating from the Soret band and not the $Q$ bands, as illustrated with the previous examples. Indeed, the azulenefused porphyrin 127 exhibits unusual red-shifted Soret and Q

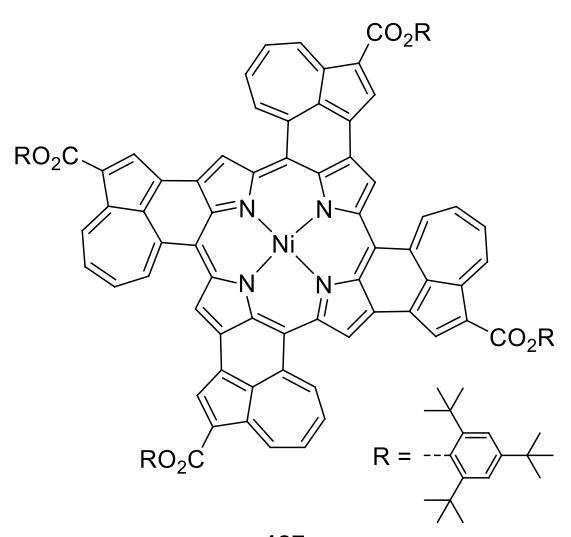

127

$\sigma_{2 \mathrm{PA}}=7170 \mathrm{GM}$ at $1310 \mathrm{~nm}$ (fs-z-scan)

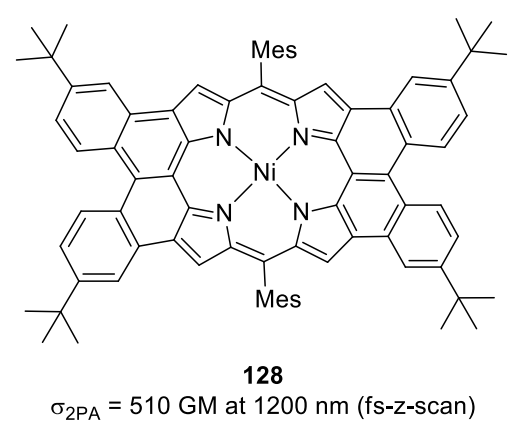

Figure 42. Fused $\mathrm{Ni}(\mathrm{II})$ porphyrins showing 2PA in the SWIR region. bands, respectively found at 684 and $1036 \mathrm{~nm}$. The authors attribute the high 2PA to a very effective $\pi$-electron delocalization pathway through the macrocycle. In 2012, a fused quinoidal porphyrin $\mathbf{1 2 8}$ was prepared by Kim, Wu and coworkers, ${ }^{296}$ for which the extension of the conjugation leads to a reduced cross-section ( $510 \mathrm{GM}$ at $1200 \mathrm{~nm}$ ) compared to the previous examples.

Another approach to extend the electronic delocalization in porphyrinoid systems consists in the increase of the number of pyrrolic units per macrocycle. For that purpose, expanded porphyrins like pentaphyrin 129, sapphyrin 130 and isosmaragdyrin 131 were studied and present a strong 2PA, ca. $3000 \mathrm{GM}$ between $1300 \mathrm{~nm}$ and $1600 \mathrm{~nm}$ (Figure 43).297 Furthermore, hexaphyrins $132 \mathrm{a}-\mathrm{d}^{298}$ and $\mathbf{1 3 3}^{299}$ reported by Kim, Osuka and co-workers offer the possibility to monitor the impact of the aromatic or non-aromatic character of the molecule. 300 Importantly, it was demonstrated that the 2PA cross-section increases when the ring is aromatic. In the case of 133, the larger central cavity allows the insertion of two $\mathrm{Au}(\mathrm{III})$ atoms and a $12700 \mathrm{GM} 2 \mathrm{PA}$ cross-section is recorded at 1410 $\mathrm{nm}$. The macrocycle $\mathbf{1 3 4}$ is a contracted and doubly $\mathrm{N}$-confused hexaphyrin radical whose stability is ensured by the delocalization of the unpaired electron over the whole structure. ${ }^{301}$ This compound shows a remarkable increase of the maximum 2PA cross-section ( $2100 \mathrm{GM}$ at $1500 \mathrm{~nm}$ ) compared to the uncontracted analogue $\mathrm{N}$-confused hexaphyrin at the same wavelength (900 GM). This observation let foresee the strong impact of $\pi$-radical structures on the 2PA properties (vide infra). In this context, additional studies reported the formation of aromatic expanded porphyrins with a Möbius loop topology, a specific case of non-planar conformation adopted by the $\mathrm{Pd}$ (II) bimetallic complex 135, featuring a $6400 \mathrm{GM}$ cross section at $1440 \mathrm{~nm} .^{302-305}$ In silico studies on octaphyrin theorized in 2020 that the Möbius topology lead to higher second order hyperpolarisabilities, and thus higher 2PA, compared to the Hückel one. ${ }^{306}$

Always within the porphyrin family, an alternative strategy to achieve giant 2PA cross-sections consists in the design of oligomeric architectures. Indeed, the formation of conjugated oligomers leading to an increase of the $\pi$-electrons delocalization and consequently to the improvement of 2PA was already illustrated in the visible region. ${ }^{273}$ Osuka and coworkers generalized this observation in the SWIR region and demonstrated the importance of the planarity between successive porphyrin units in oligomers via the modulation of the dihedral angle $(\theta)$ that defines the relative spatial alignment of the $\pi$ orbitals between the porphyrin units. To underline the direct relation between the 2PA and the dihedral angle formed between meso-meso-linked porphyrin arrays, the authors developed a series of zinc porphyrins 136a-f where this angle is controlled by the length of an aliphatic side chain linking the two macrocycles of the dimer (Figure 44). ${ }^{307}$ This elegant study clearly evidences the increase of 2PA cross-section with the decrease of dihedral angle $\theta$ towards planarity. 


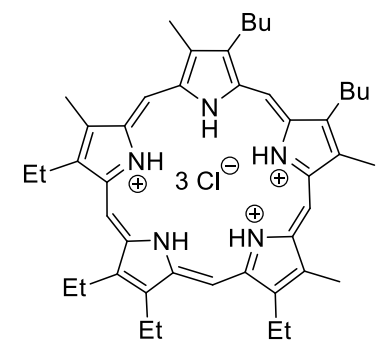

129

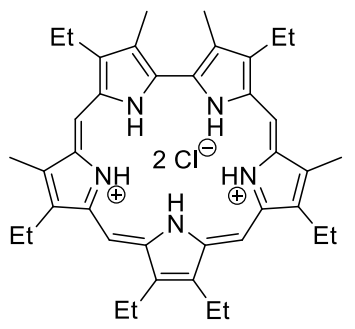

130

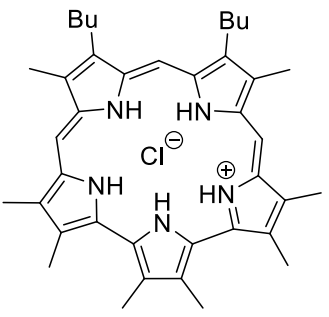

131

$\sigma_{2 \mathrm{PA}}=3300 \mathrm{GM}$ at $1580 \mathrm{~nm}$ (fs-z-scan) $\quad \sigma_{2 \mathrm{PA}}=2900 \mathrm{GM}$ at $1280 \mathrm{~nm}$ (fs-z-scan) $\quad \sigma_{2 \mathrm{PA}}=2700 \mathrm{GM}$ at $1360 \mathrm{~nm}$ (fs-z-scan)

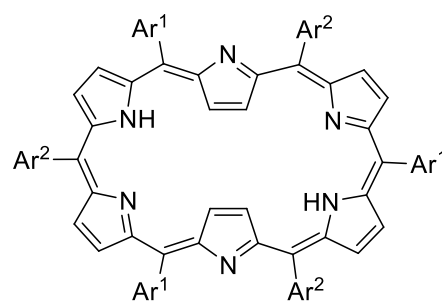

Excitation at $1200 \mathrm{~nm}$ (fs-z-scan)

132a $\mathrm{Ar}^{1}=\mathrm{Ar}^{2}=\mathrm{C}_{6} \mathrm{~F}_{5} \quad \sigma_{2 \mathrm{PA}}=9890 \mathrm{GM}$

132b $\mathrm{Ar}^{1}=\mathrm{C}_{6} \mathrm{~F}_{5} \quad \sigma_{2 \mathrm{PA}}=9490 \mathrm{GM}$ $\mathrm{Ar}^{2}=2,4,6-\mathrm{Ph}(\mathrm{OMe})_{3}$

132c $\mathrm{Ar}^{1}=\mathrm{C}_{6} \mathrm{~F}_{5} \quad \sigma_{2 \mathrm{PA}}=7790 \mathrm{GM}$ $A r^{2}=9$-anthryl

132d $\operatorname{Ar}^{1}=\mathrm{Ar}^{2}=$ mesityl $\quad \sigma_{2 \mathrm{PA}}=7640 \mathrm{GM}$<smiles>CC(C)C(F)(F)C(F)(F)C(F)(F)C(F)(F)C(F)(F)C(F)(F)C(F)(F)F</smiles>

134

$\sigma_{2 \mathrm{PA}}=2100 \mathrm{GM}$ at $1500 \mathrm{~nm}$ (fs-z-scan)

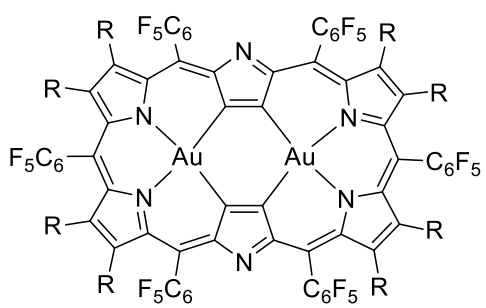<smiles>[R]=C=Cc1ccccc1</smiles>

133

$\sigma_{2 \mathrm{PA}}=12700 \mathrm{GM}$ at $1410 \mathrm{~nm}$ (fs-z-scan)

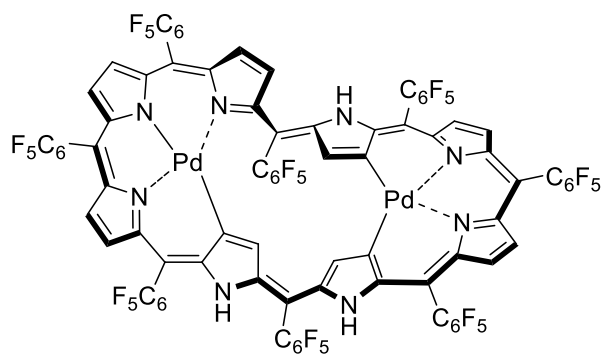

135

$\sigma_{2 \mathrm{PA}}=6400 \mathrm{GM}$ at $1440 \mathrm{~nm}$ (fs-z-scan)

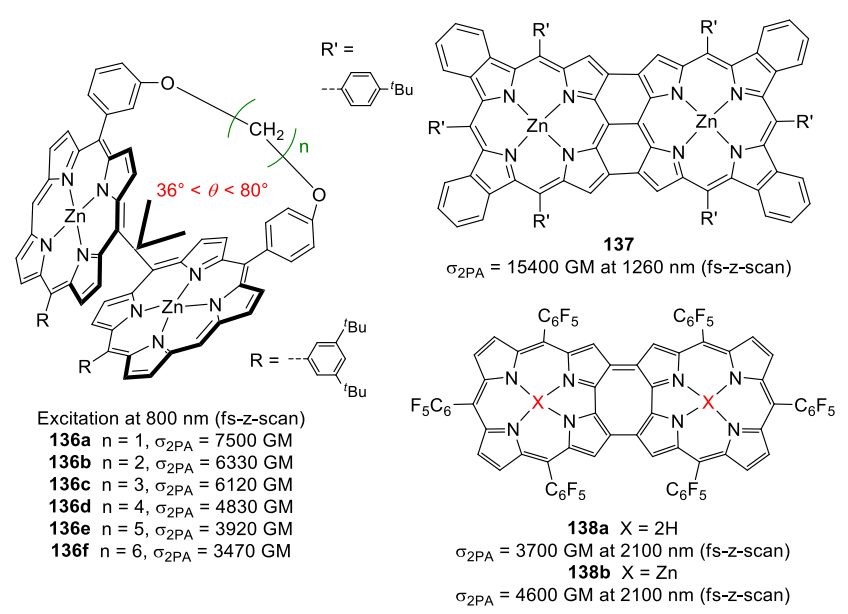

Figure 44. Study relative to the influence of the planarity of porphyrin oligomers and structure of fused porphyrin and corrole dimers

Thus, it is assumable that an optimized $\pi$-conjugation is achieved for rigidified meso-meso, $6-6$ and $B^{\prime}-B^{\prime}$ triply linked porphyrins. In 2005, a study of fused porphyrin dimers reports substantial cross-sections at $800 \mathrm{~nm}$ (2PA excitation of the Soret band) depending on the transition metal, showing an increase in the following order: $\mathrm{Cu}(\mathrm{II})$ (12000 GM), free base (13000 GM), $\mathrm{Zn}$ (II) (14000 GM) and Ni(II) (15000 GM) porphyrin dimers. ${ }^{308}$ This evolution is justified by an enhancement of the electronic delocalization over the two fused rings. In parallel, the 2PA of the $\mathrm{Ni}(\mathrm{II})$ dibenzoporphyrin dimer $\mathbf{1 3 7}$ was measured following excitation of the $Q$ bands and revealed a larger cross-section of $15400 \mathrm{GM}$ at $1260 \mathrm{~nm} .{ }^{309}$ Doubly linked corroles 138a-b present strong interactions between the molecular orbitals of the two adjacent macrocycles that give rise to exceptionally red-shifted $Q$ bands $\left(\lambda_{1 P A}\right.$ beyond $1300 \mathrm{~nm}$ ). Thus, these compounds show considerable 2PA in the SWIR region with cross-sections below and above $4000 \mathrm{GM}$ for the free base and the $\mathrm{Zn}$ (II) complex, respectively. ${ }^{310,311}$ Note that the corrole 138a was converted to its reduced analogue $(X=3 \mathrm{H})$, which shows significantly blueshifted linear and nonlinear absorptions, the 2PA maximum being found at $1400 \mathrm{~nm}$ (1100 GM). 
In this context, an optimized $\pi$-conjugation is achieved for rigidified meso- $B$ and $B$-meso linked oligomers $139 a-d^{312}$ or meso-meso, $B-B$ and $B^{\prime}-B^{\prime}$ triply-linked oligomers 140a-c (Figure

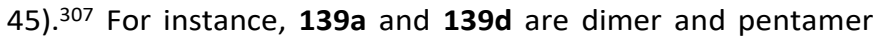
that feature 2PA maximal cross-sections of 8000 and $41400 \mathrm{GM}$ at 1400 and $2100 \mathrm{~nm}$, respectively. In these families of fused oligomers, the increase of the elementary units number $n$ leads to a red-shift of the linear and nonlinear optical properties accompanied by a regular increase of the molar absorption coefficient and of the global 2PA cross-section, the highest value being $93000 \mathrm{GM}$ for trimer 140c. Noteworthy, the crosssection evolution per unit does not remain constant and a cooperative effect between the monomers is observed. A comparison between $139 \mathrm{~d}$ and $140 \mathrm{c}$ highlights the strong enhancement of $\sigma_{2 \mathrm{PA}} / n$, with 8280 and $23400 \mathrm{GM}$ respectively, depending on the linking pattern. However, it is relevant underlining that the 2PA measurements for such porphyrin oligomers can be overestimated because of the overlap of the 2PA and the Q bands 1PA ca. $1200 \mathrm{~nm}$. To overcome such uncertainty, the $2 \mathrm{PA}$ cross-sections of $140 \mathrm{~b}$ and $140 \mathrm{c}$ were measured at $2300 \mathrm{~nm}$, still giving the largest values measured at this wavelength, with 18500 and $41200 \mathrm{GM}$, respectively. ${ }^{313}$ This approach was also undertaken for the 2D-extended porphyrins trimer 141 and tetramer 142 that present crosssections of 8700 and $35700 \mathrm{GM}$ at $2300 \mathrm{~nm}$, where there is no contribution from 1PA. These values highlight that the 2D extension of the delocalization in porphyrin arrays is not a pledge of larger 2PA and the authors underline that the molecular polarizability is the important parameter to consider for increasing cross sections.

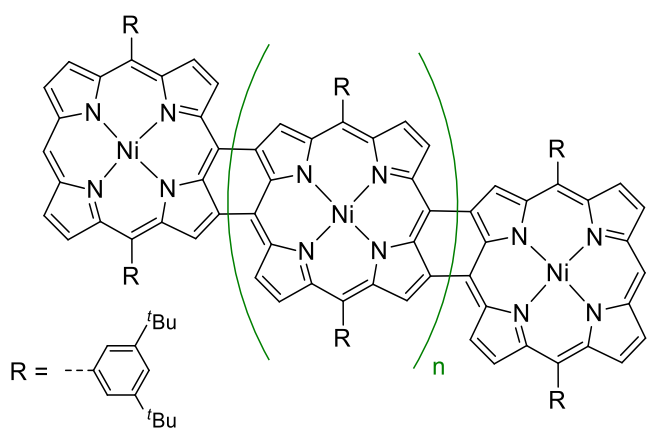

139a $\mathrm{n}=0, \sigma_{2 \mathrm{PA}}=8000 \mathrm{GM}$ at $1400 \mathrm{~nm}$ (fs-z-scan) $139 \mathrm{~b} n=1, \sigma_{2 \mathrm{PA}}=16900 \mathrm{GM}$ at $1700 \mathrm{~nm}$ (fs-z-scan) 139c $\mathrm{n}=2, \sigma_{2 \mathrm{PA}}=29900 \mathrm{GM}$ at $1900 \mathrm{~nm}$ (fs-z-scan) $139 \mathrm{~d} n=3, \sigma_{2 \mathrm{PA}}=41400 \mathrm{GM}$ at $2100 \mathrm{~nm}$ (fs-z-scan) $\sigma_{2 \mathrm{PA}} / \mathrm{n}=8280 \mathrm{GM}$

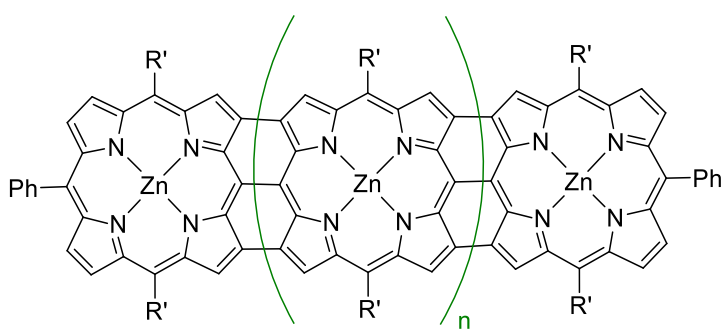

Excitation at $1200 \mathrm{~nm}$ (fs-z-scan) Excitation at $2300 \mathrm{~nm}$ (fs-z-scan) $140 \mathrm{a} \mathrm{n}=0, \sigma_{2 \mathrm{PA}}=11900 \mathrm{GM}$ $140 \mathrm{~b} n=1, \sigma_{2 \mathrm{PA}}=33100 \mathrm{GM}$ $140 \mathrm{c} n=2, \sigma_{2 \mathrm{PA}}=93600 \mathrm{GM}$ $\sigma_{2 \mathrm{PA}} / \mathrm{n}=23400 \mathrm{GM}$

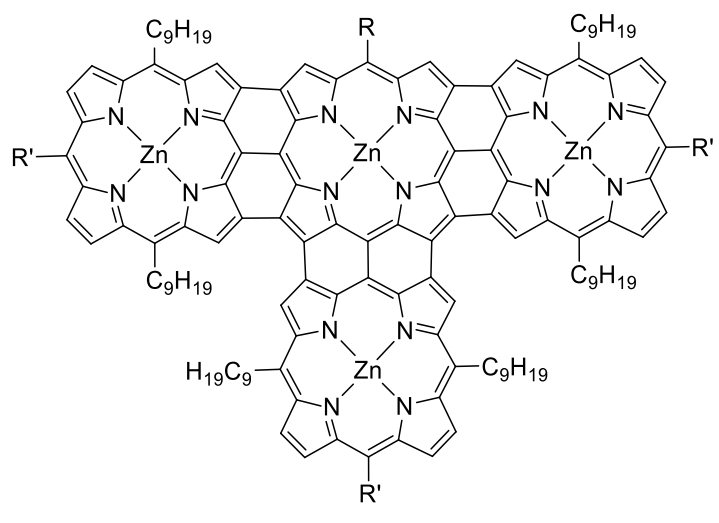

142

$\sigma_{2 \mathrm{PA}}=43000 \mathrm{GM}$ at $2100 \mathrm{~nm}$ (fs-z-scan) $\sigma_{2 \mathrm{PA}}=35700 \mathrm{GM}$ at $2300 \mathrm{~nm}$ (fs-z-scan)
$140 \mathrm{~b} n=1, \sigma_{2 \mathrm{PA}}=18500 \mathrm{GM}$ $140 \mathrm{c} n=2, \sigma_{2 \mathrm{PA}}=41200 \mathrm{GM}$ $\sigma_{2 \mathrm{PA}} / \mathrm{n}=10300 \mathrm{GM}$

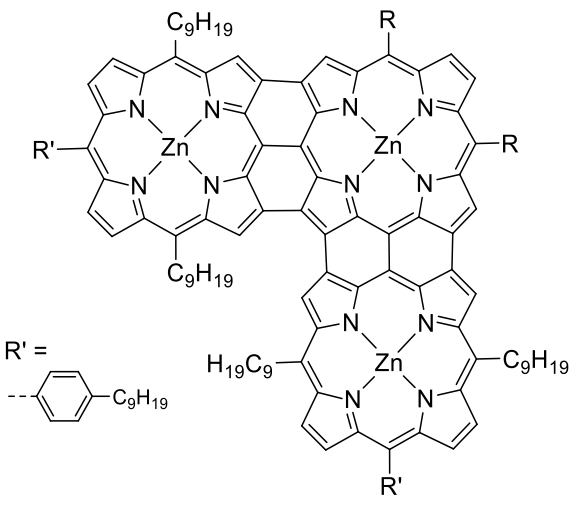

141

$\sigma_{2 \mathrm{PA}}=9560 \mathrm{GM}$ at $2100 \mathrm{~nm}$ (fs-z-scan) $\sigma_{2 \mathrm{PA}}=8700 \mathrm{GM}$ at $2300 \mathrm{~nm}$ (fs-z-scan)

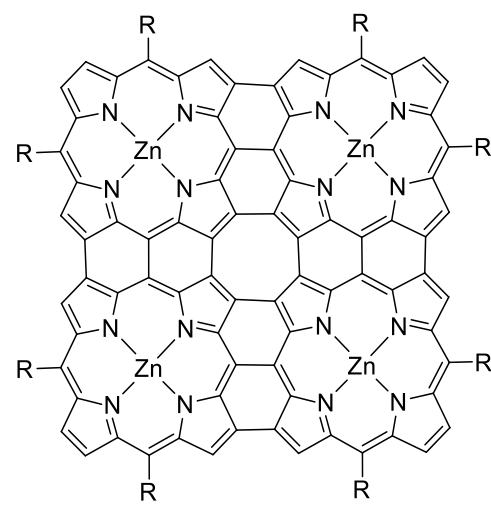

143

$\sigma_{2 \mathrm{PA}}=2750 \mathrm{GM}$ at $1600 \mathrm{~nm}$ (fs-Z-scan)

Figure 45. Fused porphyrin oligomers with 2PA in the SWIR. 
Surprisingly, the tetrameric porphyrin sheet $\mathbf{1 4 3}$ shows only a cross-section of $2750 \mathrm{GM}$ at $1600 \mathrm{~nm}$, which is a rather modest value compared to the linear and $2 \mathrm{D}$ tetramers $140 \mathrm{c}$ and $142 .{ }^{314}$ The authors suggested that the delocalization pattern was significantly different within these two architectures. The reader interested into a deeper analysis and comparison on the 2PA of porphyrin arrays is invited to consult the complete review by Osuka, Kim and co-authors published in 2008. ${ }^{274}$

Rebane and co-workers synthesized the original supramolecular ladder-shaped porphyrin oligomers 144a-c, obtained from the association of two diethynyl-porphyrin oligomers and 4,4'-bipyridine linkers (Figure 46). ${ }^{315}$ Compared to the single-strand arrays, the peak cross-section per macrocycle $\left(\sigma_{2 \mathrm{PA}} / \mathrm{n}\right)$ is magnified by the ladder structure, and reaches $\sigma_{2 \mathrm{PA}} / \mathrm{n}=8900 \mathrm{GM}$ at $1325 \mathrm{~nm}$ for $144 \mathrm{c}$, whereas the non-organised oligomer does not exceed $6400 \mathrm{GM}$ per unit at $980 \mathrm{~nm}$. The measured effective cross-sections are impressive; nevertheless, the use of such supramolecular assemblies remains challenging for the elaboration of materials. Porphyrins were also used in conjunction with other dyes within alternated conjugated oligomers. As example, the 2PA values of the alternated $\mathrm{Zn}(\mathrm{II})$ porphyrin-perylene diimide $146^{316,317}$ or zinc porphyrin-dithienocoronene diimide in oligomers $\mathbf{1 4 7 3 1 8}$ are larger than that reached with the pure meso-meso-linked lead porphyrin polymer $145 .{ }^{319}$ Regarding the 2PA cross-section per repeated unit, these values are part of the highest measured in the $1300-1600 \mathrm{~nm}$ spectral range, with $\sigma_{2 \mathrm{PA}} / \mathrm{n}$ reaching $c a .7800$ GM at $1520 \mathrm{~nm}$ for 146 and 147.

Smaller porphyrin structures were designed so that the lowest energetic transitions ( $Q$ bands) can overlap with the electronic absorption transition of a second dye, enabling an additional electronic coupling in a hybrid conjugated form of these two compounds. For instance, Zn(II) bisporphyrin 148, linked via a squaraine unit shows a 2PA cross-section superior to $780 \mathrm{GM}$ through the $900-1600 \mathrm{~nm}$ range, unlike to the constitutive porphyrin or squaraine that exhibit $\sigma_{2 \mathrm{PA}}$ values inferior to $100 \mathrm{GM}$ beyond $900 \mathrm{~nm}$ (Figure 47). ${ }^{320}$ This effect is mainly due to the superimposition of several allowed twophoton transitions. In the case of $\mathbf{1 4 9}$, the positive charge is delocalized along the molecule and 2PA reaches $3100 \mathrm{GM}$ at $1550 \mathrm{~nm} .{ }^{321}$ The conjugated bridge differs from classical cyanines since the double bonds are replaced with triple bonds, yielding a better electronic coupling between the two porphyrins and avoiding possible torsions.

Besides their limited synthetic availability, porphyrinoid derivatives appear to be the most promising candidates for 2PA in the NIR/SWIR since they offer multiple possibilities of structural optimisations to enhance the 2PA cross-sections, including i) the introduction of ICT, ii) the extension of conjugation via fusion strategies, and (iii) the design of oligomers introducing other NIR-absorbing dyes. So far, the tetrameric array 140c and the polymers 144-147 hold the records of the highest 2PA cross-sections in the SWIR region.

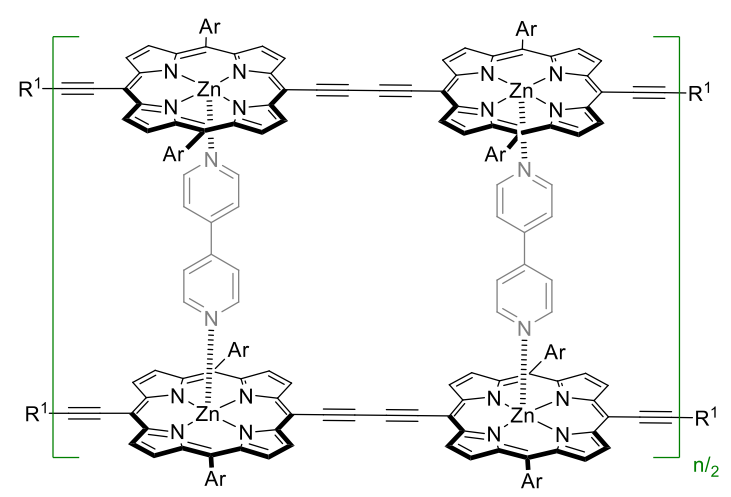

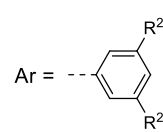

144a $n=4, R^{1}=\mathrm{SiHex}_{3}, \mathrm{R}^{2}=\mathrm{OC}_{8} \mathrm{H}_{17}$ $\sigma_{2 P A}=8800 \mathrm{GM}$ at $1305 \mathrm{~nm}$ (fs-TPEF)

144b $\mathrm{n}=8, \mathrm{R}^{1}=\mathrm{SiHex}_{3}, \mathrm{R}^{2}=\mathrm{OC}_{8} \mathrm{H}_{17}$ $\sigma_{2 \mathrm{PA}}=49000 \mathrm{GM}$ at $1315 \mathrm{~nm}$ (fs-TPEF)

144c $\left.\mathrm{n}=10-15, \mathrm{R}^{1}=\mathrm{H}, \mathrm{R}^{2}=\mathrm{CON}\left(\mathrm{CH}_{2} \mathrm{CHEtBu}\right)_{2}\right)$ $\sigma_{2 \mathrm{PA}}=115000 \mathrm{GM}$ at $1325 \mathrm{~nm}$ (fs-TPEF) $\sigma_{2 \mathrm{PA} / \mathrm{n}}=8900 \mathrm{GM}$ at $1325 \mathrm{~nm}$

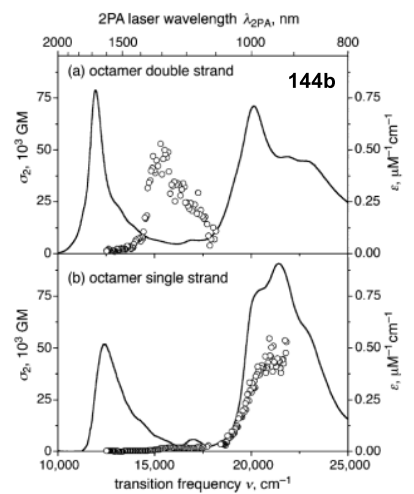

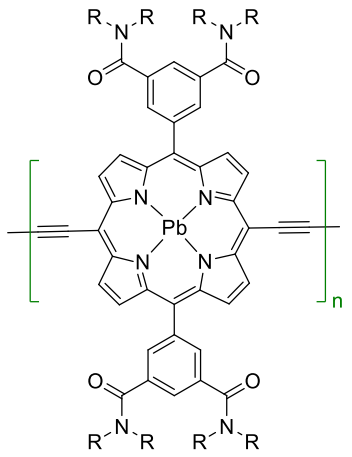

$145 \mathrm{R}=\mathrm{CH}_{2} \mathrm{CHEtBu}$ $\sigma_{2 \mathrm{PA}}=67600 \mathrm{GM}$ at $1300 \mathrm{~nm}$ (fs-z-scan) $\sigma_{2 \mathrm{PA}} / \mathrm{n}=5200 \mathrm{GM}$ at $1300 \mathrm{~nm}$

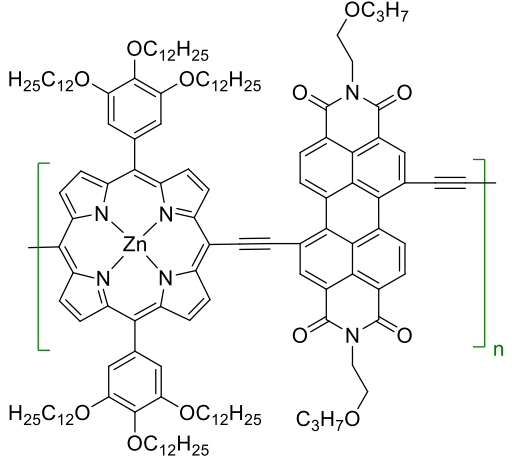

146

$\sigma_{2 \mathrm{PA}}=150000 \mathrm{GM}$ at $1520 \mathrm{~nm}$ (fs-z-scan) $\sigma_{2 \mathrm{PA}} / \mathrm{n}=7704 \mathrm{GM}$ at $1520 \mathrm{~nm}$

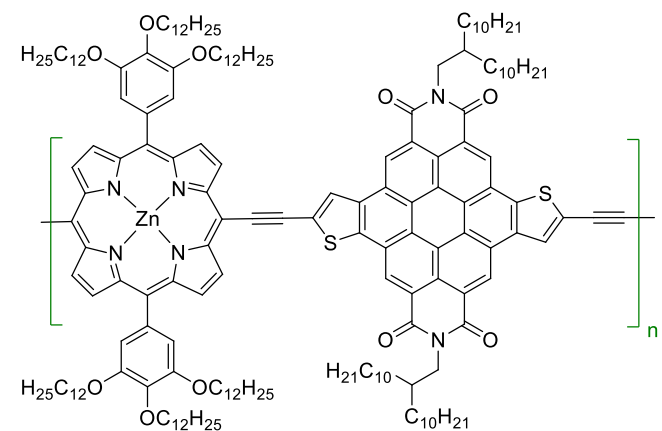

147

$\sigma_{2 \mathrm{PA}} / \mathrm{n}=7809 \mathrm{GM}$ at $1520 \mathrm{~nm}$ (fs-z-scan)

Figure 46. Ethynyl-porphyrin polymers with 2PA in the SWIR region. Plot of the 1PA (plain lines) and 2PA (circles) of single and double strand (144b) porphyrins in CCl 4 . Adapted with permission from reference ${ }^{315}$. Copyright 2006 American Chemical Society. 


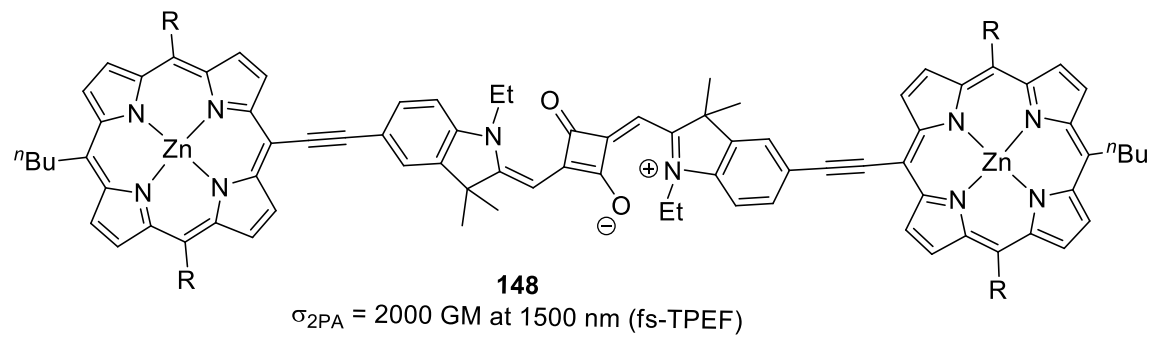

$\sigma_{2 P A}=2000 \mathrm{GM}$ at $1500 \mathrm{~nm}$ (fs-TPEF)<smiles>[R]#Cc1cc([PH])cc(C(C)C)c1</smiles>

149 $\sigma_{2 \mathrm{PA}}=3100 \mathrm{GM}$ at $1550 \mathrm{~nm}$ (fs-z-scan)
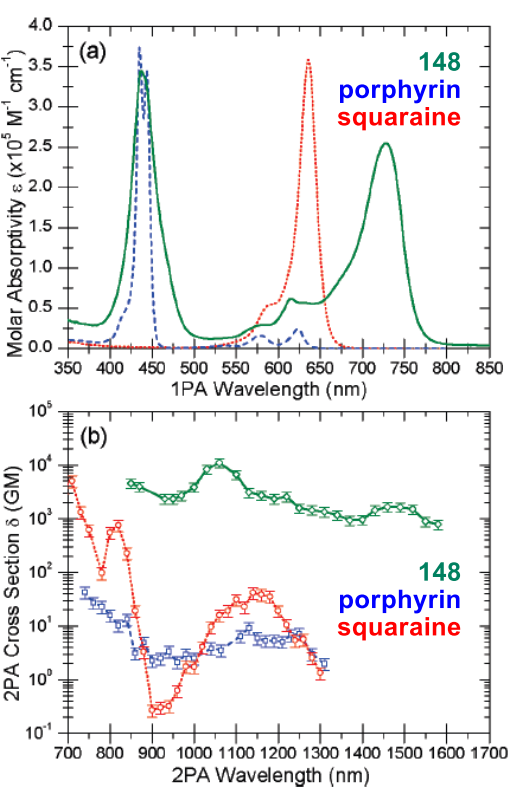

Figure 47. Porphyrin-polymethine derivatives. Linear absorption spectra (a) and 2PA spectra (b) of $\mathbf{1 4 8}$ and its constitutive units. Adapted with permission from reference 320. Copyright 2009 American Chemical Society.

\section{Diradicals}

Singlet diradicals 322 are molecular species of particular interest for 2PA. Their diradical character $\psi$, an index comprised between 0 and 1 and extracted from theoretical calculations, directly impacts their third order nonlinear response. ${ }^{323-325}$ In 2007, the first 2PA properties of two stable open-shell singlet diradicals were reported in the SWIR. Polycyclic aromatic hydrocarbons $\mathbf{5 9}$ and $\mathbf{6 0}$ are not substituted by either donor nor acceptor moieties but present a stable diradical form and feature exceptionally strong 2PA cross-sections compared to typical hydrocarbon chromophores, up to $850 \mathrm{GM}$ at $1500 \mathrm{~nm}$ for 60 (Figure 22). ${ }^{204-206} \mathrm{~A}$ comparable 2PA efficiency of $760 \mathrm{GM}$ is measured for less rigid tetrabenzo-Chichibabin hydrocarbon $\mathbf{1 5 0}$ at shorter wavelengths (Figure 48). ${ }^{326}$ In heptazethrene 151 and octazethrene 152, the most reactive sites can be blocked by the insertion of triisopropylsilylacetylene groups, enhancing the stability of the diradical form. ${ }^{327}$ These Z-shaped chromophores present closed-shell $(\gamma=0.16)$ and open-shell $(\gamma=0.43)$ structures, respectively, and 2PA comparison shows an enhancement of the cross-section increasing from 920 to 1200 GM going from molecule $\mathbf{1 5 1}$ to $\mathbf{1 5 2}$. The impact of the singlet diradical character is more striking in the instance of dibenzoheptazethrene isomers 153 and $154 .^{328}$ This combined experimental-theoretical study reports that the compound $\mathbf{1 5 4}$ has a marked diradical character ( $\gamma$ ca. 0.58) due to the stabilization of a five aromatic sextet rings structure, and thus presents a remarkable increase of 2PA cross-section, with 2800 $\mathrm{GM}$ at $1600 \mathrm{~nm}$. This tendency was later on confirmed in more simple and unsubstituted dibenzozethrene derivative $\mathbf{1 5 5}$ that presents 2PA around $1200 \mathrm{~nm}$ with cross-sections as high as 1770 GM. ${ }^{329}$ Note that a quarteranthene hydrocarbon, which structure is closely related to zigzag-edged graphene nanoribbons, exhibited a weak but unquantified 2PA lying between 1600 and $2400 \mathrm{~nm} .{ }^{330}$
A series of bisindeno-thienoacenes $\mathbf{1 5 6 - 1 5 8}$ was reported in 2014 as antiaromatic species featuring a null to small singlet diradical character (Figure 49). ${ }^{331}$ Interestingly, due to the different fusion pattern, both 156 and 158 have red-shifted 1PA $\left(\lambda_{\max }\right.$ ca. $\left.685 \mathrm{~nm}\right)$ compared to $157\left(\lambda_{\max }=606 \mathrm{~nm}\right)$. In consequence, the 2PA maxima are found at $1200 \mathrm{~nm}$ (420 GM) for 157 and at $1400 \mathrm{~nm}$ for 156 and 158, with moderate crosssections of 340 and $520 \mathrm{GM}$, respectively.

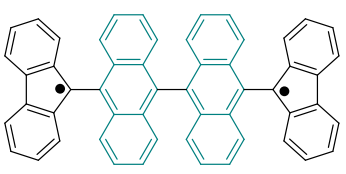

150

$\sigma_{2 \mathrm{PA}}=760 \mathrm{GM}$ at $1200 \mathrm{~nm}$ (fs-z-scan)

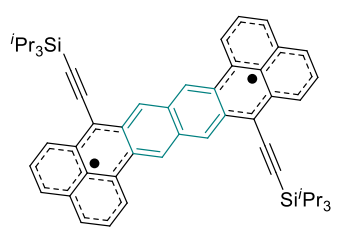

152 open-shell $(\gamma=0.43)$ $\sigma_{2 \mathrm{PA}}=1200 \mathrm{GM}$ at $1250 \mathrm{~nm}$ (fs-z-scan)

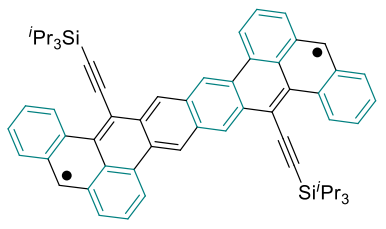

154 open-shell $(\gamma=0.58)$ $\sigma_{2 \mathrm{PA}}=2800 \mathrm{GM}$ at $1600 \mathrm{~nm}$ (fs-z-scan)

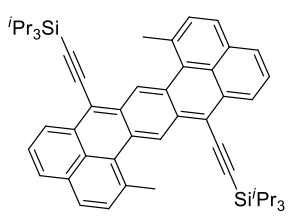

151 closed-shell $(\gamma=0.16)$

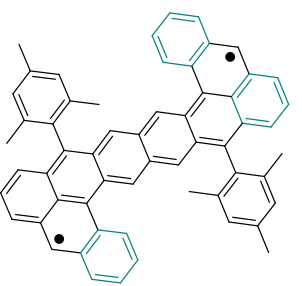

153 open-shell $(\gamma=0.31)$ $\sigma_{2 \mathrm{PA}}=530 \mathrm{GM}$ at $1400 \mathrm{~nm}$ (fs-z-scan)

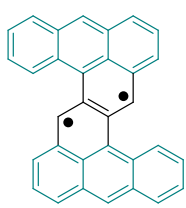

155 open-shell $(\gamma=0.48)$ $\sigma_{2 \mathrm{PA}}=1770 \mathrm{GM}$ at $1180 \mathrm{~nm}$ (fs-TPEF) $\sigma_{2 \mathrm{PA}}=920 \mathrm{GM}$ at $1250 \mathrm{~nm}$ (fs-z-scan)

Figure 48. Hydrocarbon diradicals exhibiting $2 \mathrm{PA}$ in the NIR/SWIR. 

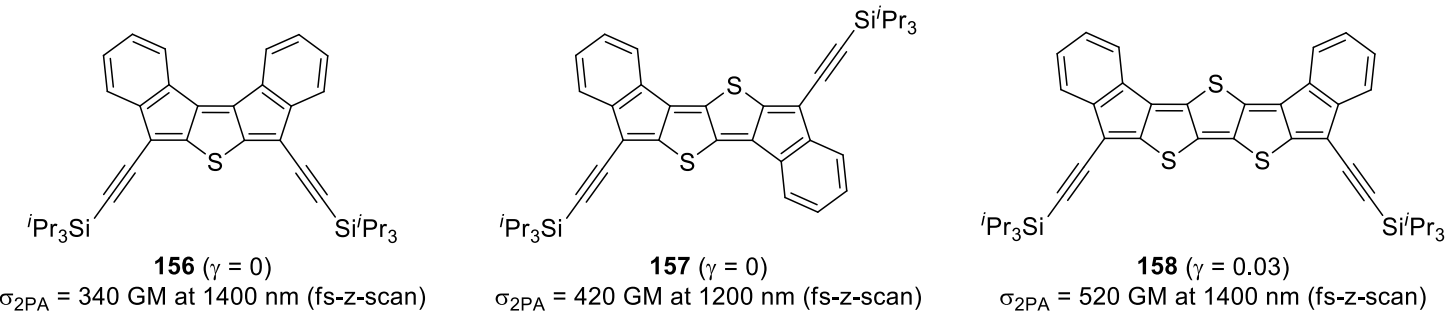

Figure 49. Antiaromatic thienoacene-based derivatives.

The series of $p$-quinodimethane derivatives 159a-f $\mathbf{f}^{332}$ reported by $\mathrm{Wu}, \mathrm{Kim}$ and co-workers is particularly interesting: while the monomer 159a is a closed shell quinoidal compound, singlet biradical structures are found for the dimer 159b $(\gamma=$ $0.85)$, trimer 159c $(\gamma=0.99)$ or tetramer 159d $(\gamma=0.99)$, and higher oligomers 159e-f are triplet biradicals (Figure 50). On one hand, the monomer 159a $\left(\lambda_{\max }=626 \mathrm{~nm}\right.$ ) exhibits an inherent large $1300 \mathrm{GM} 2 \mathrm{PA}$ cross-section at $1200 \mathrm{~nm}$ that the authors explain by a contribution of the quinoidal electronic structure that may generate high hyperpolarisabilities. ${ }^{296}$ On the other hand, varying the length of the oligomers leads to a red-shift of the one-photon lowest energy transition ( $\lambda_{\max }$ between 900-930 $\mathrm{nm}$ ), shifting the 2PA in the $1650-2100 \mathrm{~nm}$ region, with however $\sigma_{2 \mathrm{PA}}$ of 1060, 770, 710, 730 and $710 \mathrm{GM}$ for chromophores 159b-f, respectively. Such result may suggest that large 2PA is favoured when the biradical indices have intermediate values, i.e. when the species have not pure closed- or open-shell character.

Analogous dipolar structures 160a-c were prepared by linking a benzo-1,3-dithiol-2-ylidene donor to a dicyanomethylene acceptor through one or several $\mathrm{N}$ annulated perylene-quinodimethane units (Figure 51). ${ }^{333}$ In addition to the expected closed-open shell equilibrium, these push-pull dyes may be stabilized under a zwitterionic structure in polar solvents, especially in the case of the smallest oligomer. However, the 2PA properties show similar tendencies to the pull-pull series, with the exception that slight decreases of the maximum cross-sections are observed upon increasing the solvent polarity, e.g. from $1300 \mathrm{GM}$ in toluene to $\mathrm{ca}$. $900 \mathrm{GM}$ in DCM/DMSO for 160a.

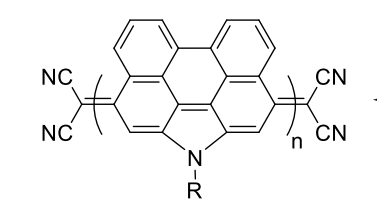

$159 a$

$\mathrm{n}=1, \mathrm{R}=\mathrm{R}^{1}$, closed-she

$\sigma_{2 \mathrm{PA}}=1300 \mathrm{GM}$ at $1200 \mathrm{~nm}$ (fs-z-scan)

$R^{1}=: \underbrace{\mathrm{C}_{2} \mathrm{H}_{5}}_{C_{4} \mathrm{H}_{9}} \quad R^{2}=: \underbrace{\mathrm{C}_{10} \mathrm{H}_{21}}_{\mathrm{C}_{12} \mathrm{H}_{25}}$

Figure 50. Pull-pull perylene-based diradicaloids.
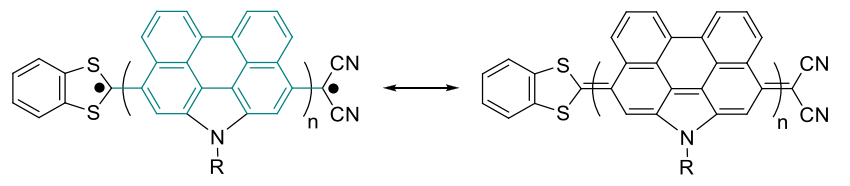

160a $n=1 \quad R=R^{1} \quad(\gamma=0.123)$ $\sigma_{2 \mathrm{PA}}=1000 \mathrm{GM}$ at $1500 \mathrm{~nm}$ (fs-z-scan) $160 \mathrm{~b} n=2 \mathrm{R}=\mathrm{R}^{2}(\gamma=0.899)$ $\sigma_{2 \mathrm{PA}}=660 \mathrm{GM}$ at $1900 \mathrm{~nm}$ (fs-z-scan) 160c $n=3 R=R^{2} \quad(\gamma=0.995)$ $\sigma_{2 \mathrm{PA}}=670 \mathrm{GM}$ at $1900 \mathrm{~nm}$ (fs-z-scan)
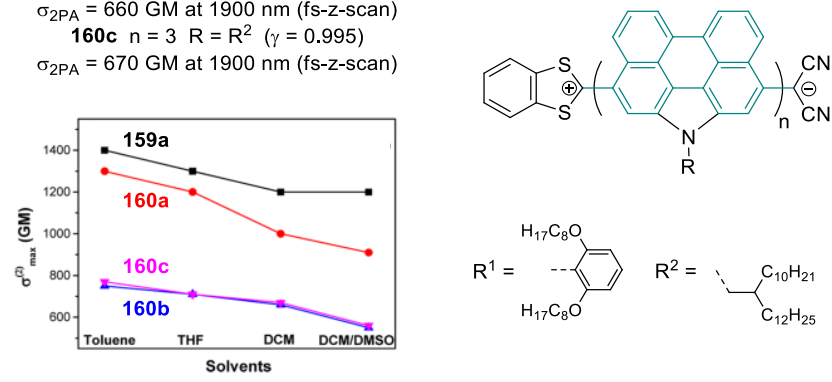

Figure 51. Push-pull perylene-based diradicaloids and plot of the solvent-depending 2PA cross-section maxima of the series $\mathbf{1 6 0}$. Adapted with permission from reference ${ }^{333}$. Copyright 2015 American Chemical Society.

In 2015, Kim and Würthner isolated a stable perylene diimide derivative 161 via the chemical oxidation of the corresponding dianion (Figure 52). ${ }^{334}$ This species is a stable diradical with a half-life $c a$. 54 hours in solution and shows a moderate $\sigma_{2 \mathrm{PA}}$ of $350 \mathrm{GM}$ at $1550 \mathrm{~nm}$. In 2012, a comparative 2PA study was achieved between the bis-acridinium singlet diradicaloid 162a ( $\gamma=0.682)$ and its closed-shell counterpart 162b $(\gamma=0)$ having the exact same atom composition and backbone structure. ${ }^{335}$ At $1200 \mathrm{~nm}$, the diradicaloid dimer exhibits a 3600 GM 2PA cross-section whereas the closed-shell equivalent obtained via chemical reduction presents a very small value of $10 \mathrm{GM}$. In 2016, Kim and Wu reported two bodipy-based fused dimers 163 and 164 that feature linear absorption around $1100 \mathrm{~nm} .{ }^{336} \mathrm{It}$ was found that the structural isomerization, using $p$ - or m-quinodimethane bridges, influenced strongly the diradical character and the optical properties of the bodipys. Despite their moderate diradical character, 163 and $\mathbf{1 6 4}$ feature large $2 \mathrm{PA}$ at 2200 and $2300 \mathrm{~nm}$, with $\sigma_{2 \mathrm{PA}}$ of 1300 and $1500 \mathrm{GM}$, respectively.
Excitation at $1700 \mathrm{~nm}$ (fs-z-scan) $n=2-6, R=R^{2}$, open-shell $159 \mathrm{~b} n=2 \quad \sigma_{2 \mathrm{PA}}=1060 \mathrm{GM}$ 159c $\mathrm{n}=3 \quad \sigma_{2 \mathrm{PA}}=770 \mathrm{GM}$ $159 \mathrm{~d} n=4 \quad \sigma_{2 \mathrm{PA}}=710 \mathrm{GM}$ 159e $n=5 \quad \sigma_{2 \mathrm{PA}}=730 \mathrm{GM}$ 159f $n=6 \quad \sigma_{2 \mathrm{PA}}=710 \mathrm{GM}$ 

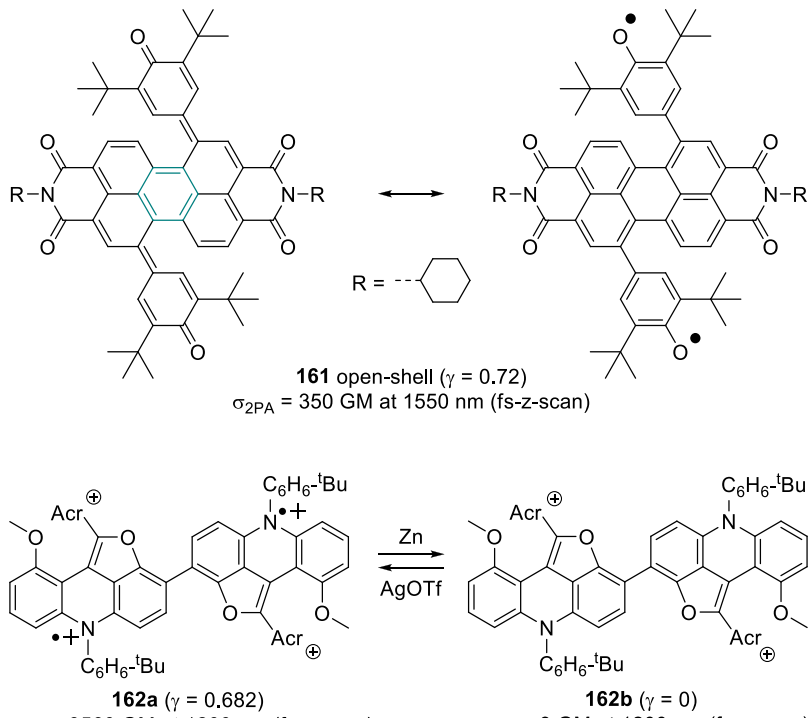

$\sigma_{2 \mathrm{PA}}=3560 \mathrm{GM}$ at $1200 \mathrm{~nm}$ (fs-z-scan)

$\sigma_{2 \mathrm{PA}}<9 \mathrm{GM}$ at $1200 \mathrm{~nm}$ (fs-z-scan)

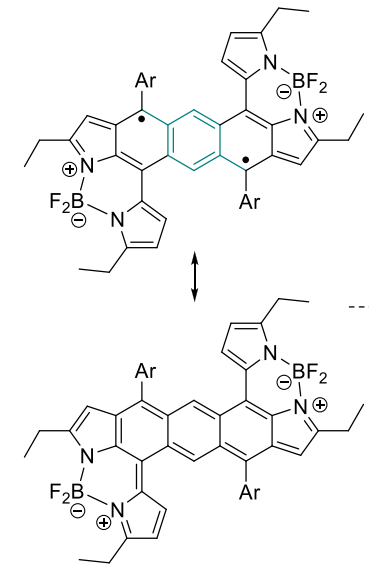

$163(\gamma=0.069)$

$\sigma_{2 \mathrm{PA}}=1300 \mathrm{GM}$ at $2200 \mathrm{~nm}$ (fs-z-scan)

Figure 52. Perylene diimide-, acridin- and bodipy-based diradicaloids exhibiting 2PA in the SWIR.

In 2013, Shi, Kim, Wu and co-workers designed an elegant bis-porphyrin structure built around a $p$-quinodimethane bridge (165) that shows an extended conjugation over the two units due to a closed-shell ground-state (Figure 53). ${ }^{337}$ Consequently its linear absorption is red-shifted at $955 \mathrm{~nm}$ compared to the keto-bridged $p$-phenylene dimers 166a-c ( $\lambda_{\max }$ between 800$920 \mathrm{~nm}$ ), and its 2PA reaches $2080 \mathrm{GM}$ at $1800 \mathrm{~nm}$. The series 166a-c exhibit lower cross-sections that strongly depends on the transition metal incorporated. While the $\mathrm{Ni}(\mathrm{II})$ porphyrin shows a $\sigma_{2 \mathrm{PA}}$ of $650 \mathrm{GM}$ at $1500 \mathrm{~nm}$, the $\mathrm{Zn}$ (II) and $\mathrm{Mg}$ (II) ones are characterized by cross-sections ca. $1500-1600 \mathrm{GM}$ at 1800 $\mathrm{nm}$. In 2019, the porphyrin dimers were modified to introduce 2,6- or 1,5-naphtoquinodimethane bridges in 167 and 168.338 Both compounds have open-shell structures, nevertheless the high diradical index of $\mathbf{1 6 8}(\gamma=0.77)$ leads to moderate 2PA at $1600 \mathrm{~nm}(1750 \mathrm{GM})$ whereas the dimer 167, with an in-between $\psi$ value of 0.5 , has two-fold larger cross-section of $3500 \mathrm{GM}$.

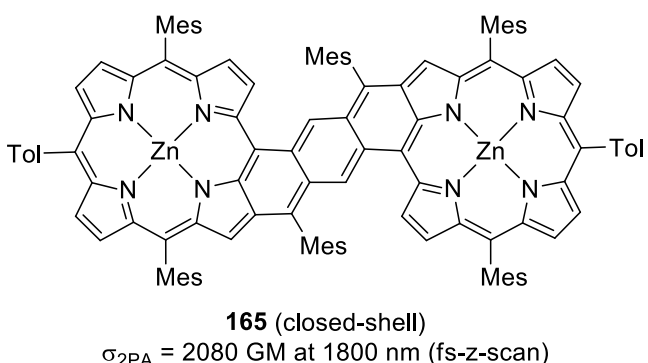

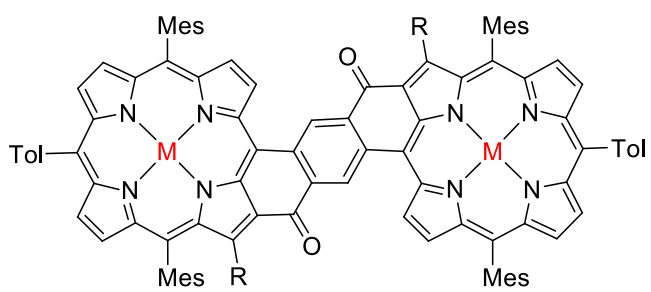

166a $M=N i, R=H$ $\sigma_{2 \mathrm{PA}}=650 \mathrm{GM}$ at $1500 \mathrm{~nm}$ (fs-z-scan) 166b $M=Z n, R=H$ $\sigma_{2 P A}=1600 \mathrm{GM}$ at $1800 \mathrm{~nm}$ (fs-z-scan) 166c $M=M g, R=4-{ }^{t} \mathrm{BuPh}$ $\sigma_{2 \mathrm{PA}}=1490 \mathrm{GM}$ at $1800 \mathrm{~nm}$ (fs-z-scan)

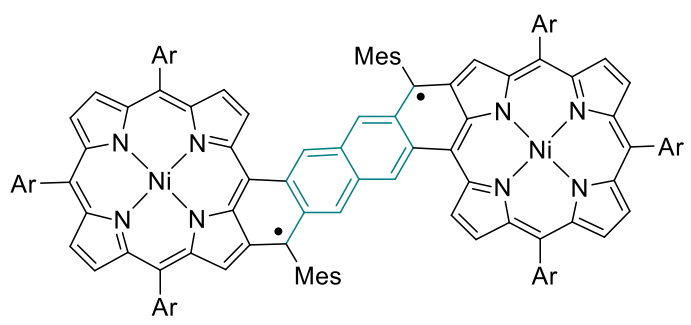

$167(\gamma=0.501)$ $\sigma_{2 \mathrm{PA}}=3500 \mathrm{GM}$ at $1400 \mathrm{~nm}$ (fs-z-scan)

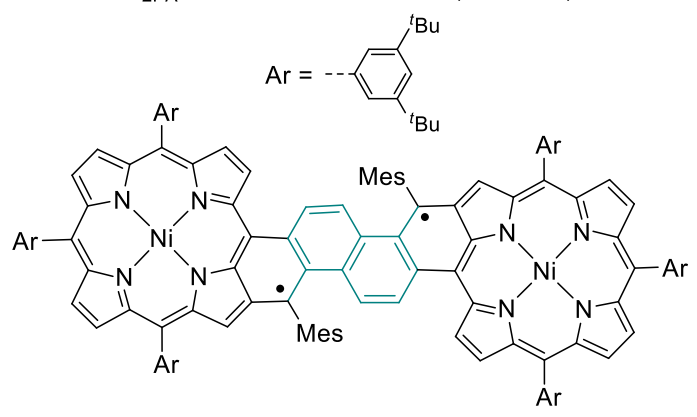

$168(\gamma=0.772)$

$\sigma_{2 \mathrm{PA}}=1750 \mathrm{GM}$ at $1600 \mathrm{~nm}$ (fs-z-scan)

Figure 53. Porphyrin-based diradicaloids and related structures.

\section{Metal complexes}

The 2PA properties of NIR-absorbing metal complexes were scarcely investigated and only two examples with 2PA beyond $1100 \mathrm{~nm}$ are described here. A large 2PA was reported in the literature for the NIR-absorbing nickel (II) bis(dithiolene) 169, a square-planar and centrosymmetric coordination complex with electron-donor extremities that exhibits $5300 \mathrm{GM}$ at $1200 \mathrm{~nm}$ (Figure 54). ${ }^{339}$ The lowest energy transition was attributed to a metal centred $d$ - $d$ transition. In addition, the organometallic 

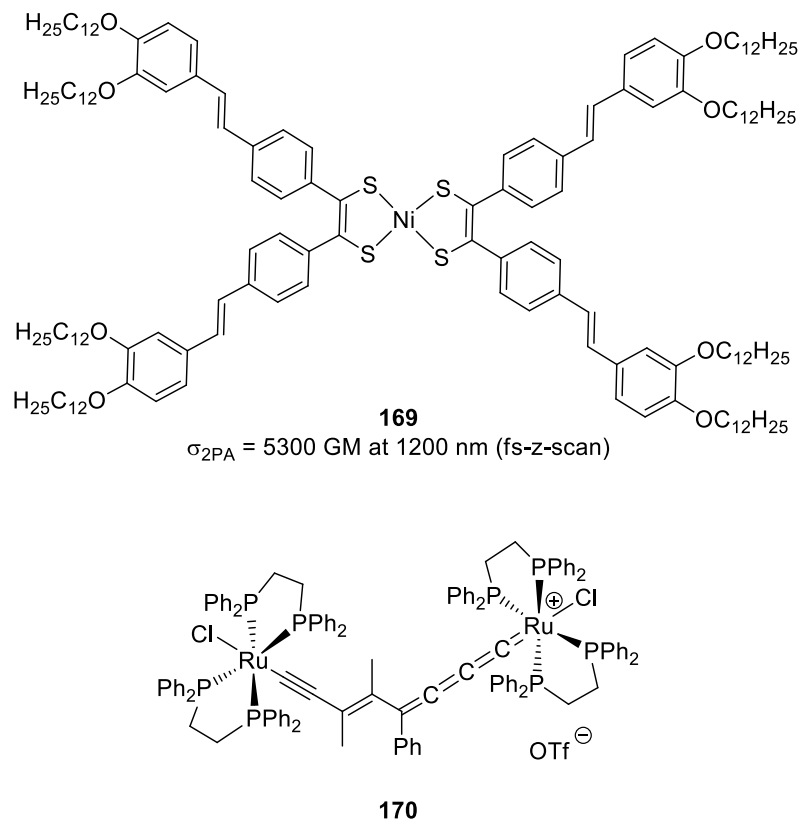

$\sigma_{2 \mathrm{PA}}=133 \mathrm{GM}$ at $1408 \mathrm{~nm}$ (fs-z-scan) diruthenium (II) complex 170 possesses a weak 2PA with 133 $\mathrm{GM}$ at $1408 \mathrm{~nm} \cdot{ }^{242}$ Its conjugated structure involves the full delocalization of a cationic charge through a seven carbon unsaturated bridge, thus the species displays a broad and intense absorption $\left(\varepsilon^{764}=109000 \mathrm{M}^{-1} \mathrm{~cm}^{-1}\right.$ in $\left.\mathrm{CH}_{2} \mathrm{Cl}_{2}\right),{ }^{340}$ and can be therefore considered as an organometallic polymethine.

Numerous structures were presented exhibiting efficient 2PA in the SWIR region (see summary in Table 1), however the range of available chromophores is still limited and many molecular structures can be envisaged in the future, including the new generations of NIR-absorbers developed for photovoltaic and bio-imaging applications. 2PA cross-section optimization is necessary to elaborate effective materials, but additional factors have to be taken into account for further applications: the stability and appropriate solubility and processability of the species, as well as simple and flexible synthetic methods allowing large-scale production. In the last section, we will focus on the application of SWIR nonlinear absorbers for optical power limiting.

Figure 54. Coordination and organometallic complexes with 2PA in the NIR/SWIR.

Table 1. Summary of the linear absorptions ( $\lambda_{1 \mathrm{PA}}$ and corresponding extinction coefficients $\varepsilon$, when available), nonlinear absorptions ( $\lambda_{2 \mathrm{PA}}$ and corresponding cross-sections $\left.\sigma_{2 \mathrm{PA}}\right)$ for the reported chromophores that show 2PA beyond $1100 \mathrm{~nm}$. The solvent, rate and method used for recording the 2PA are provided so that the cross-sections values can be compared with caution.

\begin{tabular}{|c|c|c|c|c|c|c|}
\hline Dye & $\lambda_{1 \mathrm{PA}}[\mathrm{nm}]$ (solvent) & $\varepsilon\left[\mathrm{M}^{-1} \mathrm{~cm}^{-1}\right]$ & $\lambda_{2 \mathrm{PA}}[\mathrm{nm}]$ (solvent) & $\sigma_{2 \mathrm{PA}}[\mathrm{GM}]$ & rate-method & ref. \\
\hline $4 f$ & $552\left(\mathrm{CHCl}_{3}\right)$ & 38900 & $1190\left(\mathrm{CHCl}_{3}\right)$ & 600 & fs-TPEF & 51 \\
\hline 31 & 794 (DMSO) & 286000 & 1552 (DMSO) & 590 & fs-TPEF & 244 \\
\hline 59 & $746\left(\mathrm{CH}_{2} \mathrm{Cl}_{2}\right)$ & 178000 & $1425\left(\mathrm{CHCl}_{3}\right)$ & 424 & fs-z-scan & 206 \\
\hline 60 & 865 (hexane/2\% $\mathrm{CH}_{2} \mathrm{Cl}_{2}$ ) & 78400 & $1500\left(\mathrm{CHCl}_{3}\right)$ & 890 & fs-z-scan & 206 \\
\hline 64 & $718(\mathrm{THF})$ & 57000 & 1440 (THF) & 1500 & fs-WLC & 226 \\
\hline 66 & 889 (THF) & 158000 & 1240 (THF) & 5900 & fs-z-scan & 227 \\
\hline 68 & $678\left(\mathrm{CH}_{2} \mathrm{Cl}_{2}\right)$ & 86000 & $1300\left(\mathrm{CH}_{2} \mathrm{Cl}_{2}\right)$ & 1400 & fs-TPEF & 228 \\
\hline $69 a$ & $551\left(\mathrm{CH}_{3} \mathrm{CN}\right)$ & 59100 & 1130 (DMF) & 280 & fs-z-scan & 230 \\
\hline $69 b$ & $571\left(\mathrm{CH}_{3} \mathrm{CN}\right)$ & 52000 & 1130 (DMF) & 550 & fs-z-scan & 230 \\
\hline $69 c$ & $527\left(\mathrm{CH}_{3} \mathrm{CN}\right)$ & 62100 & 1130 (DMF) & 165 & fs-z-scan & 230 \\
\hline $70 a$ & $551\left(\mathrm{CH}_{3} \mathrm{CN}\right)$ & 35700 & 1190 (DMF) & 260 & fs-z-scan & 230 \\
\hline $70 b$ & $568\left(\mathrm{CH}_{3} \mathrm{CN}\right)$ & 37700 & 1190 (DMF) & 670 & fs-z-scan & 230 \\
\hline $70 c$ & $528\left(\mathrm{CH}_{3} \mathrm{CN}\right)$ & 42000 & 1130 (DMF) & 310 & fs-z-scan & 230 \\
\hline 71 & 710 (PhMe) & $\sim 38000$ & $1150\left(\mathrm{CH}_{2} \mathrm{Cl}_{2}\right)$ & 200 & fs-z-scan & 231 \\
\hline 72 & 725 (PhMe) & $\sim 28000$ & $1350\left(\mathrm{CH}_{2} \mathrm{Cl}_{2}\right)$ & 700 & fs-z-scan & 231 \\
\hline 73 & $\sim 650\left(\mathrm{CH}_{2} \mathrm{Cl}_{2}\right)$ & $\sim 2500$ & $1550 / 1350\left(\mathrm{CH}_{2} \mathrm{Cl}_{2}\right)$ & $100 / 200$ & fs-z-scan & 232 \\
\hline 74 & $504\left(\mathrm{CH}_{2} \mathrm{Cl}_{2}\right)$ & $\sim 60000$ & $1200\left(\mathrm{CH}_{2} \mathrm{Cl}_{2}\right)$ & 200 & fs-z-scan & 232 \\
\hline 75 & $774\left(\mathrm{CHCl}_{3}\right)$ & 276000 & $1344 / 1122\left(\mathrm{CHCl}_{3}\right)$ & $14000 / 19000$ & fs-ND-2PA & 234 \\
\hline 76 & $799\left(\mathrm{CHCl}_{3}\right)$ & 200000 & $1346\left(\mathrm{CHCl}_{3}\right)$ & 27000 & fs-ND-2PA & 234 \\
\hline 77 & $\sim 620\left(\mathrm{CHCl}_{3}\right)$ & $\sim 50000$ & $1240\left(\mathrm{CHCl}_{3}\right)$ & 780 & fs-TPEF & 46 \\
\hline $78 b$ & $654(\mathrm{EtOH})$ & $\sim 230000$ & 1170 (EtOH) & 100 & fs-TPEF & 236 \\
\hline $78 \mathrm{c}$ & 760 (EtOH) & 225000 & 1310 (EtOH) & 200 & fs-TPEF & 236 \\
\hline $79 b$ & $650(\mathrm{EtOH})$ & $\sim 240000$ & 1180 (EtOH) & 140 & fs-TPEF & 236 \\
\hline $79 c$ & 756 (EtOH) & 300000 & 1330 (EtOH) & 600 & fs-TPEF & 236 \\
\hline 80 & 648 (EtOH) & - & 1160 (EtOH) & 55 & fs-TPEF & 236 \\
\hline 81 & 770 (EtOH) & - & 1340 (EtOH) & 60 & fs-TPEF & 236 \\
\hline 82 & 862 (EtOH) & 230000 & $1480(\mathrm{EtOH})$ & 600 & fs-TPEF & 236 \\
\hline
\end{tabular}




\begin{tabular}{|c|c|c|c|c|c|c|}
\hline Dye & $\lambda_{1 \mathrm{PA}}[\mathrm{nm}]$ (solvent) & $\varepsilon\left[\mathrm{M}^{-1} \mathrm{~cm}^{-1}\right]$ & $\lambda_{2 \mathrm{PA}}[\mathrm{nm}]$ (solvent) & $\sigma_{2 P A}[G M]$ & rate-method & ref. \\
\hline 83 & $794\left(\mathrm{CH}_{2} \mathrm{Cl}_{2}\right)$ & 350000 & $1437\left(\mathrm{CH}_{2} \mathrm{Cl}_{2}\right)$ & 731 & fs-z-scan & 241 \\
\hline 84 & $810\left(\mathrm{CH}_{2} \mathrm{Cl}_{2}\right)$ & 91000 & $1445\left(\mathrm{CH}_{2} \mathrm{Cl}_{2}\right)$ & 792 & fs-z-scan & 241 \\
\hline 85 & $900\left(\mathrm{CH}_{2} \mathrm{Cl}_{2}\right)$ & 325000 & $1592\left(\mathrm{CH}_{2} \mathrm{Cl}_{2}\right)$ & 890 & fs-z-scan & 242 \\
\hline 86 & $833\left(\mathrm{CH}_{2} \mathrm{Cl}_{2}\right)$ & 270000 & $1495\left(\mathrm{CH}_{2} \mathrm{Cl}_{2}\right)$ & 544 & fs-z-scan & 241 \\
\hline 87 & 825 (DMSO) & 204000 & 1552 (DMSO) & 950 & fs-TPEF & 244 \\
\hline 88 & 809 (DMSO) & 163000 & 1552 (DMSO) & 900 & fS-TPEF & 244 \\
\hline $89 a$ & $556\left(\mathrm{CH}_{2} \mathrm{Cl}_{2}\right)$ & 1840 & $1170\left(\mathrm{CH}_{2} \mathrm{Cl}_{2}\right)$ & $\sim 2$ & fs-z-scan & 245 \\
\hline $89 b$ & $542\left(\mathrm{CH}_{2} \mathrm{Cl}_{2}\right)$ & 2130 & $1300 / 1100\left(\mathrm{CH}_{2} \mathrm{Cl}_{2}\right)$ & $\sim 7 / 90$ & fs-z-scan & 247 \\
\hline 90 & $\sim 1060\left(\mathrm{CH}_{2} \mathrm{Cl}_{2}\right)$ & 320000 & $1305\left(\mathrm{CH}_{2} \mathrm{Cl}_{2}\right)$ & 13 & fs-z-scan & 246 \\
\hline 91 & $\sim 1040\left(\mathrm{CH}_{2} \mathrm{Cl}_{2}\right)$ & $\sim 60000$ & $1410 / 1305\left(\mathrm{CH}_{2} \mathrm{Cl}_{2}\right)$ & $11 / 46$ & fs-z-scan & 246 \\
\hline $92 a$ & $678\left(\mathrm{CH}_{3} \mathrm{CN}\right)$ & 231000 & $1250\left(\mathrm{CH}_{3} \mathrm{CN}\right)$ & $\sim 800$ & fs-z-scan & 249 \\
\hline $92 b$ & $777\left(\mathrm{CH}_{3} \mathrm{CN}\right)$ & 232000 & $1450\left(\mathrm{CH}_{3} \mathrm{CN}\right)$ & $\sim 1000$ & fs-z-scan & 249 \\
\hline $93 a$ & $615\left(\mathrm{CH}_{3} \mathrm{CN}\right)$ & 252000 & $1120\left(\mathrm{CH}_{3} \mathrm{CN}\right)$ & 140 & fs-z-scan & 250 \\
\hline $93 \mathrm{~b}$ & $711\left(\mathrm{CH}_{3} \mathrm{CN}\right)$ & 300000 & $1300\left(\mathrm{CH}_{3} \mathrm{CN}\right)$ & 710 & fs-z-scan & 250 \\
\hline $93 c$ & $812\left(\mathrm{CH}_{3} \mathrm{CN}\right)$ & 286000 & $1450\left(\mathrm{CH}_{3} \mathrm{CN}\right)$ & 1100 & fs-z-scan & 250 \\
\hline 94 & $921\left(\mathrm{CH}_{3} \mathrm{CN}\right)$ & 195000 & $1600 / 1100\left(\mathrm{CH}_{3} \mathrm{CN}\right)$ & $2200 / 17000$ & fs-z-scan & 250 \\
\hline 95 & $\sim 1060\left(\mathrm{CH}_{2} \mathrm{Cl}_{2}\right)$ & $\sim 250000$ & $1800\left(\mathrm{CH}_{2} \mathrm{Cl}_{2}\right)$ & 2250 & fs-z-scan & 253 \\
\hline 96 & $785\left(\mathrm{CHCl}_{3} / 2 \%\right.$ TFA $)$ & 76000 & 1600 / 1350 ( $\mathrm{CHCl}_{3} / 2 \%$ TFA $)$ & $<50 / 150$ & fs-ND-2PA & 254 \\
\hline 97 & $704\left(\mathrm{CHCl}_{3} / 2 \% \mathrm{TFA}\right)$ & 69000 & $1300\left(\mathrm{CHCl}_{3} / 2 \%\right.$ TFA $)$ & 200 & fs-ND-2PA & 254 \\
\hline 98 & $682(\mathrm{EtOH})$ & 212000 & $1250(\mathrm{EtOH})$ & 700 & fs-z-scan & 237 \\
\hline 99 & $668\left(\mathrm{CH}_{2} \mathrm{Cl}_{2}\right)$ & 345000 & $1250\left(\mathrm{CH}_{2} \mathrm{Cl}_{2}\right)$ & 650 & fs-z-scan & 237 \\
\hline 100 & 624 (EtOH) & 230900 & 1150 (EtOH) & 650 & fs-z-scan & 237 \\
\hline 101 & $669\left(\mathrm{CHCl}_{3}\right)$ & 293000 & $1240\left(\mathrm{CHCl}_{3}\right)$ & 483 & ns-TPEF & 256 \\
\hline 103 & $650\left(\mathrm{CH}_{2} \mathrm{Cl}_{2}\right)$ & 400000 & $1200\left(\mathrm{CH}_{2} \mathrm{Cl}_{2}\right)$ & 100 & fs-z-scan & 259 \\
\hline 104 & 650 (THF) & 860000 & 1200 (THF) & 1000 & fs-z-scan & 258 \\
\hline 105 & 832 (THF) & 290000 & $1500 / 1100$ (THF) & $800 / 18000$ & fs-z-scan & 52 \\
\hline 106 & $808\left(\mathrm{CHCl}_{3}\right)$ & $40000^{a}$ & $1640\left(\mathrm{CHCl}_{3}\right)$ & $2300^{\mathrm{a}}$ & fs-z-scan & 260 \\
\hline 107 & $764\left(\mathrm{CHCl}_{3}\right)$ & 214000 & $1640\left(\mathrm{CHCl}_{3}\right)$ & 704 & fs-z-scan & 260 \\
\hline 108 & 615 (THF) & 152000 & 1200 (THF) & 162 & fs-TPEF & 261 \\
\hline 109 & 665 (PhMe) & 805000 & $1212(\mathrm{PhMe})$ & 470 & TPEF & 262 \\
\hline 110 & 721 (PhMe) & 637000 & 1307 (PhMe) & 465 & TPEF & 262 \\
\hline 111 & $\sim 700\left(\mathrm{CH}_{2} \mathrm{Cl}_{2}\right)$ & 90000 & $1310\left(\mathrm{CH}_{2} \mathrm{Cl}_{2}\right)$ & 101 & $\mathrm{fs}-\mathrm{NLT}$ & 264 \\
\hline 112 & $695\left(\mathrm{CH}_{2} \mathrm{Cl}_{2}\right)$ & 80000 & $1440\left(\mathrm{CH}_{2} \mathrm{Cl}_{2}\right)$ & 80 & fs-z-scan & 265 \\
\hline 113 & $745\left(\mathrm{CH}_{2} \mathrm{Cl}_{2}\right)$ & 57000 & $1220\left(\mathrm{CH}_{2} \mathrm{Cl}_{2}\right)$ & 1070 & fs-z-scan & 265 \\
\hline 114 & $694\left(\mathrm{CH}_{2} \mathrm{Cl}_{2}\right)$ & 100000 & $1410\left(\mathrm{CCl}_{4}\right)$ & 57 & fs-z-scan & 271 \\
\hline 115 & $716\left(\mathrm{CH}_{2} \mathrm{Cl}_{2}\right)$ & 66000 & $1490 / 1210\left(\mathrm{CCl}_{4}\right)$ & $1125 / 3000$ & fs-z-scan & 271 \\
\hline 116 & $824\left(\mathrm{CH}_{2} \mathrm{Cl}_{2}\right)$ & 39000 & $1400\left(\mathrm{CH}_{2} \mathrm{Cl}_{2}\right)$ & 970 & fs-z-scan & 271 \\
\hline 117 & $590(\mathrm{PhMe})$ & $\sim 3700$ & 1200 (PhMe) & 6 & fs-TPEF & 278 \\
\hline 118a & 659 (PhMe) & 50100 & 1100 (PhMe) & 14 & fS-TPEF & 279 \\
\hline $118 \mathrm{~b}$ & 632 (PhMe) & 83200 & $1100(\mathrm{PhMe})$ & 19 & fs-TPEF & 279 \\
\hline 119 & $\sim 780\left(\mathrm{CCl}_{4}\right)$ & $\sim 550000$ & $1400\left(\mathrm{CCl}_{4}\right)$ & 35 & fS-TPEF & 46 \\
\hline 120 & 602 (glass) $^{b}$ & - & 1350 (glass) $^{\mathrm{b}}$ & 36 & fs-z-scan & 283 \\
\hline 121 & $694\left(\mathrm{CH}_{2} \mathrm{Cl}_{2}\right)$ & 51300 & $1240\left(\mathrm{CCl}_{4}\right)$ & 70 & fs-z-scan & 291 \\
\hline 122 & 641 (PhMe) & - & 1260 (PhMe) & 1890 & fs-z-scan & 286 \\
\hline 123 & 685 (PhMe) & - & 1360 (PhMe) & 3520 & fs-z-scan & 286 \\
\hline 124 & 713 (PhMe) & - & $1400(\mathrm{PhMe})$ & 8030 & fs-z-scan & 286 \\
\hline 125 & 723 (PhMe) & - & 1430 (PhMe) & 5490 & fs-z-scan & 286 \\
\hline 126 & $681\left(\mathrm{CHCl}_{3}\right)$ & 32700 & $\sim 1360\left(\mathrm{CHCl}_{3}\right)$ & $\sim 1500$ & TPEF & 294 \\
\hline 127 & $684\left(\mathrm{CHCl}_{3}\right)$ & 65000 & 1310 (PhMe) & 7170 & fs-z-scan & 295 \\
\hline 128 & $780\left(\mathrm{CH}_{2} \mathrm{Cl}_{2}\right)$ & $\sim 220000$ & $1200\left(\mathrm{CH}_{2} \mathrm{Cl}_{2}\right)$ & 510 & fs-z-scan & 296 \\
\hline 129 & $801\left(\mathrm{CH}_{2} \mathrm{Cl}_{2}\right)$ & - & $1580\left(\mathrm{CH}_{2} \mathrm{Cl}_{2}\right)$ & 3300 & fs-z-scan & 297 \\
\hline 130 & $712\left(\mathrm{CH}_{2} \mathrm{Cl}_{2}\right)$ & - & $1280\left(\mathrm{CH}_{2} \mathrm{Cl}_{2}\right)$ & 2900 & fs-z-scan & 297 \\
\hline 131 & $700\left(\mathrm{CH}_{2} \mathrm{Cl}_{2}\right)$ & - & $1360\left(\mathrm{CH}_{2} \mathrm{Cl}_{2}\right)$ & 2700 & fs-z-scan & 297 \\
\hline $132 a$ & $568\left(\mathrm{CH}_{2} \mathrm{Cl}_{2}\right)$ & 436500 & $1200(\mathrm{PhMe})$ & 9890 & fs-z-scan & 298 \\
\hline $132 b$ & $574\left(\mathrm{CH}_{2} \mathrm{Cl}_{2}\right)$ & 190000 & $1200(\mathrm{PhMe})$ & 9490 & fs-z-scan & 298 \\
\hline $132 \mathrm{c}$ & $574\left(\mathrm{CH}_{2} \mathrm{Cl}_{2}\right)$ & 200000 & $1200(\mathrm{PhMe})$ & 7790 & fs-z-scan & 298 \\
\hline 132d & $568\left(\mathrm{CH}_{2} \mathrm{Cl}_{2}\right)$ & 25000 & $1200(\mathrm{PhMe})$ & 7640 & fs-z-scan & 298 \\
\hline 133 & $715\left(\mathrm{CH}_{2} \mathrm{Cl}_{2}\right)$ & 161000 & $1410\left(\mathrm{CH}_{2} \mathrm{Cl}_{2}\right)$ & 12700 & fs-z-scan & 299 \\
\hline 134 & $637\left(\mathrm{CH}_{2} \mathrm{Cl}_{2}\right)$ & 59000 & $1500\left(\mathrm{CH}_{2} \mathrm{Cl}_{2}\right)$ & 2100 & fs-z-scan & 301 \\
\hline 135 & $735\left(\mathrm{CH}_{2} \mathrm{Cl}_{2}\right)$ & 220000 & $1440\left(\mathrm{CH}_{2} \mathrm{Cl}_{2}\right)$ & 6400 & fs-z-scan & 305 \\
\hline 137 & $632\left(\mathrm{CH}_{2} \mathrm{Cl}_{2} / 1 \% \mathrm{BuNH}_{2}\right)$ & 126000 & $1260\left(\mathrm{CH}_{2} \mathrm{Cl}_{2} / 1 \% \mathrm{BuNH}_{2}\right)$ & 15400 & fs-z-scan & 309 \\
\hline
\end{tabular}




\begin{tabular}{|c|c|c|c|c|c|c|}
\hline Dye & $\lambda_{1 \mathrm{PA}}[\mathrm{nm}]$ (solvent) & $\varepsilon\left[\mathrm{M}^{-1} \mathrm{~cm}^{-1}\right]$ & $\lambda_{2 P A}[n m]$ (solvent) & $\sigma_{2 \mathrm{PA}}[\mathrm{GM}]$ & rate-method & ref. \\
\hline 138a & $1053\left(\mathrm{CH}_{2} \mathrm{Cl}_{2}\right)$ & 16200 & $2100\left(\mathrm{CH}_{2} \mathrm{Cl}_{2}\right)$ & 3700 & fs-z-scan & 311 \\
\hline 138b & $1110\left(\mathrm{CH}_{2} \mathrm{Cl}_{2}\right)$ & 9700 & $2100\left(\mathrm{CH}_{2} \mathrm{Cl}_{2}\right)$ & 4600 & fs-z-scan & 311 \\
\hline 139a & $741\left(\mathrm{CHCl}_{3}\right)$ & 22800 & $1400\left(\mathrm{CHCl}_{3}\right)$ & 8000 & fs-z-scan & 312 \\
\hline $139 b$ & $892\left(\mathrm{CHCl}_{3}\right)$ & 60200 & $1700\left(\mathrm{CHCl}_{3}\right)$ & 16900 & fs-z-scan & 312 \\
\hline 139c & $996\left(\mathrm{CHCl}_{3}\right)$ & 143000 & $1900\left(\mathrm{CHCl}_{3}\right)$ & 29900 & fs-z-scan & 312 \\
\hline 139d & $1075\left(\mathrm{CHCl}_{3}\right)$ & - & $2100\left(\mathrm{CHCl}_{3}\right)$ & 41400 & fs-z-scan & 312 \\
\hline 140a & $1064\left(\mathrm{CHCl}_{3}\right)$ & - & $1200\left(\mathrm{PhMe} / 5 \% \mathrm{BuNH}_{2}\right)$ & 11900 & fs-z-scan & 307 \\
\hline 140b & $1333\left(\mathrm{CHCl}_{3}\right)$ & - & $1200 / 2300\left(\mathrm{PhMe} / 5 \% \mathrm{BuNH}_{2}\right)$ & 33100 / 18500 & fs-z-scan & 307 \\
\hline $140 c$ & $1515\left(\mathrm{CHCl}_{3}\right)$ & - & $1200 / 2300\left(\mathrm{PhMe} / 5 \% \mathrm{BuNH}_{2}\right)$ & $93600 / 41200$ & fs-z-scan & 307 \\
\hline 141 & $1622\left(\mathrm{PhMe} / 5 \% \mathrm{BuNH}_{2}\right)$ & 9800 & $2100 / 2300\left(\mathrm{PhMe} / 5 \% \mathrm{BuNH}_{2}\right)$ & 9560 / 8700 & fs-z-scan & 313 \\
\hline 142 & $1805\left(\mathrm{PhMe} / 5 \% \mathrm{BuNH}_{2}\right)$ & 28100 & $2100 / 2300\left(\mathrm{PhMe} / 5 \% \mathrm{BuNH}_{2}\right)$ & $43000 / 35700$ & fs-z-scan & 313 \\
\hline 143 & $756\left(\mathrm{CHCl}_{3} / 1 \% \mathrm{BuNH}_{2}\right)$ & 77000 & $1600\left(\mathrm{PhMe} / 1 \% \mathrm{BuNH}_{2}\right)$ & 2750 & fs-z-scan & 314 \\
\hline 144a & $\sim 800\left(\mathrm{CCl}_{4}\right)$ & 280000 & $1305\left(\mathrm{CCl}_{4}\right)$ & 8800 & fs-TPEF & 315 \\
\hline 144b & $\sim 840\left(\mathrm{CCl}_{4}\right)$ & 800000 & $1315\left(\mathrm{CCl}_{4}\right)$ & 49000 & fs-TPEF & 315 \\
\hline $144 c$ & $\sim 860\left(\mathrm{CCl}_{4}\right)$ & 1500000 & $1325\left(\mathrm{CCl}_{4}\right)$ & $115000 / 8900^{\mathrm{a}}$ & fs-TPEF & 315 \\
\hline 145 & $784\left(\mathrm{CH}_{2} \mathrm{Cl}_{2} / 1 \%\right.$ pyridine $)$ & 53700 & $1300\left(\mathrm{CHCl}_{3}\right)$ & $5200^{\mathrm{a}}$ & fs-z-scan & 319 \\
\hline 146 & $912\left(\mathrm{CHCl}_{3}\right)$ & - & $1520\left(\mathrm{CHCl}_{3}\right)$ & $7704^{a}$ & fs-z-scan & 317 \\
\hline 147 & $722\left(\mathrm{CHCl}_{3}\right)$ & 34000 & $1520\left(\mathrm{CHCl}_{3}\right)$ & $7809^{a}$ & fs-z-scan & 318 \\
\hline 148 & $732\left(\mathrm{CH}_{2} \mathrm{Cl}_{2}\right)$ & 255000 & $1500\left(\mathrm{CH}_{2} \mathrm{Cl}_{2}\right)$ & 2000 & fs-TPEF & 320 \\
\hline 149 & $1243\left(\mathrm{CHCl}_{3} / 2 \% \mathrm{TFA}\right)$ & 170000 & $1550\left(\mathrm{CHCl}_{3} / 2 \% \mathrm{TFA}\right)$ & 3100 & fs-z-scan & 321 \\
\hline 150 & $\sim 570\left(\mathrm{CH}_{2} \mathrm{Cl}_{2}\right)$ & $\sim 1500$ & $1200\left(\mathrm{CCl}_{4}\right)$ & 760 & fs-z-scan & 326 \\
\hline 151 & $634\left(\mathrm{CHCl}_{3}\right)$ & 60000 & $1250\left(\mathrm{CHCl}_{3}\right)$ & 920 & fs-z-scan & 327 \\
\hline 152 & $668\left(\mathrm{CHCl}_{3}\right)$ & 83300 & $1250\left(\mathrm{CHCl}_{3}\right)$ & 1200 & fs-z-scan & 327 \\
\hline 153 & $687\left(\mathrm{CHCl}_{3}\right)$ & 72000 & $1400\left(\mathrm{CHCl}_{3}\right)$ & 530 & fs-z-scan & 328 \\
\hline 154 & $804\left(\mathrm{CHCl}_{3}\right)$ & 148900 & $1600\left(\mathrm{CHCl}_{3}\right)$ & 2800 & fs-z-scan & 328 \\
\hline 155 & $592\left(\mathrm{CH}_{2} \mathrm{Cl}_{2}\right)$ & 20700 & $1180\left(\mathrm{CH}_{2} \mathrm{Cl}_{2}\right)$ & 1770 & fs-TPEF & 329 \\
\hline 156 & $684\left(\mathrm{CHCl}_{3}\right)$ & 7600 & 1400 (PhMe) & 340 & fs-z-scan & 331 \\
\hline 157 & $606\left(\mathrm{CHCl}_{3}\right)$ & 31000 & 1200 (PhMe) & 420 & fs-z-scan & 331 \\
\hline 158 & $687\left(\mathrm{CHCl}_{3}\right)$ & 23300 & 1400 (PhMe) & 520 & fs-z-scan & 331 \\
\hline 159a & $626\left(\mathrm{CHCl}_{3}\right)$ & 66000 & 1200 (THF) & 1300 & fs-z-scan & 332 \\
\hline $159 b$ & $901\left(\mathrm{CHCl}_{3}\right)$ & 54700 & 1700 (THF) & 1060 & fs-z-scan & 332 \\
\hline 159c & $930\left(\mathrm{CHCl}_{3}\right)$ & 22600 & 1700 (THF) & 770 & fs-z-scan & 332 \\
\hline 159d & $930\left(\mathrm{CHCl}_{3}\right)$ & 21400 & 1700 (THF) & 710 & fs-z-scan & 332 \\
\hline $159 e$ & $929\left(\mathrm{CHCl}_{3}\right)$ & 17300 & 1700 (THF) & 730 & fs-z-scan & 332 \\
\hline $159 f$ & $927\left(\mathrm{CHCl}_{3}\right)$ & 13000 & 1700 (THF) & 710 & fs-z-scan & 332 \\
\hline 160a & $760\left(\mathrm{CH}_{2} \mathrm{Cl}_{2}\right)$ & 54300 & $1500\left(\mathrm{CH}_{2} \mathrm{Cl}_{2}\right)$ & 1000 & fs-z-scan & 333 \\
\hline $160 \mathrm{~b}$ & $929\left(\mathrm{CH}_{2} \mathrm{Cl}_{2}\right)$ & 9900 & $1900\left(\mathrm{CH}_{2} \mathrm{Cl}_{2}\right)$ & 660 & fs-z-scan & 333 \\
\hline $160 c$ & $936\left(\mathrm{CH}_{2} \mathrm{Cl}_{2}\right)$ & 6800 & $1900\left(\mathrm{CH}_{2} \mathrm{Cl}_{2}\right)$ & 670 & fs-z-scan & 333 \\
\hline 161 & 783 (PhMe) & 41000 & 1550 (PhMe) & 350 & fs-z-scan & 334 \\
\hline $162 a$ & $1005\left(\mathrm{CH}_{2} \mathrm{Cl}_{2}\right)$ & 31000 & $1200\left(\mathrm{CH}_{2} \mathrm{Cl}_{2}\right)$ & 3560 & fs-z-scan & 335 \\
\hline $162 b$ & $916\left(\mathrm{CH}_{2} \mathrm{Cl}_{2}\right)$ & $\sim 8000$ & $1200\left(\mathrm{CH}_{2} \mathrm{Cl}_{2}\right)$ & $<9$ & fs-z-scan & 335 \\
\hline 163 & $1088\left(\mathrm{CH}_{2} \mathrm{Cl}_{2}\right)$ & 665000 & $2200\left(\mathrm{CH}_{2} \mathrm{Cl}_{2}\right)$ & 1300 & fs-z-scan & 336 \\
\hline 164 & $1136\left(\mathrm{CH}_{2} \mathrm{Cl}_{2}\right)$ & 644000 & $2300\left(\mathrm{CH}_{2} \mathrm{Cl}_{2}\right)$ & 1500 & fs-z-scan & 336 \\
\hline 165 & $955\left(\mathrm{CH}_{2} \mathrm{Cl}_{2}\right)$ & 45400 & 1800 (THF) & 2080 & fs-z-scan & 337 \\
\hline 166a & $800\left(\mathrm{CH}_{2} \mathrm{Cl}_{2}\right)$ & 64600 & 1500 (THF) & 650 & fs-z-scan & 337 \\
\hline 166b & $865\left(\mathrm{CH}_{2} \mathrm{Cl}_{2}\right)$ & 45300 & 1800 (THF) & 1600 & fs-z-scan & 337 \\
\hline $166 c$ & $922\left(\mathrm{CH}_{2} \mathrm{Cl}_{2}\right)$ & 42100 & 1800 (THF) & 1490 & fs-z-scan & 337 \\
\hline 167 & 976 (THF) & 71000 & 1400 (THF) & 3500 & fs-z-scan & 338 \\
\hline 168 & 1147 (THF) & 18000 & 1600 (THF) & 1750 & fs-z-scan & 338 \\
\hline 169 & 960 (THF) & $\sim 50000$ & 1200 (THF) & 5300 & fs-z-scan & 339 \\
\hline 170 & $764\left(\mathrm{CH}_{2} \mathrm{Cl}_{2}\right)$ & 109000 & $1408\left(\mathrm{CH}_{2} \mathrm{Cl}_{2}\right)$ & 133 & fs-z-scan & 242 \\
\hline
\end{tabular}

a Per repeat unit. ${ }^{b}$ Molecule doped in boric acid glass. 


\section{Optical power liming in the SWIR band}

Due to the serious danger for human eyes that $\mathrm{Nd}$ :YAG based systems represent, ${ }^{341}$ these laser sources tend to be replaced by eye-safe lasers operating around $1550 \mathrm{~nm}$ (Figure $55)$, which facilitates the use of optronic systems in new fields. Indeed, recent research on autonomous vehicles are studying the possibility to use eye-safe laser systems for on-board LIDAR to determine its position in real time. This particular wavelength is also of great interest for defence applications as it is located in the transparency window of the atmosphere (Figure 55), and is also less impacted by perturbations such as clouds, fog or smoke, which makes it particularly useful for active imaging applications, guiding system or telemetry. The switching of optronic systems at this new wavelength does not exempt for the need of optical power limiting (OPL) devices as on-board detectors need to be protected from potentially dangerous irradiations. Even for civilian applications where hostile irradiations could be excluded, there is still a risk of potential jamming or destruction of the detectors from self-irradiation caused by laser beam reflections, for example on road-signs or other reflective surfaces present in our daily life.
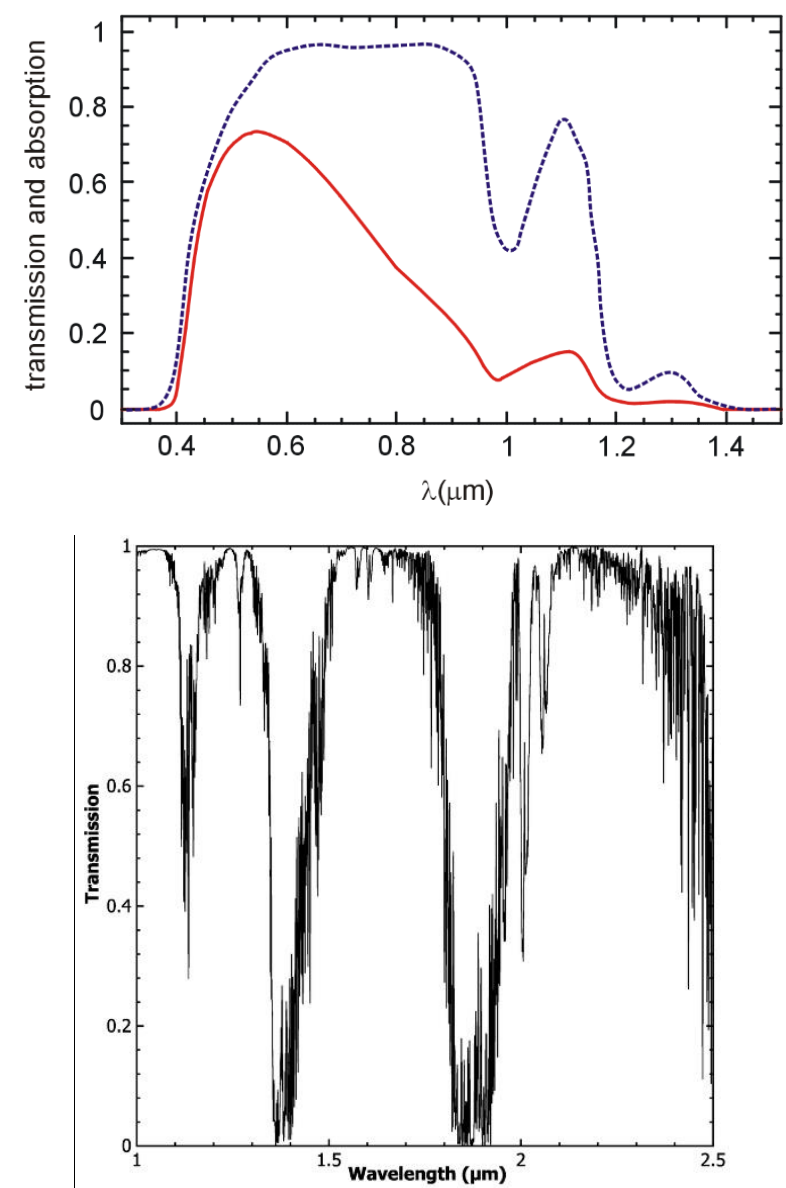

Figure 55. Top: optical properties of the human eye, with transmission curve from cornea to retina (blue), and fraction of the incident power on the cornea that is absorbed by the retina (red); reprinted with permission from reference ${ }^{341}$ (c) The Optical Society. Bottom: Transmission spectrum of the Earth's atmosphere; reproduced from reference ${ }^{342}$ by permission of IOP Publishing. (c) The Astronomical Society of the Pacific. All rights reserved.
To answer this particular challenge, the OPL device must fulfil some essential requirements (Figure 56): ${ }^{343}$ i) the highest transmission below the critical threshold intensity, ii) a maximum transmission $\left(I_{\max }\right)$ inferior to the detector damage threshold, iii) a fast and auto-activated response, iv) an activity over the broadest spectral and temporal range, vi) stay active at input intensity far greater than the threshold intensity and finally vi) the OPL process must be fully reversible. Several photophysical processes are known to produce OPL effects, namely multiphoton absorption, reverse saturable absorption, nonlinear refraction and nonlinear scattering. In 2016, Dini, Calvete and Hanack have written a very complete review ${ }^{344}$ listing the molecular optical limiting systems utilizing all the different phenomena listed above for the visible-NIR range and the reader is invited to read this reference article for exhaustive information.

Among all OPL processes, multiphoton absorption - and particularly 2PA -based OPL systems show many advantages compared to others as they present: i) negligible linear attenuation with nearly complete transmission for a low intensity incident energy, ii) an auto-activated and instantaneous response to higher energy of the input laser signal, and iii) no saturation phenomenon. In addition, multiphoton absorption-based OPL devices rely on a molecular process and therefore the active dye has to be stable enough to overcome high light intensities and must exhibit a good solubility in organic media since the OPL experiments require high concentrations (ca. $0.1 \mathrm{M}$ ). Consequently, large amounts of dyes are generally required and ideally, their synthesis would present good overall yields with a limited number of steps. The following paragraph will be only focused on multiphoton absorption-based OPL in the SWIR range.
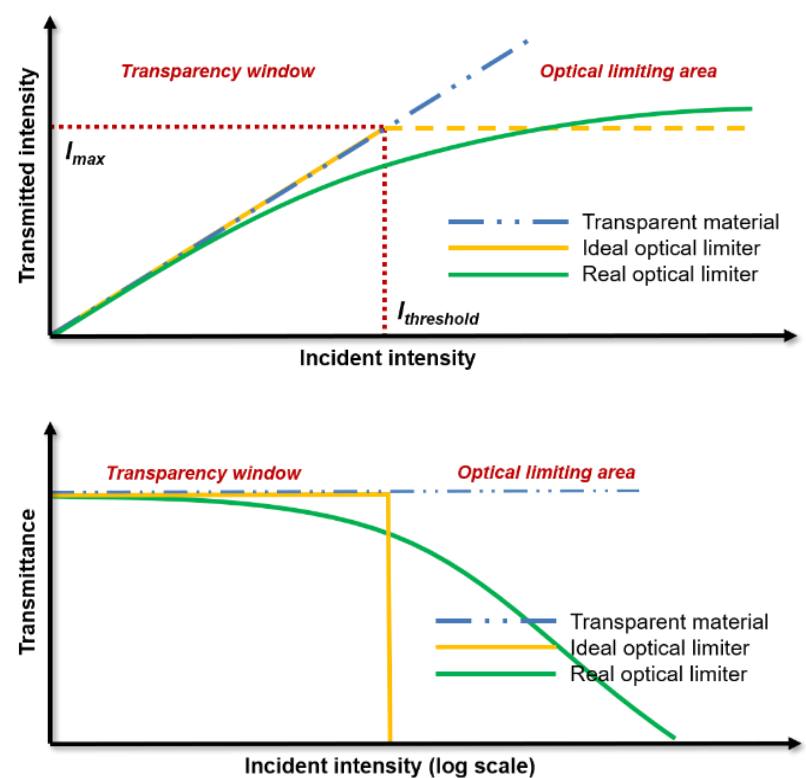

Figure 56. Principle of optical power limiting. Two representations are mostly used in the literature: transmitted vs incident intensity (or fluence, top); transmittance vs incident intensity (or fluence, in log scale, bottom). 


\section{Three-photon based OPL}

The first examples of SWIR OPL were based on three-photon absorption (3PA) as this technique permitted to use dyes that were initially developed for 2PA in the NIR and valorise them for 3PA in the SWIR. The three-photon absorption phenomenon needs very high photon flux to occur, several order of magnitude higher than for 2PA and consequently generally requires the use of ultra-short laser pulses $\left(10^{-15}-10^{-12} \mathrm{~s}\right)$.

Prasad and co-workers described among the first example of 3PA-based OPL devices above $1064 \mathrm{~nm}$ using dipolar chromophores 171, $\mathbf{1 7 2}^{345}$ and $\mathbf{1 7 3}^{346}$ (Figure 57) absorbing in the visible spectral range $\left(\lambda_{\max }=394,400\right.$ and $510 \mathrm{~nm}$, respectively, recorded in chloroform for compound $\mathbf{1 7 1}$ and 172 and in benzyl alcohol for compound 173). As explained above, it is possible to trigger 3PA in the SWIR band for this type of dye using femtosecond laser pulses, which therefore induce an OPL behaviour at $1300 \mathrm{~nm}$, as illustrated in Figure 57. The maximum 3PA cross-section for these dyes is obtained for $171\left(\sigma_{3 \mathrm{PA}}=\right.$ $3.75 \times 10^{-25} \mathrm{~cm}^{6} \mathrm{GW}^{-2}$ at $1260 \mathrm{~nm}$ ) but, the maximum OPL efficiency is obtained for 173. In fact, if this very simple liquid dye shows a lower 3PA cross-section, its fluid form and high miscibility with benzyl alcohol permitted to reach concentrations as high as $1 \mathrm{M}$, which resulted in a high 3PA coefficient $\left(\alpha_{3}=1.6 \times 10^{-5} \mathrm{~cm}^{3} \mathrm{GW}^{-2}\right.$ at $\left.1300 \mathrm{~nm}\right)$ and consequently a better OPL behaviour.

Quickly after, the same group reported the 3PA OPL behaviour of a series of branched chromophores (Figure 58). ${ }^{347-}$ 350 In this context, the series 174-176, based on fused fluorene moieties, proved the efficiency of cooperative enhancement observed for octupolar chromophores in order to increase 3PA and consequently OPL performances with a reported $\alpha_{3}=4.3 \times 10^{-6} \mathrm{~cm}^{3} \mathrm{GW}^{-2}$ at $1310 \mathrm{~nm}$ for 176 (Figure 59). ${ }^{347}$ Satisfactory OPL performances were also recorded for similar quadrupolar and octupolar compound $177^{348}$ and $178 . .^{350}$ Using this approach, the best OPL performances based on 3Pabsorbers were
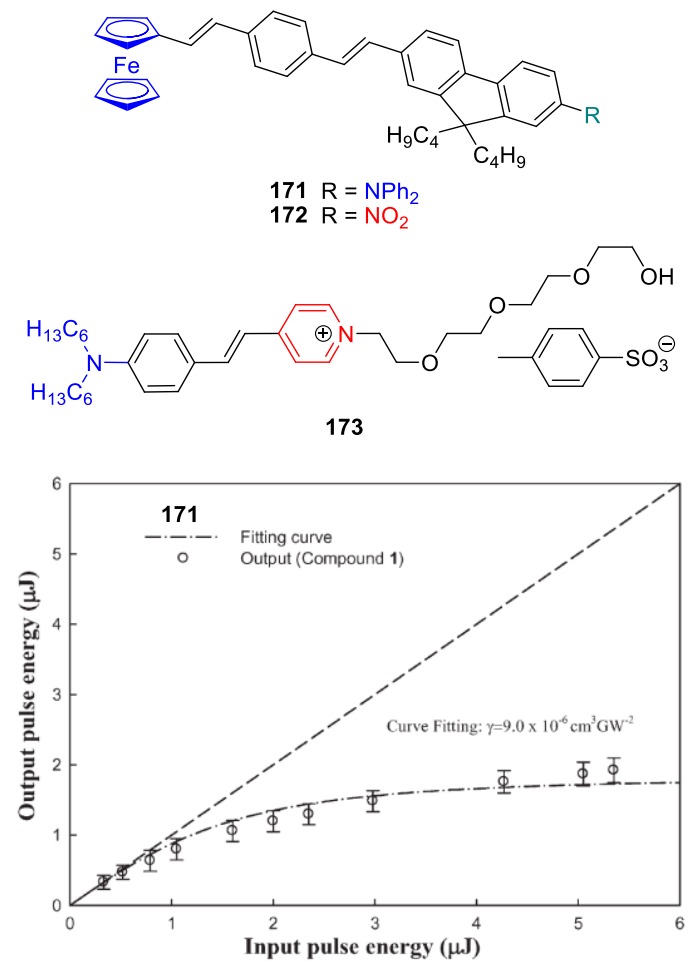

Figure 57. Top: structures of 3P-absorbing compounds 171-173. Bottom: OPL curve of dye 171 at $1260 \mathrm{~nm}\left(0.04 \mathrm{M}\right.$ in $\mathrm{CHCl}_{3}, 160 \mathrm{fs}$ pulses, $1 \mathrm{kHz}$ repetition rate). Reproduced from reference ${ }^{345}$ with permission from The Royal Society of Chemistry.

reported by Cui et al., with $179,{ }^{349}$ a dye originally described by Prasad et al. for 2PA around $800 \mathrm{~nm} .{ }^{57}$ For this octupole, a 3PA cross section $\sigma_{3 P A}=2.16 \times 10^{23} \mathrm{~cm}^{6} \mathrm{GW}^{-2}$ and a 3PA coefficient of $\alpha_{3}=1.6 \times 10^{-4} \mathrm{~cm}^{3} \mathrm{GW}^{-2}$ at $1250 \mathrm{~nm}$ were reported (Figure 58 and Table 2). However, comparison must be made with extreme caution, as different measurements methods were used to obtain $\alpha_{3}$ values. Finally, it is worth noting that CdSe quantum dots were described for OPL based on 3PA for femtosecond pulses at $1300 \mathrm{~nm} .^{339}$

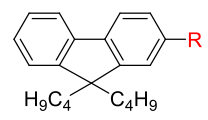

174

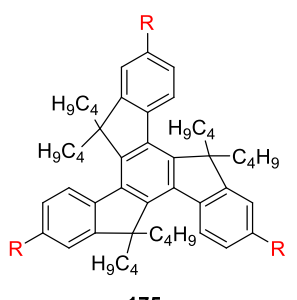

175

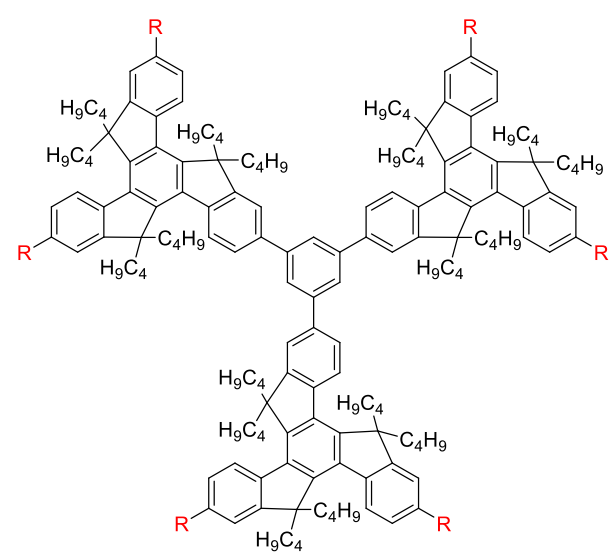

176<smiles></smiles><smiles>[R7]C([R7])=Cc1ccc(N(c2ccc(C=C([R7])[R7])cc2)c2ccc(C=C([R7])[R7])cc2)cc1</smiles>

178

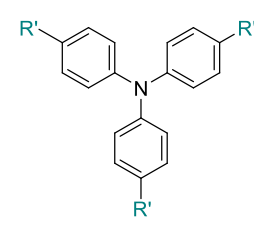

179<smiles>[R]=CC=Cc1ccc(C=Cc2ccc(-c3ccc(N(c4ccccc4)c4ccccc4)cc3C(C)(C)C)c(C)c2)cc1</smiles><smiles>[R]C#Cc1ccc(/C=C/c2ccc(-c3nnc(-c4ccc(C(C)(C)C)cc4)o3)cc2)cc1</smiles><smiles>[R]=Cc1ccc2c(c1)[C@](C)(CCCCC)c1cc(N(c3ccccc3)c3ccccc3)ccc1-2</smiles> 
Figure 58. Branched chromophores used for three-photon absorption based OPL.

Table 2. Relevant data for 3PA dyes used for OPL. Typical OPL experiment were conducted using $1 \mathrm{~cm}$ cuvettes, $\mathrm{f}=10 \mathrm{~cm}$ focusing, $1 \mathrm{kHz}$ repetition rate, $160 \mathrm{fs}$ pulses, except for compound $\mathbf{1 7 8}$ (150 fs) and $\mathbf{1 7 9}(80 \mathrm{fs})$.

\begin{tabular}{cccccc}
\hline Dye & $\begin{array}{c}\lambda_{\mathrm{OPL}} \\
(\mathrm{nm})\end{array}$ & $\begin{array}{c}\sigma_{3 \mathrm{PA}} \mathrm{(b)}^{6} \\
{\left[\mathrm{~cm}^{6} \mathrm{GW}^{-2}\right]}\end{array}$ & $\begin{array}{c}\text { Concentration } \\
{[\mathrm{M}]}\end{array}$ & $\begin{array}{c}\alpha_{3}{ }^{(\mathrm{b})} \\
{\left[\mathrm{cm}^{3} \mathrm{GW}^{-2}\right]}\end{array}$ & Ref. \\
\hline 171 & 1260 & $3.75 \times 10^{-25}$ & $0.04 \mathrm{M}$ & $9.0 \times 10^{-6}$ & 345 \\
172 & 1260 & $3.00 \times 10^{-25}$ & $0.04 \mathrm{M}$ & $7.2 \times 10^{-6}$ & 345 \\
173 & 1300 & $2.66 \times 10^{-26}(\mathrm{a})$ & $1 \mathrm{M}$ & $1.6 \times 10^{-5}$ & 346 \\
174 & 1310 & $2.08 \times 10^{-25}(\mathrm{a})$ & 0.02 & $2.5 \times 10^{-6}$ & 347 \\
175 & 1310 & $9.31 \times 10^{-25}(\mathrm{a})$ & 0.0066 & $3.7 \times 10^{-6}$ & 347 \\
176 & 1310 & $18.0 \times 10^{-25}$ & 0.0033 & $4.3 \times 10^{-6}$ & 347 \\
177 & 1300 & $3.20 \times 10^{-25}$ & 0.02 & $3.85 \times 10^{-6}$ & 348 \\
178 & 1300 & $22.1 \times 10^{-24}$ & $0.04 \mathrm{M}$ & $6.6 \times 10^{-5}$ & 350 \\
179 & 1250 & $2.16 \times 10^{23}$ & $0.01 \mathrm{M}$ & $1.3 \times 10^{-4}$ & 349 \\
\hline
\end{tabular}

a Calculated from available data according to the formula $\sigma_{3 P A}=\frac{\alpha_{3}}{N_{a} C * 10^{-3}}$

b Obtained using nonlinear transmission curve fitting.

As demonstrated above, it is possible to turn a 2PA based OPL in the NIR into a 3PA based OPL in the SWIR, taking advantage of the great number of $2 \mathrm{P}$-absorbers described for NIR applications. However, these devices can only be efficient by using femtosecond lasers, producing the sufficient amount of instantaneous light intensity to trigger the 3PA process. Nowadays, lasers used for LIDAR systems and active imaging are based on nanosecond lasers whose pulse widths are too long to trigger such 3PA process, hence prohibiting the use of such 3PAbased OPL devices. It is therefore necessary to switch to 2PAbased OPL systems using $2 \mathrm{P}$-absorbers in the SWIR, as described in the Section 3.

\section{Two-photon based OPL in the SWIR range}

The first example of 2PA based optical limiting system working in the SWIR band was reported by Prasad and coworkers in 2007 not from organic dyes, but using CdTe quantum dots. ${ }^{351}$ An $80 \%$ attenuation was measured for an incident intensity of $10 \mu \mathrm{J}$ at $1300 \mathrm{~nm}$. However, the measured 2PA coefficient was quite low with a reported value of $\alpha_{2}=0.02$ $\mathrm{cm} \mathrm{GW}^{-1}$. Concerning organic dyes, the same group reported in 2009 the OPL characteristics of the bodipy derivative 111
(Figure 38) at $1310 \mathrm{~nm}$ and used it to reduce laser pulses fluctuations (Figure 60). ${ }^{264}$ This compound is of first importance because of the possible introduction of various functions at the meso position for further elaboration of a device. Nevertheless, no optimization of the 2PA properties was carried out for this dye family and $\mathbf{1 1 1}$ presents a 2PA coefficient of only $0.06 \mathrm{~cm} \mathrm{GW}^{-1}$. It is worth mentioning that for these two examples all OPL measurements were reported only with femtosecond laser pulses and not nanosecond pulses, as used in real applications.

All the examples reported in the literature that will be described hereafter were developed for nanosecond laser pulses. With such pulse duration, multiphoton absorption is hardly never the only photophysical phenomenon contributing to the transmission loss observed in OPL experiments. To fully describe and explain the OPL performances, all photophysical processes must be decorrelated to provide some insight into the importance of each parameters and guide further dye development.

As already observed in the visible spectral range, ${ }^{344}$ the most common mechanism explaining OPL behaviour for nanoseconds pulses in the SWIR range is a stepwise three-photon absorption process: 2PA followed by a 2PA induced excited-state absorption (ESA). In fact, in the case of a nanosecond pulsed laser, reabsorption from an excited state, is temporally possible and this additional absorption process generally enhances the whole optical limiting effect. $35,352,353$ A common model to represent the 2PA induced ESA mechanism is depicted Figure 61 where ESA occurs from the lowest excited singlet state $\left(S_{1}\right)$ towards higher singlet state $\left(S_{n}\right)$, or after intersystem crossing (ISC) and internal conversion (IC) from the lowest excited triplet state $\left(T_{1}\right)$ towards higher triplet excited state $\left(T_{n}\right)$. It is however possible to observe some ESA from a singlet excited state of higher energy before relaxation to $S_{1} .{ }^{319}$ It is important to note that both processes occur during the same laser pulse (ns), and consequently at the same wavelength, thus the best OPL systems will be obviously obtained with the joint optimization of the efficiency and spectral overlapping of the two processes, ${ }^{354}$ which is extremely challenging.
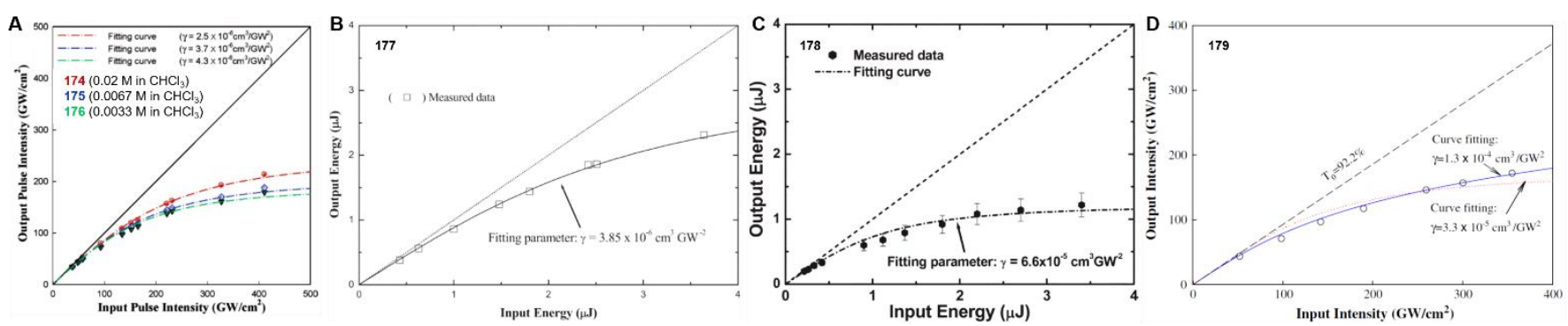

Figure 59. OPL performances for compounds 174-176 ( $\mathrm{A}, 0.02-0.03 \mathrm{M}$ in $\mathrm{CHCl}_{3}, 1310 \mathrm{~nm}, 160 \mathrm{fs}$ pulses, $1 \mathrm{KHz}$ ), 177 ( $\mathrm{B}$, in $0.02 \mathrm{M}$ in CHCl $3,1300 \mathrm{~nm}, 160 \mathrm{fs}$ pulses, $1 \mathrm{KHz}$ ), 178 (C, 0.04 $\mathrm{M}$ in $\mathrm{CHCl}_{3}, 1300 \mathrm{~nm}, 150 \mathrm{fs}$ pulses, $1 \mathrm{KHz}$ ) and 179 (D, $0.01 \mathrm{M}$ in $\mathrm{CH}_{2} \mathrm{Cl}_{2}, 1250 \mathrm{~nm}, 80 \mathrm{fs}$ pulses, $1 \mathrm{KHz}$ ). A: Adapted with permission from reference ${ }^{347}$. Copyright 2006 American Chemical Society. B: Reproduced from reference ${ }^{348}$ with permission from The Royal Society of Chemistry. C: Reproduced from reference ${ }^{350}$ with permission from The Royal Society of Chemistry. D: Adapted from reference ${ }^{349}$. Copyright 2008 Elsevier Science B.V. All rights reserved. 


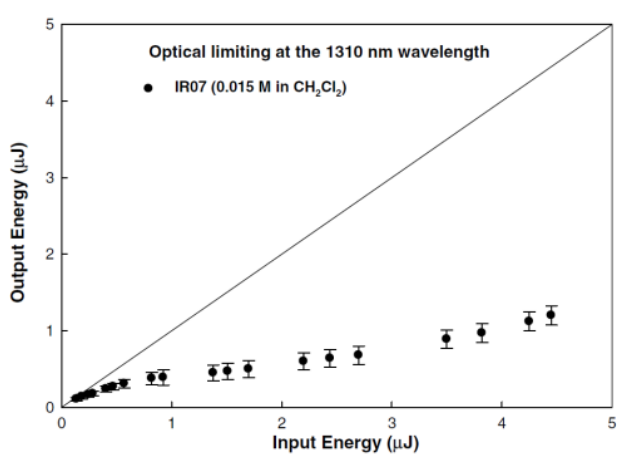

(a) Input 1310-nm laser pulses

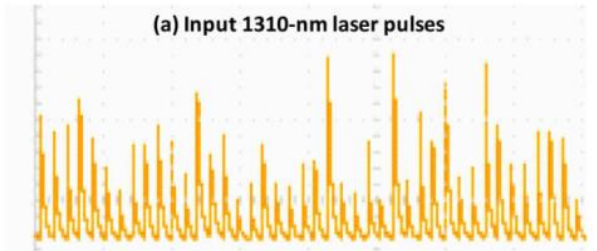

(b) Output 1310-nm laser pulses

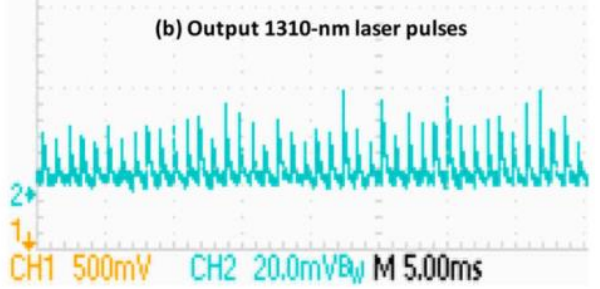

Figure 60. Left: Optical power limiting experiment at $\lambda=1310 \mathrm{~nm}$ using bodipy 111 in $\mathrm{CH}_{2} \mathrm{Cl}_{2}$ solution $(0.015 \mathrm{M}, 160 \mathrm{fs}$ pulses, centre). Right: Laser pulses stabilization experiments ( $\lambda_{\mathrm{ex}}=1310 \mathrm{~nm}, 3 \mu \mathrm{J}, 1 \mathrm{kHz}$ ) using dye $111\left(0.015 \mathrm{M}\right.$ in $\left.\mathrm{CH}_{2} \mathrm{Cl}_{2}\right)$. Adapted from reference ${ }^{264}$. Copyright 2009 Elsevier Science B.V. All rights reserved.

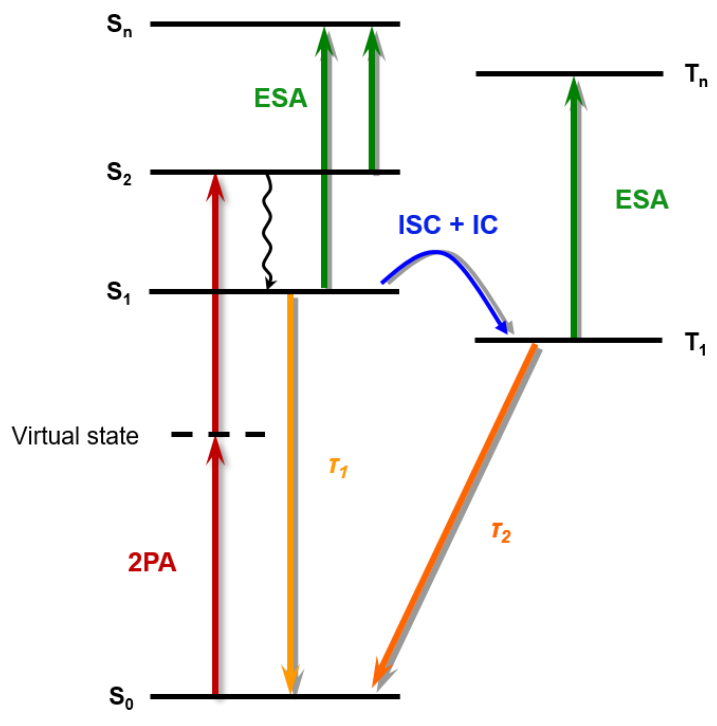

Figure 61. 2PA-induced excited state absorption (ESA).

The combination of $2 \mathrm{PA}$ and ESA processes in the SWIR range and more specifically at $1550 \mathrm{~nm}$ was nicely highlighted by Perry and co-workers with a lead (II) porphyrin polymer 145 (Figure 46). ${ }^{319}$ This material presents a very effective OPL behaviour in solution with a $40 \%$ transmission for an incident energy of $50 \mu \mathrm{J}$ at $1550 \mathrm{~nm}$ (Figure 62). The detailed transient
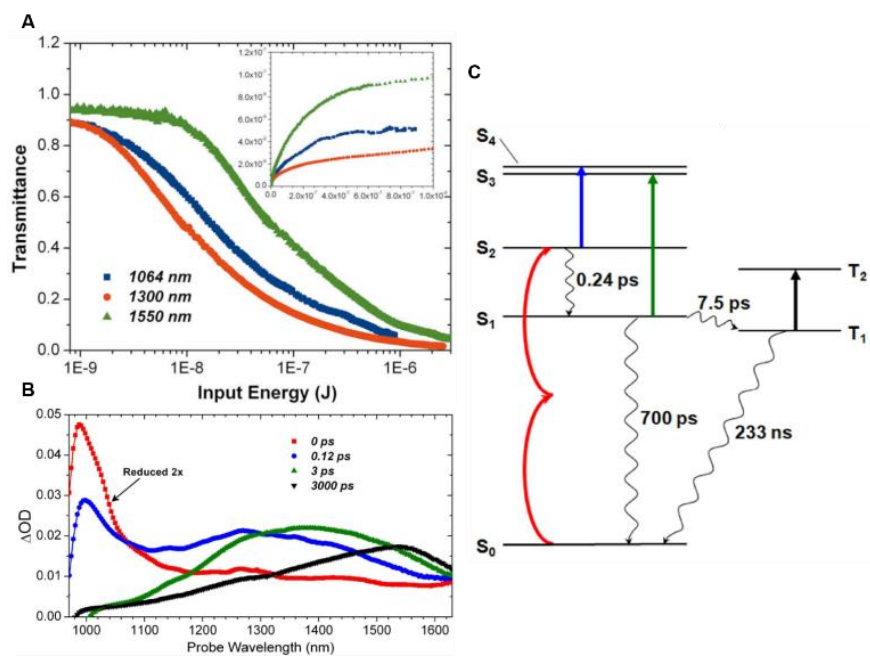

Figure 62. OPL ( $\mathrm{A}, 0.003-0.01 \mathrm{M}$ in $\mathrm{CHCl}_{3} / 10 \%$ pyridine, 75 fs pulses, $50 \mathrm{~Hz}$ ), ESA (B), and photophysical processes (C) associated with lead porphyrin polymer 145. Adapted with permission from reference ${ }^{319}$ (c) The Optical Society.

absorption experiment carried out between 1000-1600 nm allows identifying the different excited states involved in the ESA process and clearly shows the importance of 2PA and ESA spectral overlapping for reaching high OPL efficiency.

In this context, our group studied polymethines dyes for their OPL properties using nanosecond pulses. In 2007, heptamethines 83,84 and 86 (Figure 29), ${ }^{241}$ together with closely related compounds, allowed to measure the OPL properties at $\sim 1500 \mathrm{~nm}$ (Figure 63 ) thanks to the exceptionally high solubility of the dyes (high concentration in DCM was reached up to $320 \mathrm{~g} \mathrm{~L}^{-1}$ ). A $50 \%$ transmission was obtained within a 7-10 $\mathrm{J} \mathrm{cm}^{-2}$ fluence range depending on the dye used. Once again, the importance of ESA was highlighted by the difference between the simulated pure 2PA OPL and the experimental data (respectively blue and green lines, Figure 63).

Later on, an analogue heptamethine structure was decorated with 2,2-bis(methylol)propionic acid dendrons, which help reducing possible aggregation and interaction between chromophores without deterioration of the OPL properties. ${ }^{355}$ The efficiency of 2PA induced ESA for OPL was

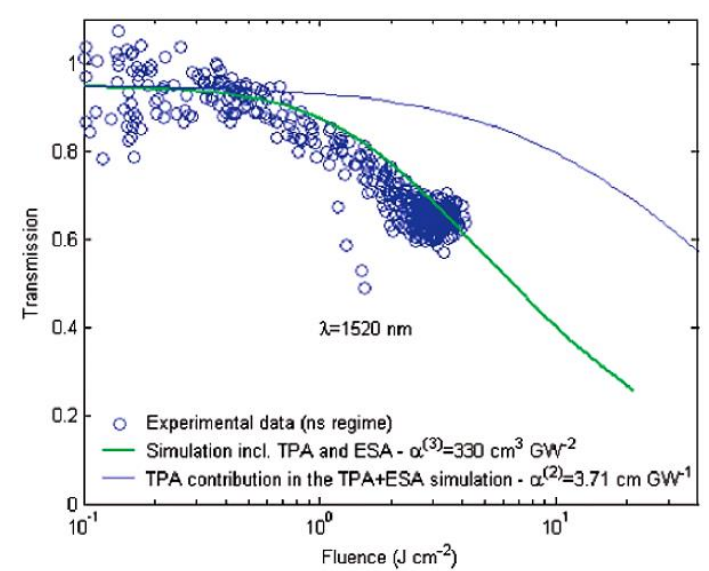

Figure 63. OPL experiment using dye $84\left(92.3 \mathrm{~g} \mathrm{~L}^{-1}\right.$ in $\mathrm{CH}_{2} \mathrm{Cl}_{2}, \lambda_{\text {ex }}=1520 \mathrm{~nm}, 7 \mathrm{~ns}$ pulses, $10 \mathrm{~Hz}$ ). Reprinted with permission from reference ${ }^{241}$. Copyright 2007 American Chemical Society. 
also further studied on cationic $\mathbf{8 3}$, anionic $\mathbf{8 5}$ (Figure 29) and organometallic polymethine $\mathbf{1 7 0}$ (Figure 54). ${ }^{356}$ The latter compound, despite having significantly smaller 2PA cross section, exhibits the best OPL efficiency thanks to higher ESA at the wavelength of interest, $1500 \mathrm{~nm}$ (Figure 64). Nevertheless, such OPL results appear to be less satisfactory than the previously studied cyanine with a maximum attenuation of around $30 \%$ at the maximum input fluence of $2 \mathrm{~J} \mathrm{~cm}^{-2}$.

Aza-bodipy dyes were also studied by our group in the $1300-$ $1600 \mathrm{~nm}$ spectral range. ${ }^{265}$ For example, dye 113 (Figure 38) produced a laser beam attenuation up to $60 \%$ at $1350 \mathrm{~nm}$ for a fluence of $7 \mathrm{~J} \mathrm{~cm}^{-2}$ (Figure 65). This chromophore presents OPL characteristics similar to that of the best cyanines and this result opened the way to fine chemical engineering of this family to optimize their NLO properties, since aza-bodipys have the great advantage to present several positions for possible substitutions to optimise their photophysical properties.

In a recent study, we reported the OPL, 2PA and ESA properties over the $1300-1600 \mathrm{~nm}$ region of a series of aza-bodipys functionalized with strong electron-donating substituents. ${ }^{271}$ In concentrated solution and under $1400 \mathrm{~nm}$ ns-laser irradiation, the compounds 113, 115, 180 and 181 are efficient optical limiters, with a $50 \%$ transmission obtained with compound $\mathbf{1 8 1}$ at an input fluence of only $2 \mathrm{~J} \mathrm{~cm}^{-2}$, while showing a good linear transmission ( $>90 \%$ ) at low fluences $\left(<0.2 \mathrm{~J} \mathrm{~cm}^{-2}\right.$, Figure 66$)$. In addition, the tetra-functionalized aza-bodipy 181 presents broadband OPL over the whole $1200-1600 \mathrm{~nm}$ range.
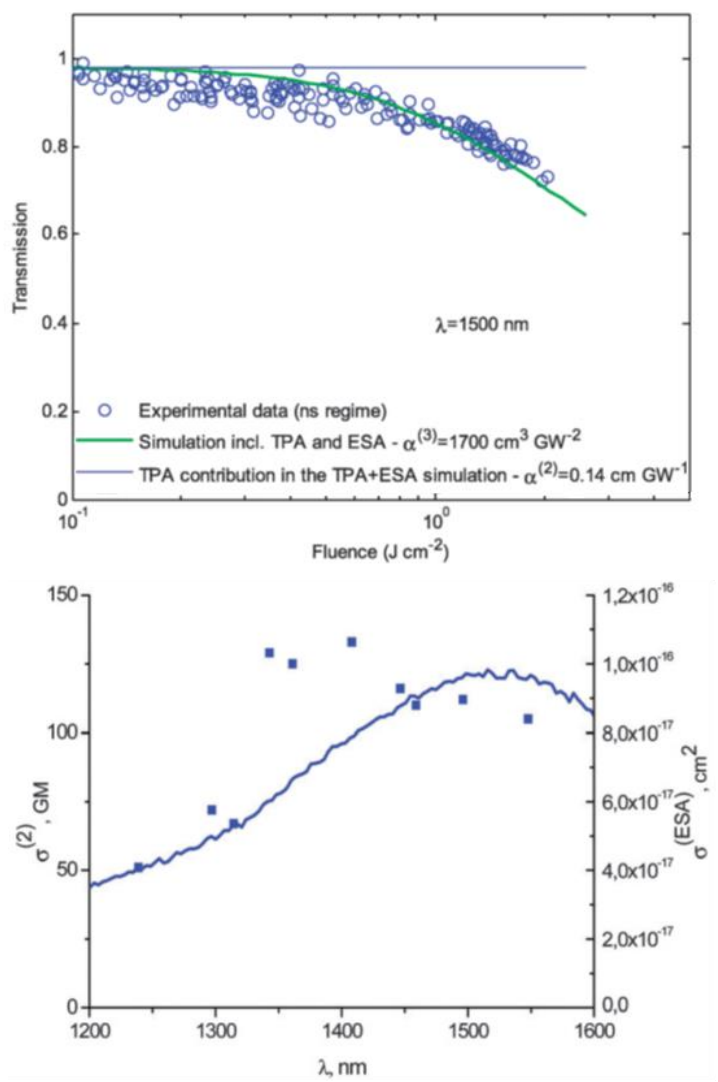

Figure 64. Top: OPL performances of compound 170 ( $0.1 \mathrm{M}$ in $\mathrm{CH}_{2} \mathrm{Cl}_{2}, \lambda_{\mathrm{ex}}=1500 \mathrm{~nm}, 7 \mathrm{~ns}$ pulses, $10 \mathrm{~Hz}$ ). Bottom: comparison between 2PA (squares) and ESA (line) in the NIR range. Reproduced from reference ${ }^{356}$ with permission from the PCCP Owner Societies.

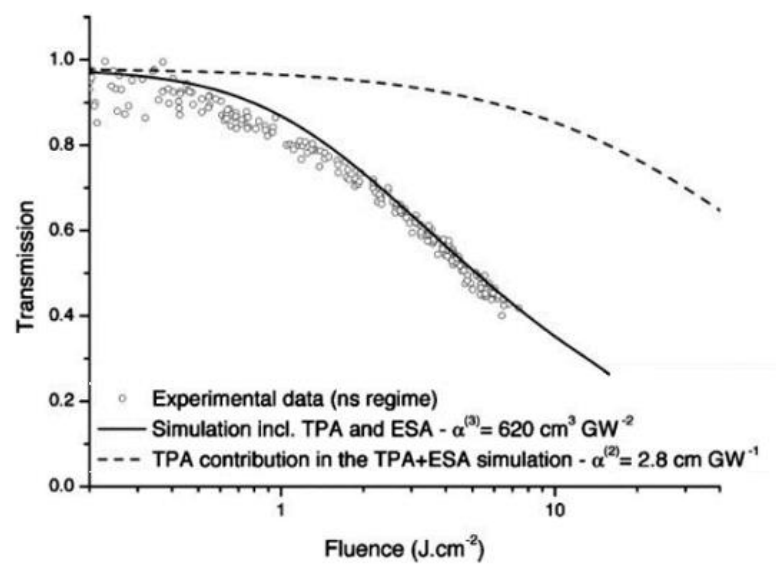

Figure 65. OPL performances of dye $113\left(106 \mathrm{~g} \mathrm{~L}^{-1}\right.$ in $\mathrm{CH}_{2} \mathrm{Cl}_{2}, \lambda_{\text {ex }}=1350 \mathrm{~nm}, 7$ ns pulses, $10 \mathrm{~Hz}$ ). Reprinted from reference ${ }^{265}$. Copyright 2009 WILEY-VCH Verlag GmbH \& Co. KGaA, Weinheim.

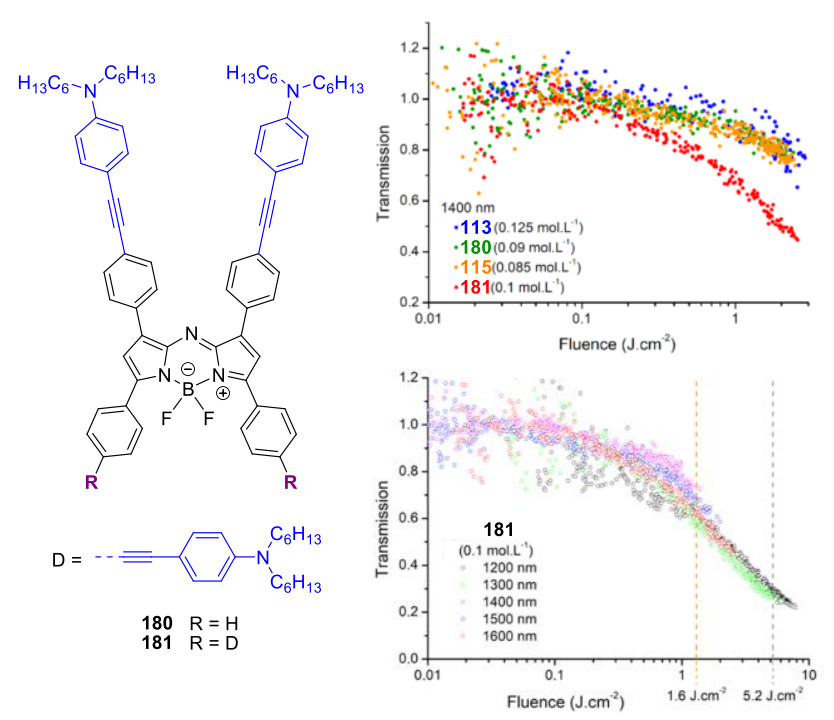

Figure 66. OPL behaviour of selected aza-bodipys under $1400 \mathrm{~nm}$ irradiation (ca. $0.1 \mathrm{M}$ in $\mathrm{CH}_{2} \mathrm{Cl}_{2}, 7$ ns pulses, $10 \mathrm{~Hz}$ ) and wavelength-dependent $\mathrm{OPL}$ of 181 in $\mathrm{CH}_{2} \mathrm{Cl}_{2}$. Adapted with permission from reference ${ }^{271}$. Copyright 2019 American Chemical Society.

Excellent maximum attenuations, ca. $60 \%$ and $80 \%$ were recorded, for fluences of 1.6 and $5.2 \mathrm{~J} \mathrm{~cm}^{-2}$, respectively. These results were also rationalized by the adequate spectral overlapping between 2PA and ESA for compound 181 revealed by ultrafast transient absorption experiments.

The remarkable chemical stability of the aza-bodipy family enabled to design the first solid-state material for OPL in the SWIR by introduction of these dyes as dopant in sol-gel monolithic matrixes in 2014, using dye 113. Unfortunately, the doping ratio was limited to $8 \mathrm{wt} . \%$ due to the modest compatibility of the dye with the matrix. ${ }^{357}$ Solid state OPL performances using aza-bodipys were further improved with class-II sol-gel materials where the covalent grafting of dye $\mathbf{1 8 2}$ permitted to greatly increase the maximum dye concentration in the matrix up to $40 \mathrm{wt} . \%$, resulting in strong enhancement of the OPL performances, with a $50 \%$ transmission reached for an input fluence of $5 \mathrm{~J} \mathrm{~cm}^{-2}$ (Figure 67). ${ }^{358}$ 


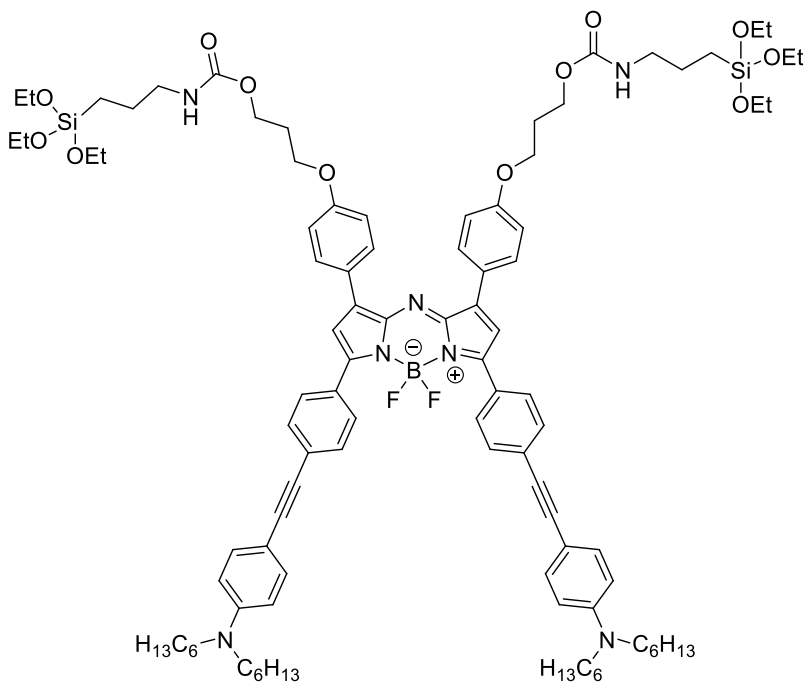

182

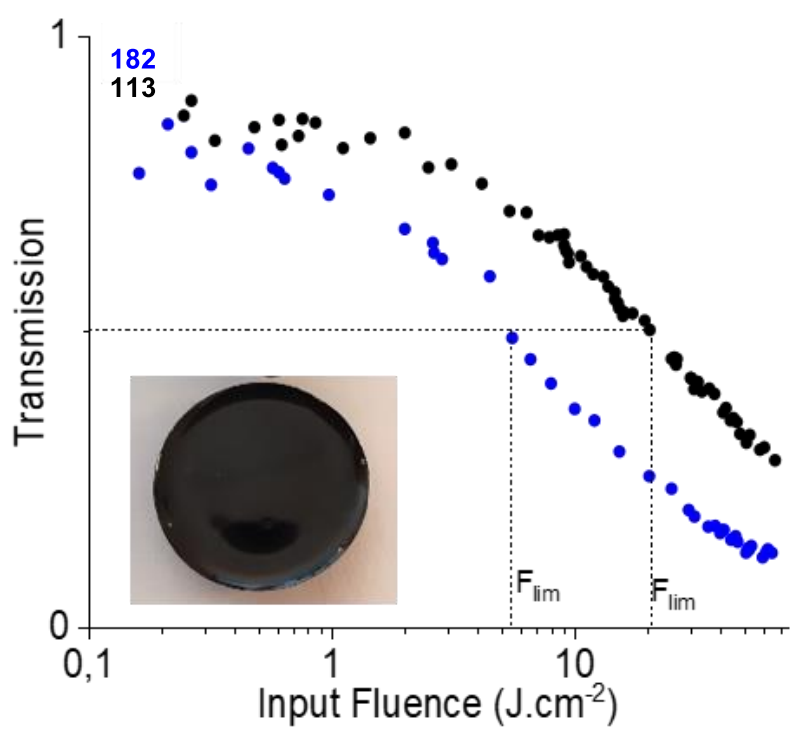

Figure 67 Top: structure of functionalized aza-bodipy 182. Bottom: optical limiting performances for sol-gel materials at $1550 \mathrm{~nm}$ with dye $\mathbf{1 8 2}$ (blue dots, grafted at a 40 wt.\% ratio) and dye $\mathbf{1 1 3}$ (black dots, doped at a 5 wt.\% ratio) under the same irradiation conditions ( $5 \mathrm{~ns}$ pulses). $50 \%$ transmission thresholds are indicated by dotted lines. The picture represents a typical class II xerogel obtained by grafting of dye $\mathbf{1 8 2}$ in a sol-gel matrix. Adapted with permission from reference ${ }^{358}$. Copyright 2020 American Chemical Society.

\section{Concluding remarks}

Sixty years after the discovery of the laser and the experimental proof of 2PA, chemists and physicists have been working together to design, engineer and produce a tremendous amount of two-photon absorbing dyes whose absorption is continuously drifting toward the red, NIR and SWIR spectral ranges. The introduction of "eye-safe" laser sources contributed to a regain of interests for 2PA dyes absorbing in the SWIR and renewed the challenge for synthetic chemists. In this review, a huge diversity of dyes has been described with 2PA cross-sections spanning from a few tens to tens of thousand GM in this particular spectral range. Yet optimization is still to be done to find chromophores that not only present high 2PA cross sections, but also fulfil the entire set of requirements for practical photonic application in the SWIR.

As usually observed, extension of spectral range of lasers generally triggered simultaneously the development of new materials to protect related detectors or human eyes. That is the reason why OPL in the SWIR was the first application developed during this last decade. These researches were initially stimulated by applications in defence aeronautics, where LIDAR telemetry in the SWIR was developed, but find nowadays a new perspective for civil application in guiding systems of autonomous vehicles. The challenges for scientists to prepare efficient 2PA-based OPL devices are multiple: (i) from a synthetic point of view, it requires to build highly concentrated, perfectly homogenous material featuring all photochemical and mechanical stability to be polished and incorporated in an optical set-up submitted to high intensity laser irradiations; (ii) from a fundamental point of view, it has been demonstrated that 2PA induced ESA is an extremely straightforward process to optimize the OPL efficiency of the material. However, whereas chemists are capable today of designing dyes with high 2PA cross-sections following the engineering rules described in the literature, it is still challenging to control the efficiency and the spectral position of ESA. Dye engineering rules for ESA are still to be found, from the visible to the SWIR, and advances in this field could lead to a breakthrough in the future for OPL in the SWIR.

In a long-term perspective, the SWIR range presents exceptional potentialities in terms of transparency (and scattering) of the atmosphere, silica or biological media that will offer numerous opportunities for other type of applications in material science and biology. As an example, the design of luminescent molecular probes for deep imaging in the second transparency window (NIR-II region) for biphotonic microscopy imaging in the SWIR ${ }^{244}$ is an emerging field of research that will require to optimize the two-photon brightness, which is the product of the two-photon cross-section in the SWIR by the emission quantum yield in the NIR. Another example concerns the development of 2PA-based photochemistry in this spectral range, as illustrated by recent photopolymerization at telecommunications wavelength, 359,360 but many other application can be envisaged. All these perspectives will encourage chemists to design new molecules combining 2PA in the SWIR with other properties (emission, ESA, electron transfer...) and further take into account all the constraints for the targeted application (solubility in biological medium or organic solvents, stability, functionalisation for bio-conjugation or grafting...).

Finally, if this last decade started the exploration of 2PA in the SWIR, one can clearly anticipate for the next decade a rapid development of advanced molecules for innovative and surprising applications in this spectral domain where a lot remains to be discovered. 


\section{Abbreviations}

$\begin{array}{ll}\text { 1PA } & \text { one-photon absorption } \\ \text { 2PA } & \text { two-photon absorption } \\ \text { 3PA } & \text { three-photon absorption } \\ \text { BLA } & \text { bond length alternation } \\ \text { DMF } & \text { N,N-dimethylformamide } \\ \text { DMSO } & \text { dimethylsulfoxide } \\ \text { ECL } & \text { effective conjugation length } \\ \text { ESA } & \text { excited state absorption } \\ \text { fS } & \text { femtosecond } \\ \text { GM } & \text { Göppert-Mayer } \\ \text { HLG } & \text { HOMO-LUMO gap } \\ \text { HOMO } & \text { highest occupied molecular orbital } \\ \text { IC } & \text { internal conversion } \\ \text { ICT } & \text { intramolecular charge transfer } \\ \text { ISC } & \text { intersystem crossing } \\ \text { LIDAR } & \text { light detection and ranging } \\ \text { LUMO } & \text { lowest occupied molecular orbital } \\ \text { ND } & \text { non-degenerate } \\ \text { NIR } & \text { near infrared } \\ \text { NLO } & \text { nonlinear optics } \\ \text { NLT } & \text { nonlinear transmission } \\ \text { nS } & \text { nanosecond } \\ \text { OPL } & \text { optical power limiting } \\ \text { OPO } & \text { optical parametric oscillator } \\ \text { SWIR } & \text { short-wavelength infrared } \\ \text { TFA } & \text { trifluoroacetic acid } \\ \text { THF } & \text { tetrahydrofuran } \\ \text { TPEF } & \text { two-photon excited fluorescence } \\ \text { WLC } & \text { white-light continuum } \\ \varepsilon & \text { molar extinction coefficient } \\ \lambda & \text { wavelength } \\ \sigma & \text { cross-section } \\ & \end{array}$

\section{Acknowledgements}

We thank the Centre National de la Recherche Scientifique, the ministère de l'Enseignement supérieur, de la Recherche et de l'Innovation and the Ecole Normale Supérieure de Lyon. We are indebted to the many authors cited in this review for their contribution to the development of new molecules, materials and techniques in the contexts of dyes chemistry, nonlinear optics and optical power limiting. Our group is also very grateful to the French Direction Recherche de l'Armement (DGA) and Thales company, in particular Drs. G. Berginc and P. Feynerou for their continuous support over the last decade. We are also highly indebted to our physicists and computational chemists collaborators Dr. K. Kamada, Pr. J. W. Perry, Dr. C. Lopes, Drs. D. Hagan and E. Van Stryland, and Dr. B. Le Guennic and Pr. D. Jacquemin for their essential contribution to this long term research project. We would like to acknowledge also Dr. D. Chateau and Pr. S. Parola for their expertise and discussions. Finally, CA and OM would like to warmly thank the famous "blue team" composed of four PhDs over these last 15 years whose names are indicated in the publications for their exceptional involvement in dyes synthesis and spectroscopy.

\section{References}

1. T. H. Maiman, Nature, 1960, 187, 493.

2. M. Göppert-Mayer, Annalen der Physik, 1931, 9, 273.

3. W. Kaiser and C. G. B. Garrett, Phys. Rev. Lett., 1961, 7, 229.

4. W. L. Peticolas, J. P. Goldsborough and K. E. Rieckhoff, Phys. Rev. Lett., 1963, 10, 43.

5. S. J. Lalama and A. F. Garito, Phys. Rev. A, 1979, 20, 1179.

6. J. Zyss, J. F. Nicoud and M. Coquillay, J. Chem. Phys., 1984, 81, 4160.

7. D. Burland, Chem. Rev., 1994, 94, 1.

8. T. J. Marks and M. A. Ratner, Angew. Chem. Int. Ed., 1995, 34, 155.

9. G. S. He, L.-S. Tan, Q. Zheng and P. N. Prasad, Chem. Rev., 2008, 108, 1245.

10. K. D. Belfield, S. Yao and M. V. Bondar, Adv. Polym. Sci., 2008, 213, 97.

11. H. Myung Kim and B. Rae Cho, Chem. Commun., 2009, 153.

12. M. Pawlicki, H. A. Collins, R. G. Denning and H. L. Anderson, Angew. Chem. Int. Ed., 2009, 48, 3244.

13. C. Andraud and O. Maury, Eur. J. Inorg. Chem., 2009, 2009, 4343.

14. S. Yao and K. D. Belfield, Eur. J. Org. Chem., 2012, 2012, 3199.

15. W. Denk, J. Strickler and W. Webb, Science, 1990, 248, 73.

16. Y. Imanishi, K. H. Lodowski and Y. Koutalos, Biochemistry, 2007, 46, 9674.

17. D. Kim, H. G. Ryu and K. H. Ahn, Org. Biomol. Chem., 2014, 12, 4550.

18. H. M. Kim and B. R. Cho, Chem. Asian. J., 2011, 6, 58.

19. A. R. Sarkar, D. E. Kang, H. M. Kim and B. R. Cho, Inorg. Chem., 2014, 53, 1794.

$20 . \quad$ L. Hong-Wen, L. Yongchao, W. Peng and Z. Xiao-Bing, Methods Appl. Fluoresc., 2017, 5, 012003.

21. S. Maruo, O. Nakamura and S. Kawata, Opt. Lett., 1997, 22, 132.

22. B. H. Cumpston, S. P. Ananthavel, S. Barlow, D. L. Dyer, J. E. Ehrlich, L. L. Erskine, A. A. Heikal, S. M. Kuebler, I. Y. S. Lee, D. McCord-Maughon, J. Qin, H. Rockel, M. Rumi, X.-L. Wu, S. R. Marder and J. W. Perry, Nature, 1999, 398, 51.

23. K. D. Belfield, K. J. Schafer, Y. Liu, J. Liu, X. Ren and E. W. V. Stryland, J. Phys. Org. Chem., 2000, 13, 837.

24. S. Kawata, H.-B. Sun, T. Tanaka and K. Takada, Nature, 2001, 412, 697.

25. K.-S. Lee, R. H. Kim, D.-Y. Yang and S. H. Park, Prog. Polym. Sci., 2008, 33, 631.

26. D. Parthenopoulos and P. M. Rentzepis, Science, 1989, 245, 843.

27. J. H. Strickler and W. W. Webb, Opt. Lett., 1991, 16, 1780.

28. A. S. Dvornikov, E. P. Walker and P. M. Rentzepis, J. Phys. Chem. A, 2009, 113, 13633.

29. K. Ogawa and Y. Kobuke, Org. Biomol. Chem., 2009, 7, 2241.

30. J. P. Celli, B. Q. Spring, I. Rizvi, C. L. Evans, K. S. Samkoe, S. Verma, B. W. Pogue and T. Hasan, Chem. Rev., 2010, 110, 2795.

31. Y. Shen, A. J. Shuhendler, D. Ye, J.-J. Xu and H.-Y. Chen, Chem. Soc. Rev., 2016, 45, 6725.

32. Y. Haketa, K. Kamada and H. Maeda, ChemPlusChem, 2020, 85, 1719.

33. G. S. He, G. C. Xu, P. N. Prasad, B. A. Reinhardt, J. C. Bhatt, R. McKellar and A. G. Dillard, Opt. Lett., 1995, 20, 435. 

Phys. Lett., 1995, 67, 2433.

35. C. W. Spangler, J. Mater. Chem., 1999, 9, 2013.

36. R. L. Sutherland, Handbook of Nonlinear Optics, Taylor \& Francis Inc, 2003.

37. R. W. Boyd, Nonlinear Optics, Third Edition edn., 2008.

38. T. Kogej, D. Beljonne, F. Meyers, J. W. Perry, S. R. Marder and J. L. Brédas, Chem. Phys. Lett., 1998, 298, 1.

39. B. J. Orr and J. F. Ward, Mol. Phys., 1971, 20, 513.

40. F. Meyers, S. R. Marder, B. M. Pierce and J. L. Bredas, J. Am. Chem. Soc., 1994, 116, 10703.

41. J. E. Ehrlich, X. L. Wu, I. Y. S. Lee, Z. Y. Hu, H. Röckel, S. R. Marder and J. W. Perry, Opt. Lett., 1997, 22, 1843.

42. H. Lei, H. Z. Wang, Z. C. Wei, X. J. Tang, L. Z. Wu, C. H. Tung and G. Y. Zhou, Chem. Phys. Lett., 2001, 333, 387.

43. J. Swiatkiewicz, P. N. Prasad and B. A. Reinhardt, Opt. Commun., 1998, 157, 135.

44. K. Kamada, K. Matsunaga, A. Yoshino and K. Ohta, J. Opt. Soc. Am. B, 2003, 20, 529.

45. C. Xu and W. W. Webb, J. Opt. Soc. Am. B, 1996, 13, 481.

46. N. S. Makarov, M. Drobizhev and A. Rebane, Opt. Express, 2008, 16, 4029.

47.

A. Bourdolle, M. Allali, A. D'Aléo, P. L. Baldeck, K. Kamada, J. A. G. Williams, H. Le Bozec, C. Andraud and O. Maury, ChemPhysChem, 2013, 14, 3361.

48.

K. D. Belfield, D. J. Hagan, E. W. Van Stryland, K. J. Schafer and R. A. Negres, Org. Lett., 1999, 1, 1575.

M. Albota, D. Beljonne, J.-L. Brédas, J. E. Ehrlich, J.-Y. Fu, A. A. Heikal, S. E. Hess, T. Kogej, M. D. Levin, S. R. Marder, D. McCord-Maughon, J. W. Perry, H. Röckel, M. Rumi, G. Subramaniam, W. W. Webb, X.-L. Wu and C. Xu, Science, 1998, 281, 1653.

50. M. Wielgus, W. Bartkowiak and M. Samoc, Chem. Phys. Lett., 2012, 554, 113.

E. Genin, V. Hugues, G. Clermont, C. Herbivo, M. C. R. Castro, A. Comel, M. M. M. Raposo and M. BlanchardDesce, Photochem. Photobiol. Sci., 2012, 11, 1756.

S.-J. Chung, S. Zheng, T. Odani, L. Beverina, J. Fu, L. A. Padilha, A. Biesso, J. M. Hales, X. Zhan, K. Schmidt, A. Ye, E. Zojer, S. Barlow, D. J. Hagan, E. W. Van Stryland, Y. Yi, Z. Shuai, G. A. Pagani, J.-L. Brédas, J. W. Perry and S. R. Marder, J. Am. Chem. Soc., 2006, 128, 14444.

53. S. J. K. Pond, M. Rumi, M. D. Levin, T. C. Parker, D. Beljonne, M. W. Day, J.-L. Brédas, S. R. Marder and J. W. Perry, J. Phys. Chem. A, 2002, 106, 11470.

54. J. Zyss and I. Ledoux, Chem. Rev., 1994, 94, 77.

55. O. Maury and H. Le Bozec, Acc. Chem. Res., 2005, 38, 691. 56. H. M. Kim and B. R. Cho, J. Mater. Chem., 2009, 19, 7402.

57. S.-J. Chung, K.-S. Kim, T.-C. Lin, G. S. He, J. Swiatkiewicz and P. N. Prasad, J. Phys. Chem. B., 1999, 103, 10741.

58. C. Katan, F. Terenziani, O. Mongin, M. H. V. Werts, L. Porrès, T. Pons, J. Mertz, S. Tretiak and M. BlanchardDesce, J. Phys. Chem. A, 2005, 109, 3024.

59. W. J. Yang, C. H. Kim, M.-Y. Jeong, S. K. Lee, M. J. Piao, S.-J. Jeon and B. R. Cho, Chem. Mater., 2004, 16, 2783.

60. D. Beljonne, W. Wenseleers, E. Zojer, Z. Shuai, H. Vogel, S. J. K. Pond, J. W. Perry, S. R. Marder and J. L. Brédas, Adv. Funct. Mater., 2002, 12, 631.

61. R. Fortrie, R. Anémian, O. Stephan, J.-C. Mulatier, P. L. Baldeck, C. Andraud and H. Chermette, J. Phys. Chem. C, 2007, 111, 2270.
C. Andraud, R. Fortrie, C. Barsu, O. Stéphan, H. Chermette and P. L. Baldeck, Adv. Polym. Sci., 2008, 214, 149.

M. Rumi, J. E. Ehrlich, A. A. Heikal, J. W. Perry, S. Barlow, Z. $\mathrm{Hu}$, D. McCord-Maughon, T. C. Parker, H. Röckel, S. Thayumanavan, S. R. Marder, D. Beljonne and J.-L. Brédas, J. Am. Chem. Soc., 2000, 122, 9500.

K. D. Belfield, A. R. Morales, J. M. Hales, D. J. Hagan, E. W. Van Stryland, V. M. Chapela and J. Percino, Chem. Mater., 2004, 16, 2267.

S. Lee, K. R. J. Thomas, S. Thayumanavan and C. J. Bardeen, J. Phys. Chem. A, 2005, 109, 9767.

O. Mongin, L. Porrès, M. Charlot, C. Katan and M. Blanchard-Desce, Chem. Eur. J., 2007, 13, 1481.

L. Ventelon, S. Charier, L. Moreaux, J. Mertz and M. Blanchard-Desce, Angew. Chem. Int. Ed., 2001, 40, 2098.

X. Zheng, W. Du, L. Gai, X. Xiao, Z. Li, L. Xu, Y. Tian, M. Kira and H. Lu, Chem. Commun., 2018, 54, 8834.

Y. Ren, X.-Q. Yu, D.-J. Zhang, D. Wang, M.-L. Zhang, G.-B. Xu, X. Zhao, Y.-P. Tian, Z.-S. Shao and M.-H. Jiang, J. Mater. Chem., 2002, 12, 3431.

C.-K. Wang, K. Zhao, Y. Su, Y. Ren, X. Zhao and Y. Luo, J. Chem. Phys., 2003, 119, 1208.

H. Y. Woo, B. Liu, B. Kohler, D. Korystov, A. Mikhailovsky and G. C. Bazan, J. Am. Chem. Soc., 2005, 127, 14721.

Z. A. Dreger, G. Yang, J. O. White, Y. Li and H. G. Drickamer, J. Phys. Chem. B, 1998, 102, 4380.

L. De Boni, E. Piovesan, L. Misoguti, S. C. Zílio and C. R. Mendonca, J. Phys. Chem. A, 2007, 111, 6222.

M. G. Vivas and C. R. Mendonca, J. Phys. Chem. A, 2012, 116, 7033.

J. Fabian, H. Nakazumi and M. Matsuoka, Chem. Rev., 1992, 92, 1197.

A. J. C. Kuehne and M. C. Gather, Chem. Rev., 2016, 116, 12823.

G. de la Torre, C. G. Claessens and T. Torres, Chem. Commun., 2007, 2000.

G. Qian and Z. Y. Wang, Chem. Asian J., 2010, 5, 1006.

W. Li, K. H. Hendriks, M. M. Wienk and R. A. J. Janssen, Acc. Chem. Res., 2016, 49, 78.

J. W. Jung, J. W. Jo, E. H. Jung and W. H. Jo, Org. Electron., 2016, 31, 149.

G. Zhang, J. Zhao, P. C. Y. Chow, K. Jiang, J. Zhang, Z. Zhu, J. Zhang, F. Huang and H. Yan, Chem. Rev., 2018, 118, 3447.

P. P. Ghoroghchian, P. R. Frail, K. Susumu, D. Blessington, A. K. Brannan, F. S. Bates, B. Chance, D. A. Hammer and M. J. Therien, Proc. Natl. Acad. Sci. U. S. A., 2005, 102, 2922.

K. Kiyose, H. Kojima and T. Nagano, Chem. Asian. J., 2008, 3, 506.

L. Yuan, W. Lin, K. Zheng, L. He and W. Huang, Chem. Soc. Rev., 2013, 42, 622.

K. Umezawa, D. Citterio and K. Suzuki, Anal. Sci., 2014, 30, 327.

G. Hong, A. L. Antaris and H. Dai, Nature Biomed. Eng., 2017, 1, 0010.

Y. Jiang and K. Pu, Adv. Biosys., 2018, 2, 1700262.

J. Roncali, Chem. Rev., 1997, 97, 173.

J. L. Bredas, R. Silbey, D. S. Boudreaux and R. R. Chance, J. Am. Chem. Soc., 1983, 105, 6555.

R. E. Martin and F. Diederich, Angew. Chem. Int. Ed., 1999, 38, 1350.

H. Meier, U. Stalmach and H. Kolshorn, Acta Polym., 1997, 48, 379. 
100.

101.
J. E. Anthony, Angew. Chem. Int. Ed., 2008, 47, 452. C. Li and H. Wonneberger, Adv. Mater., 2012, 24, 613. F. Würthner, C. R. Saha-Möller, B. Fimmel, S. Ogi, P. Leowanawat and D. Schmidt, Chem. Rev., 2016, 116, 962. T. Weil, T. Vosch, J. Hofkens, K. Peneva and K. Müllen, Angew. Chem. Int. Ed., 2010, 49, 9068.

S. S. Zade and M. Bendikov, Angew. Chem. Int. Ed., 2010, 49, 4012.

Y. Geerts, H. Quante, H. Platz, R. Mahrt, M. Hopmeier, A. Bohm and K. Mullen, J. Mater. Chem., 1998, 8, 2357.

N. G. Pschirer, C. Kohl, F. Nolde, J. Qu and K. Müllen, Angew. Chem. Int. Ed., 2006, 45, 1401.

Y. Avlasevich and K. Mullen, Chem. Commun., 2006, 4440. M. Müller, L. Ahrens, V. Brosius, J. Freudenberg and U. H. F. Bunz, J. Mater. Chem. C, 2019, 7, 14011.

M. Stępień, E. Gońka, M. Żyła and N. Sprutta, Chem. Rev., 2017, 117, 3479.

C. Reichardt, Chem. Rev., 1994, 94, 2319.

H. Meier, Angew. Chem. Int. Ed., 2005, 44, 2482.

M. Blanchard-Desce, V. Alain, P. V. Bedworth, S. R. Marder, A. Fort, C. Runser, M. Barzoukas, S. Lebus and R. Wortmann, Chem. Eur. J., 1997, 3, 1091.

G. Qian, Z. Zhong, M. Luo, D. Yu, Z. Zhang, Z. Y. Wang and D. Ma, Adv. Mater., 2009, 21, 111.

A. Mishra, R. K. Behera, P. K. Behera, B. K. Mishra and G. B. Behera, Chem. Rev., 2000, 100, 1973.

M. Panigrahi, S. Dash, S. Patel and B. K. Mishra, Tetrahedron, 2012, 68, 781.

J. L. Bricks, A. D. Kachkovskii, Y. L. Slominskii, A. O. Gerasov and S. V. Popov, Dyes Pigm., 2015, 121, 238.

L. G. S. Brooker, R. H. Sprague, C. P. Smyth and G. L. Lewis, J. Am. Chem. Soc., 1940, 62, 1116.

L. M. Tolbert and X. Zhao, J. Am. Chem. Soc., 1997, 119, 3253.

S. Barlow, L. M. Henling, M. W. Day and S. R. Marder, Chem. Commun., 1999, 1567.

R. S. Lepkowicz, O. V. Przhonska, J. M. Hales, J. Fu, D. J. Hagan, E. W. Van Stryland, M. V. Bondar, Y. L. Slominsky and A. D. Kachkovski, Chem. Phys., 2004, 305, 259.

W. Leng, F. Würthner and A. M. Kelley, J. Phys. Chem. A, 2005, 109, 1570.

F. Würthner, G. Archetti, R. Schmidt and H.-G. Kuball, Angew. Chem. Int. Ed., 2008, 47, 4529.

P.-A. Bouit, C. Aronica, L. Toupet, B. Le Guennic, C. Andraud and O. Maury, J. Am. Chem. Soc., 2010, 132, 4328.

S. Pascal, P.-A. Bouit, B. Le Guennic, S. Parola, O. Maury and C. Andraud, Proc. SPIE, 2013, 86220F, 1.

K. Funabiki, R. Yanagawa, Y. Kubota and T. Inuzuka, New J. Chem., 2019, 43, 7491.

M. Eskandari, J. C. Roldao, J. Cerezo, B. Milián-Medina and J. Gierschner, J. Am. Chem. Soc., 2020, 142, 2835.

S. Pascal, S.-H. Chi, J. W. Perry, C. Andraud and O. Maury, ChemPhysChem, 2020, 21, 2536.

S. Pascal, A. Haefele, C. Monnereau, A. Charaf-Eddin, D. Jacquemin, B. Le Guennic, C. Andraud and O. Maury, J. Phys. Chem. A, 2014, 118, 4038.

S. Pascal, A. Haefele, C. Monnereau, A. Charaf-Eddin, D. Jacquemin, B. Le Guennic, O. Maury and C. Andraud, Proc. SPIE, 2014, 9253A, 1.

L. Štacková, E. Muchová, M. Russo, P. Slavíček, P. Štacko and P. Klán, J. Org. Chem., 2020, 85, 9776.
123. B. Strehmel, C. Schmitz, C. Kütahya, Y. Pang, A. Drewitz and H. Mustroph, Beilstein J. Org. Chem., 2020, 16, 415.

124. K. Rurack and M. Spieles, Anal. Chem., 2011, 83, 1232.

125. I. Baraldi, F. Momicchioli, G. Ponterini, A. S. Tatikolov and D. Vanossi, J. Phys. Chem. A, 2001, 105, 4600.

126. P.-A. Bouit, E. Di Piazza, S. p. Rigaut, B. Le Guennic, C. Aronica, L. Toupet, C. Andraud and O. Maury, Org. Lett., 2008, 10, 4159.

127. S. Pascal, S. Denis-Quanquin, F. Appaix, A. Duperray, A. Grichine, B. Le Guennic, D. Jacquemin, J. Cuny, S.-H. Chi, J. W. Perry, B. van der Sanden, C. Monnereau, C. Andraud and O. Maury, Chem. Sci., 2017, 8, 381.

128. A. V. Kulinich and A. I. Aleksandr, Russ. Chem. Rev., 2009, 78, 141.

129. T.-D. Kim and K.-S. Lee, Macromol. Rapid Commun., 2015, 36, 943.

130. S. Pascal, Y. A. Getmanenko, Y. Zhang, I. Davydenko, M. H. Ngo, G. Pilet, S. Redon, Y. Bretonnière, O. Maury, I. LedouxRak, S. Barlow, S. R. Marder and C. Andraud, Chem. Mater., 2018, 30, 3410.

131. M. Collot, T. K. Fam, P. Ashokkumar, O. Faklaris, T. Galli, L. Danglot and A. S. Klymchenko, J. Am. Chem. Soc., 2018, 140, 5401.

132. N. A. Derevyanko, A. A. Ishchenko and A. V. Kulinich, Phys. Chem. Chem. Phys., 2020, 22, 2748.

133. K. Jyothish, R. R. Avirah and D. Ramaiah, Org. Lett., 2006, 8, 111.

134. L. Beverina and P. Salice, Eur. J. Org. Chem., 2010, 2010, 1207.

135. G. Xia and H. Wang, J. Photochem. Photobiol., C, 2017, 31, 84.

136. S. Khopkar and G. Shankarling, Dyes Pigm., 2019, 170, 107645.

137. K. llina, W. M. MacCuaig, M. Laramie, J. N. Jeouty, L. R. McNally and M. Henary, Bioconjugate Chem., 2020, 31, 194.

138. K. Takechi, P. V. Kamat, R. R. Avirah, K. Jyothish and D. Ramaiah, Chem. Mater., 2007, 20, 265.

139. D. E. Lynch and D. G. Hamilton, Eur. J. Org. Chem., 2017, 2017, 3897.

140. M. Beija, C. A. M. Afonso and J. M. G. Martinho, Chem. Soc. Rev., 2009, 38, 2410.

141. L. Yuan, W. Lin, Y. Yang and H. Chen, J. Am. Chem. Soc., 2011, 134, 1200.

142. Y. Koide, Y. Urano, K. Hanaoka, W. Piao, M. Kusakabe, N. Saito, T. Terai, T. Okabe and T. Nagano, J. Am. Chem. Soc., 2012, 134, 5029.

143. Y.-Q. Sun, J. Liu, X. Lv, Y. Liu, Y. Zhao and W. Guo, Angew. Chem. Int. Ed., 2012, 51, 7634.

144. M. S. Michie, R. Götz, C. Franke, M. Bowler, N. Kumari, V. Magidson, M. Levitus, J. Loncarek, M. Sauer and M. J. Schnermann, J. Am. Chem. Soc., 2017, 139, 12406.

145. S. S. Matikonda, G. Hammersley, N. Kumari, L. Grabenhorst, V. Glembockyte, P. Tinnefeld, J. Ivanic, M. Levitus and M. J. Schnermann, J. Org. Chem., 2020, 85, 5907.

146. Z. Lei, X. Li, X. Luo, H. He, J. Zheng, X. Qian and Y. Yang, Angew. Chem. Int. Ed., 2017, 56, 2979.

147. J. Bricks, A. Ryabitskii and A. Kachkovskii, Chem. Eur. J., 2010, 16, 8773 . 
148. O. V. Przhonska, H. Hu, S. Webster, J. L. Bricks, A. A Viniychuk, A. D. Kachkovski and Y. L. Slominsky, Chem. Phys., 2013, 411, 17.

149. J. Gayton, S. A. Autry, W. Meador, S. R. Parkin, G. A. Hill, N. I. Hammer and J. H. Delcamp, J. Org. Chem., 2019, 84, 687.

150. E. D. Cosco, J. R. Caram, O. T. Bruns, D. Franke, R. A. Day, E. P. Farr, M. G. Bawendi and E. M. Sletten, Angew. Chem. Int. Ed., 2017, 56, 13126.

151. E. D. Cosco, A. L. Spearman, S. Ramakrishnan, J. G. P. Lingg, M. Saccomano, M. Pengshung, B. A. Arús, K. C. Y. Wong, S. Glasl, V. Ntziachristos, M. Warmer, R. R. McLaughlin, O. T. Bruns and E. M. Sletten, Nat. Chem., 2020, 12, 1123.

152. O. Uranga-Barandiaran, D. Casanova and F. Castet, ChemPhysChem, 2020, 21, 2243.

153. M. Pengshung, P. Neal, T. L. Atallah, J. Kwon, J. R. Caram, S. A. Lopez and E. M. Sletten, Chem. Commun., 2020, 56, 6110.

154. A. Loudet and K. Burgess, Chem. Rev., 2007, 107, 4891.

155. H. Lu, J. Mack, Y. Yang and Z. Shen, Chem. Soc. Rev., 2014, 43, 4778.

156. Q. Huaulmé, A. Sutter, S. Fall, D. Jacquemin, P. Lévêque, P. Retailleau, G. Ulrich and N. Leclerc, J. Mater. Chem. C, 2018, 6, 9925.

157. Y. Ge and D. F. O'Shea, Chem. Soc. Rev., 2016, 45, 3846.

158. Z. Shi, X. Han, W. Hu, H. Bai, B. Peng, L. Ji, Q. Fan, L. Li and W. Huang, Chem. Soc. Rev., 2020, 49, 7533.

159. R. Gresser, M. Hummert, H. Hartmann, K. Leo and M. Riede, Chem. Eur. J., 2011, 17, 2939.

160. J. Killoran, L. Allen, J. F. Gallagher, W. M. Gallagher and D. F. Oshea, Chem. Commun., 2002, 1862.

161. Q. Bellier, S. Pégaz, C. Aronica, B. Le Guennic, C. Andraud and O. Maury, Org. Lett., 2010, 13, 22.

162. T. Uppal, X. Hu, F. R. Fronczek, S. Maschek, P. BobadovaParvanova and M. G. H. Vicente, Chem. Eur. J., 2012, 18, 3893.

163. Y. Wu, C. Cheng, L. Jiao, C. Yu, S. Wang, Y. Wei, X. Mu and E. Hao, Org. Lett., 2014, 16, 748.

164. H. Lim, S. Seo, S. Pascal, Q. Bellier, S. Rigaut, C. Park, H. Shin, O. Maury, C. Andraud and E. Kim, Sci. Rep., 2016, 6, 18867.

165. L. Jean-Gérard, W. Vasseur, F. Scherninski and B. Andrioletti, Chem. Commun., 2018, 54, 12914.

166. X.-D. Jiang, R. Gao, Y. Yue, G.-T. Sun and W. Zhao, Org. Biomol. Chem., 2012, 10, 6861.

167. A. Loudet, R. Bandichhor, K. Burgess, A. Palma, S. O. McDonnell, M. J. Hall and D. F. O'Shea, Org. Lett., 2008, 10, 4771.

168. H. Zhang, J. Liu, Y.-Q. Sun, M. Liu and W. Guo, J. Am. Chem. Soc., 2020, 142, 17069.

169. B. Le Guennic, O. Maury and D. Jacquemin, Phys. Chem. Chem. Phys., 2012, 14, 157.

170. G. M. Fischer, A. P. Ehlers, A. Zumbusch and E. Daltrozzo, Angew. Chem. Int. Ed., 2007, 46, 3750.

171. G. M. Fischer, M. Isomäki-Krondahl, I. GöttkerSchnetmann, E. Daltrozzo and A. Zumbusch, Chem. Eur. J., 2009, 15, 4857.

172. G. M. Fischer, E. Daltrozzo and A. Zumbusch, Angew. Chem. Int. Ed., 2011, 50, 1406.

173. R. Feng, N. Sato, T. Yasuda, H. Furuta and S. Shimizu, Chem. Commun., 2020, 56, 2975.

174. Q. Wu, Z. Kang, Q. Gong, X. Guo, H. Wang, D. Wang, L. Jiao and E. Hao, Org. Lett., 2020, 22, 7513.
175.

176.

177.

178.

179.

180.

181.

181.

182.

183.

184.

185.

186.

187.

188.

189.

190.

191.

194.

195.

196.

197.

198.

199.

200.

201.

202.

203.

204.

205.

206.

207.
A. Patra, L. J. Patalag, P. G. Jones and D. B. Werz, Angew. Chem. Int. Ed., 2021, 60, 747.

C. C. Barker and G. Hallas, J. Chem. Soc., 1961, 1529.

A. Barker and C. C. Barker, J. Chem. Soc., 1954, 1307.

H. Meier and S. Kim, Eur. J. Org. Chem., 2001, 2001, 1163.

S. Sengupta and S. Kumar Sadhukhan, J. Mater. Chem., 2000, 10, 1997.

S. Sengupta and S. K. Sadhukhan, J. Chem. Soc., Perkin Trans. 1, 2000, 4332.

I. H. Delgado, S. Pascal, A. Wallabregue, R. Duwald, C. Besnard, L. Guénée, C. Nançoz, E. Vauthey, R. C. Tovar, J. L. Lunkley, G. Muller and J. Lacour, Chem. Sci., 2016, 7, 4685. J. Bosson, G. M. Labrador, S. Pascal, F.-A. Miannay, O. Yushchenko, H. Li, L. Bouffier, N. Sojic, R. C. Tovar, G. Muller, D. Jacquemin, A. D. Laurent, B. Le Guennic, E. Vauthey and J. Lacour, Chem. Eur. J., 2016, 22, 18394.

E. L. Spitler, C. A. Johnson and M. M. Haley, Chem. Rev., 2006, 106, 5344.

T. Katakami, K. Fukui, T. Okamoto and M. Nakagawa, Bull. Chem. Soc. Jpn., 1976, 49, 297.

V. V. Roznyatovskiy, C.-H. Lee and J. L. Sessler, Chem. Soc. Rev., 2013, 42, 1921.

T. Okujima, C. Ando, S. Agrawal, H. Matsumoto, S. Mori, K. Ohara, I. Hisaki, T. Nakae, M. Takase, H. Uno and N. Kobayashi, J. Am. Chem. Soc., 2016, 138, 7540.

V. V. Roznyatovskiy, J. M. Lim, V. M. Lynch, B. S. Lee, D. Kim and J. L. Sessler, Org. Lett., 2011, 13, 5620.

J. P. Lewtak and D. T. Gryko, Chem. Commun., 2012, 48, 10069.

A. Tsuda and A. Osuka, Science, 2001, 293, 79.

H. S. Cho, D. H. Jeong, S. Cho, D. Kim, Y. Matsuzaki, K. Tanaka, A. Tsuda and A. Osuka, J. Am. Chem. Soc., 2002, 124, 14642.

H. Mori, T. Tanaka and A. Osuka, J. Mater. Chem. C, 2013, 1, 2500.

T. Tanaka and A. Osuka, Chem. Soc. Rev., 2015, 44, 943.

M. Toganoh and H. Furuta, Chem. Commun., 2012, 48, 937. Y. Matano, Chem. Rev., 2017, 117, 3138.

T. D. Lash, Org. Biomol. Chem., 2015, 13, 7846.

T. D. Lash, Chem. Rev., 2017, 117, 2313.

T. Sarma and P. K. Panda, Chem. Rev., 2017, 117, 2785.

Y. M. Sung, J. Oh, W.-Y. Cha, W. Kim, J. M. Lim, M.-C. Yoon and D. Kim, Chem. Rev., 2017, 117, 2257.

A. Alka, V. S. Shetti and M. Ravikanth, Coord. Chem. Rev., 2019, 401, 213063.

J. Waluk, Chem. Rev., 2017, 117, 2447.

S. Shimizu, Chem. Rev., 2017, 117, 2730.

B. Pucelik, A. Sułek and J. M. Dąbrowski, Coord. Chem. Rev., 2020, 416, 213340.

Y. Qin, X. Liu, P.-P. Jia, L. Xu and H.-B. Yang, Chem. Soc. Rev., 2020, 49, 5678.

T. Kubo, A. Shimizu, M. Sakamoto, M. Uruichi, K. Yakushi, M. Nakano, D. Shiomi, K. Sato, T. Takui, Y. Morita and K. Nakasuji, Angew. Chem., 2005, 117, 6722.

T. Kubo, A. Shimizu, M. Uruichi, K. Yakushi, M. Nakano, D. Shiomi, K. Sato, T. Takui, Y. Morita and K. Nakasuji, Org. Lett., 2007, 9, 81.

K. Kamada, K. Ohta, T. Kubo, A. Shimizu, Y. Morita, K. Nakasuji, R. Kishi, S. Ohta, S.-i. Furukawa, H. Takahashi and M. Nakano, Angew. Chem. Int. Ed., 2007, 46, 3544.

Z. Zeng, X. Shi, C. Chi, J. T. López Navarrete, J. Casado and J. Wu, Chem. Soc. Rev., 2015, 44, 6578. 
208. T. Y. Gopalakrishna, W. Zeng, X. Lu and J. Wu, Chem Commun., 2018, 54, 2186.

209. J. Ma, K. Zhang, K. S. Schellhammer, Y. Fu, H. Komber, C. Xu, A. A. Popov, F. Hennersdorf, J. J. Weigand, S. Zhou, W. Pisula, F. Ortmann, R. Berger, J. Liu and X. Feng, Chem. Sci., 2019, 10, 4025.

210. S. Mori, M. Akita, S. Suzuki, M. S. Asano, M. Murata, T. Akiyama, T. Matsumoto, C. Kitamura and S.-i. Kato, Chem. Commun., 2020, 56, 5881.

211. X. Hu, H. Chen, L. Zhao, M.-s. Miao, X. Zheng and Y. Zheng, J. Mater. Chem. C, 2019, 7, 10460.

212. G. Xue, X. Hu, H. Chen, L. Ge, W. Wang, J. Xiong, F. Miao and Y. Zheng, Chem. Commun., 2020, 56, 5143.

213. A. Konishi, K. Horii, D. Shiomi, K. Sato, T. Takui and M. Yasuda, J. Am. Chem. Soc., 2019, 141, 10165.

214. W. Wang, L. Ge, G. Xue, F. Miao, P. Chen, H. Chen, Y. Lin, Y. $\mathrm{Ni}$, J. Xiong, Y. Hu, J. Wu and Y. Zheng, Chem. Commun., 2020, 56, 1405.

215. R. Rausch, M. I. S. Röhr, D. Schmidt, I. Krummenacher, H. Braunschweig and F. Würthner, Chem. Sci., 2021, 12, 793.

216. T. Jousselin-Oba, M. Mamada, A. Okazawa, J. Marrot, T. Ishida, C. Adachi, A. Yassar and M. Frigoli, Chem. Sci., 2020, 20, 12194.

217. M. D. Ward and J. A. McCleverty, J. Chem. Soc., Dalton Trans., 2002, 275.

218. P. Deplano, L. Pilia, D. Espa, M. L. Mercuri and A. Serpe, Coord. Chem. Rev., 2010, 254, 1434.

219. S. Eid, M. Fourmigué, T. Roisnel and D. Lorcy, Inorg. Chem., 2007, 46, 10647.

220. M. C. Aragoni, M. Arca, F. Demartin, F. A. Devillanova, A Garau, F. Isaia, F. Lelj, V. Lippolis and G. Verani, J. Am. Chem. Soc., 1999, 121, 7098.

221. M. C. Aragoni, M. Arca, T. Cassano, C. Denotti, F. A. Devillanova, R. Frau, F. Isaia, F. Lelj, V. Lippolis, L. Nitti, P. Romaniello, R. Tommasi and G. Verani, Eur. J. Inorg. Chem., 2003, 2003, 1939.

222. H. Audi, Z. Chen, A. Charaf-Eddin, A. D'Aleo, G. Canard, D. Jacquemin and O. Siri, Chem. Commun., 2014, 50, 15140. S. Pascal and O. Siri, Coord. Chem. Rev., 2017, 350, 178.

224. L. Lavaud, Z. Chen, M. Elhabiri, D. Jacquemin, G. Canard and O. Siri, Dalton Trans., 2017, 46, 12794.

225. S. Tay, J. Thomas, M. Eralp, G. Li, B. Kippelen, S. R. Marder, G. Meredith, A. Schulzgen and N. Peyghambarian, Appl. Phys. Lett., 2004, 85, 4561.

226. L. Beverina, J. Fu, A. Leclercq, E. Zojer, P. Pacher, S. Barlow, E. W. Van Stryland, D. J. Hagan, J.-L. Brédas and S. R. Marder, J. Am. Chem. Soc., 2005, 127, 7282.

227. S. Zheng, A. Leclercq, J. Fu, L. Beverina, L. A. Padilha, E. Zojer, K. Schmidt, S. Barlow, J. Luo, S.-H. Jiang, A. K. Y. Jen, Y. Yi, Z. Shuai, E. W. Van Stryland, D. J. Hagan, J.-L. Brédas and S. R. Marder, Chem. Mater., 2007, 19, 432.

228. F. Ricci, B. Carlotti, B. Keller, C. Bonaccorso, C. G. Fortuna, T. Goodson, F. Elisei and A. Spalletti, J. Phys. Chem. C, 2017, 121, 3987.

229. G. Prévot, T. Bsaibess, J. Daniel, C. Genevois, G. Clermont I. Sasaki, S. Marais, F. Couillaud, S. Crauste-Manciet and M. Blanchard-Desce, Nanoscale Adv., 2020, 2, 1590.

230. B. J. Coe, J. Fielden, S. P. Foxon, M. Helliwell, B. S. Brunschwig, I. Asselberghs, K. Clays, J. Olesiak, K. Matczyszyn and M. Samoc, J. Phys. Chem. A, 2010, 114, 12028.
231.

Z. An, S. A. Odom, R. F. Kelley, C. Huang, X. Zhang, S. Barlow, L. A. Padilha, J. Fu, S. Webster, D. J. Hagan, E. W. Van Stryland, M. R. Wasielewski and S. R. Marder, J. Phys. Chem. A, 2009, 113, 5585.

232. Y. M. Poronik, L. M. Mazur, M. Samoć, D. Jacquemin and D. T. Gryko, J. Mater. Chem. C, 2017, 5, 2620.

233. D. H. Friese, A. Mikhaylov, M. Krzeszewski, Y. M. Poronik, A. Rebane, K. Ruud and D. T. Gryko, Chem. Eur. J., 2015, 21, 18364.

234. T. G. Allen, S. Benis, N. Munera, J. Zhang, S. Dai, T. Li, B. Jia, W. Wang, S. Barlow, D. J. Hagan, E. W. Van Stryland, X. Zhan, J. W. Perry and S. R. Marder, J. Phys. Chem. A, 2020, 124, 4367.

235. C. Ye, B. Wang, C. Ren, T. Zhang, Y. Gao, J. Zhang and T. He, Int. J. Quant. Chem., 2018, 118, e25690.

236. J. Fu, L. A. Padilha, D. J. Hagan, E. W. Van Stryland, O. V. Przhonska, M. V. Bondar, Y. L. Slominsky and A. D. Kachkovski, J. Opt. Soc. Am. B, 2007, 24, 56.

237. S. Webster, J. Fu, L. A. Padilha, O. V. Przhonska, D. J. Hagan, E. W. Van Stryland, M. V. Bondar, Y. L. Slominsky and A. D. Kachkovski, Chem. Phys., 2008, 348, 143.

238. J. M. Hales, J. Matichak, S. Barlow, S. Ohira, K. Yesudas, J.L. Brédas, J. W. Perry and S. R. Marder, Science, 2010, 327, 1485.

239. A. P. Demchenko (ed.), Advanced Fluorescence Reporters in Chemistry and Biology I: Fundamentals and Molecular Design, Springer, 2010.

240. F. Terenziani, O. V. Przhonska, S. Webster, L. A. Padilha, Y. L. Slominsky, I. G. Davydenko, A. O. Gerasov, Y. P. Kovtun, M. P. Shandura, A. D. Kachkovski, D. J. Hagan, E. W. Van Stryland and A. Painelli, J. Phys. Chem. Lett., 2010, 1, 1800. 241. P.-A. Bouit, G. Wetzel, G. Berginc, B. Loiseaux, L. Toupet, P. Feneyrou, Y. Bretonnière, K. Kamada, O. Maury and C. Andraud, Chem. Mater., 2007, 19, 5325.

242. Q. Bellier, N. S. Makarov, P.-A. Bouit, S. Rigaut, K. Kamada, P. Feneyrou, G. Berginc, O. Maury, J. W. Perry and C. Andraud, Phys. Chem. Chem. Phys., 2012, 14, 15299.

243. Z. Li, Y. Liu, H. Kim, J. M. Hales, S.-H. Jang, J. Luo, T. BaehrJones, M. Hochberg, S. R. Marder, J. W. Perry and A. K. Y. Jen, Adv. Mater., 2012, 24, OP326.

244. M. Y. Berezin, C. Zhan, H. Lee, C. Joo, W. J. Akers, S. Yazdanfar and S. Achilefu, J. Phys. Chem. B, 2011, 115, 11530.

245. G. S. He, J. Zhu, A. Baev, M. Samoć, D. L. Frattarelli, N. Watanabe, A. Facchetti, H. Ågren, T. J. Marks and P. N. Prasad, J. Am. Chem. Soc., 2011, 133, 6675.

246. Y. Shi, A. J. T. Lou, G. S. He, A. Baev, M. T. Swihart, P. N. Prasad and T. J. Marks, J. Am. Chem. Soc., 2015, 137, 4622.

247. A. J. T. Lou, S. Benis, M. Gao, A. Baev, D. Kim, E. W. Van Stryland, D. J. Hagan and T. J. Marks, J. Phys. Chem. C, 2020, 124, 5363.

248. J. M. Hales, S. Zheng, S. Barlow, S. R. Marder and J. W. Perry, J. Am. Chem. Soc., 2006, 128, 11362.

249. L. A. Padilha, S. Webster, O. V. Przhonska, H. Hu, D. Peceli, J. L. Rosch, M. V. Bondar, A. O. Gerasov, Y. P. Kovtun, M. P. Shandura, A. D. Kachkovski, D. J. Hagan and E. W. Van Stryland, J. Mater. Chem., 2009, 19, 7503.

250. L. A. Padilha, S. Webster, O. V. Przhonska, H. Hu, D. Peceli, T. R. Ensley, M. V. Bondar, A. O. Gerasov, Y. P. Kovtun, M. P. Shandura, A. D. Kachkovski, D. J. Hagan and E. W. V. Stryland, J. Phys. Chem. A, 2010, 114, 6493. 
251. J. M. Hales, S. Barlow, H. Kim, S. Mukhopadhyay, J.-L. Brédas, J. W. Perry and S. R. Marder, Chem. Mater., 2013, 26, 549.

252. R. L. Gieseking, S. Mukhopadhyay, C. Risko, S. R. Marder and J.-L. Brédas, Adv. Mater., 2014, 26, 68.

253. H. Hu, O. V. Przhonska, F. Terenziani, A. Painelli, D. Fishman, T. R. Ensley, M. Reichert, S. Webster, J. L. Bricks, A. D. Kachkovski, D. J. Hagan and E. W. Van Stryland, Phys. Chem. Chem. Phys., 2013, 15, 7666.

254. K. J. Thorley, J. M. Hales, H. Kim, S. Ohira, J.-L. Brédas, J. W. Perry and H. L. Anderson, Chem. Eur. J., 2013, 19, 10370.

255. J. Fu, L. A. Padilha, D. J. Hagan, E. W. Van Stryland, O. V. Przhonska, M. V. Bondar, Y. L. Slominsky and A. D. Kachkovski, J. Opt. Soc. Am. B, 2007, 24, 67.

256. D. Scherer, R. Dörfler, A. Feldner, T. Vogtmann, M. Schwoerer, U. Lawrentz, W. Grahn and C. Lambert, Chem. Phys., 2002, 279, 179.

257. B. T. Makowski, B. Valle, K. D. Singer and C. Weder, J. Mater. Chem., 2012, 22, 2848.

258. T. Liu, M. V. Bondar, K. D. Belfield, D. Anderson, A. E. Masunov, D. J. Hagan and E. W. V. Stryland, J. Phys. Chem. C, 2016, 120, 11099.

259. K. D. Belfield, M. V. Bondar, H. S. Haniff, I. A. Mikhailov, G. Luchita and O. V. Przhonska, ChemPhysChem, 2013, 14, 3532.

260. Q. Shi, W.-Q. Chen, J. Xiang, X.-M. Duan and X. Zhan, Macromolecules, 2011, 44, 3759.

261. Y. M. Poronik, V. Hugues, M. Blanchard-Desce and D. T. Gryko, Chem. Eur. J., 2012, 18, 9258.

262. H. Ceymann, A. Rosspeintner, M. H. Schreck, C. Mützel, A. Stoy, E. Vauthey and C. Lambert, Phys. Chem. Chem. Phys., 2016, 18, 16404.

263. Q. Zheng, G. Xu and P. N. Prasad, Chem. Eur. J., 2008, 14, 5812.

264. Q. Zheng, G. S. He and P. N. Prasad, Chem. Phys. Lett., 2009, 475, 250 .

265. P.-A. Bouit, K. Kamada, P. Feneyrou, G. Berginc, L. Toupet, O. Maury and C. Andraud, Adv. Mater., 2009, 21, 1151.

266. S. Chibani, B. Le Guennic, A. Charaf-Eddin, O. Maury, C. Andraud and D. Jacquemin, J. Chem. Theory Comput., 2012, 8, 3303.

267. B. Küçüköz, M. Hayvalı, H. Yılmaz, B. Uğuz, U. Kürüm, H. G. Yaglioglu and A. Elmali, J. Photochem. Photobiol. A, 2012, 247, 24.

268. S. Tekin, B. Küçüköz, H. Yılmaz, G. Sevinç, M. Hayvalı, H. Gul Yaglioglu and A. Elmali, J. Photochem. Photobiol. A, 2013, 256, 23.

269. X. Zhang, Y. Xiao, J. Qi, J. Qu, B. Kim, X. Yue and K. D. Belfield, J. Org. Chem., 2013, 78, 9153.

270. X. Liu, J. Zhang, K. Li, X. Sun, Z. Wu, A. Ren and J. Feng, Phys. Chem. Chem. Phys., 2013, 15, 4666.

271. S. Pascal, Q. Bellier, S. David, P.-A. Bouit, S.-H. Chi, N. S. Makarov, B. Le Guennic, S. Chibani, G. Berginc, P. Feneyrou, D. Jacquemin, J. W. Perry, O. Maury and C. Andraud, J. Phys. Chem. C, 2019, 123, 23661.

272. S. David, H.-J. Chang, C. Lopes, C. Brännlund, B. Le Guennic, G. Berginc, E. Van Stryland, M. V. Bondar, D. Hagan, D. Jacquemin, C. Andraud and O. Maury, Chem. Eur. J., 2021, 27, 3517.

273. M. O. Senge, M. Fazekas, E. G. A. Notaras, W. J. Blau, M. Zawadzka, O. B. Locos and E. M. Ni Mhuircheartaigh, Adv. Mater., 2007, 19, 2737.
274.

275.

276.

\section{7.}

278.

279.

280.

281.

282.

\section{3.}

284.

285.

286.

\section{7.}

288.

289.

290.

291.

292.

293.

294.

295.

296.

297.

298.

K. S. Kim, J. M. Lim, A. Osuka and D. Kim, J. Photochem. Photobiol., C, 2008, 9, 13.

T.-G. Zhang, Y. Zhao, I. Asselberghs, A. Persoons, K. Clays and M. J. Therien, J. Am. Chem. Soc., 2005, 127, 9710.

J. E. Reeve, H. A. Collins, K. D. Mey, M. M. Kohl, K. J. Thorley, O. Paulsen, K. Clays and H. L. Anderson, J. Am. Chem. Soc., 2009, 131, 2758.

M. M. Ayhan, A. Singh, E. Jeanneau, V. Ahsen, J. Zyss, I. Ledoux-Rak, A. G. Gürek, C. Hirel, Y. Bretonnière and C. Andraud, Inorg. Chem., 2014, 53, 4359.

M. Kruk, A. Karotki, M. Drobizhev, V. Kuzmitsky, V. Gael and A. Rebane, J. Lumin., 2003, 105, 45.

J. Arnbjerg, A. Jiménez-Banzo, M. J. Paterson, S. Nonell, J. I. Borrell, O. Christiansen and P. R. Ogilby, J. Am. Chem. Soc., 2007, 129, 5188.

A. Rebane, M. Drobizhev, N. S. Makarov, B. Koszarna, M. Tasior and D. T. Gryko, Chem. Phys. Lett., 2008, 462, 246.

A. I. Plekhanov, T. V. Basova, R. G. Parkhomenko and A. G. Gürek, Opt. Mater., 2017, 64, 13.

J. L. Humphrey and D. Kuciauskas, J. Am. Chem. Soc., 2006, 128, 3902.

T. C. Wen, L. C. Hwang, W. Y. Lin, C. H. Chen and C. H. Wu, Chem. Phys., 2003, 286, 293.

J. Humphrey and D. Kuciauskas, J. Phys. Chem. B, 2004, 108, 12016.

A. Karotki, M. Drobizhev, M. Kruk, C. Spangler, E. Nickel, N. Mamardashvili and A. Rebane, J. Opt. Soc. Am. B, 2003, 20, 321.

K. S. Kim, S. B. Noh, T. Katsuda, S. Ito, A. Osuka and D. Kim, Chem. Commun., 2007, 2479.

Y. Luo, O. Rubio-Pons, J.-D. Guo and H. Agren, J. Chem. Phys., 2005, 122, 096101.

M. Drobizhev, F. Meng, A. Rebane, Y. Stepanenko, E. Nickel and C. W. Spangler, J. Phys. Chem. B, 2006, 110, 9802.

P. C. Jha, B. Minaev and H. Agren, J. Chem. Phys., 2008, 128, 074302.

P. C. Ray and Z. Sainudeen, J. Phys. Chem. A, 2006, 110, 12342.

A. Nowak-Król, C. J. Wilson, M. Drobizhev, D. V. Kondratuk, A. Rebane, H. L. Anderson and D. T. Gryko, ChemPhysChem, 2012, 13, 3966.

M. Drobizhev, N. S. Makarov, Y. Stepanenko and A. Rebane, J. Chem. Phys., 2006, 124, 224701.

M. Drobizhev, N. S. Makarov, A. Rebane, G. de la Torre and T. Torres, J. Phys. Chem. C, 2008, 112, 848.

A. Nowak-Król, M. Grzybowski, J. Romiszewski, M. Drobizhev, G. Wicks, M. Chotkowski, A. Rebane, E. Górecka and D. T. Gryko, Chem. Commun., 2013, 49, 8368.

K. Kurotobi, K. S. Kim, S. B. Noh, D. Kim and A. Osuka, Angew. Chem. Int. Ed., 2006, 45, 3944.

W. Zeng, B. S. Lee, Y. M. Sung, K.-W. Huang, Y. Li, D. Kim and J. Wu, Chem. Commun., 2012, 48, 7684.

Z. S. Yoon, D.-G. Cho, K. S. Kim, J. L. Sessler and D. Kim, J. Am. Chem. Soc., 2008, 130, 6930.

T. K. Ahn, J. H. Kwon, D. Y. Kim, D. W. Cho, D. H. Jeong, S. K. Kim, M. Suzuki, S. Shimizu, A. Osuka and D. Kim, J. Am. Chem. Soc., 2005, 127, 12856.

S. Mori, K. S. Kim, Z. S. Yoon, S. B. Noh, D. Kim and A. Osuka, J. Am. Chem. Soc., 2007, 129, 11344.

J. M. Lim, Z. S. Yoon, J.-Y. Shin, K. S. Kim, M.-C. Yoon and D. Kim, Chem. Commun., 2009, 261. 
301. Y. Hisamune, K. Nishimura, K. Isakari, M. Ishida, S. Mori, S. Karasawa, T. Kato, S. Lee, D. Kim and H. Furuta, Angew. Chem. Int. Ed., 2015, 54, 7323.

302. R. Herges, Chem. Rev., 2006, 106, 4820.

303. J. K. Park, Z. S. Yoon, M.-C. Yoon, K. S. Kim, S. Mori, J.-Y. Shin, A. Osuka and D. Kim, J. Am. Chem. Soc., 2008, 130, 1824.

304. A. Osuka and S. Saito, Chem. Commun., 2011, 47, 4330.

305. Y. Tanaka, S. Saito, S. Mori, N. Aratani, H. Shinokubo, N. Shibata, Y. Higuchi, Z. S. Yoon, K. S. Kim, S. B. Noh, J. K. Park, D. Kim and A. Osuka, Angew. Chem., 2008, 120, 693.

306. Z. Liu and T. Lu, J. Phys. Chem. C, 2020, 124, 845.

307. T. K. Ahn, K. S. Kim, D. Y. Kim, S. B. Noh, N. Aratani, C. Ikeda, A. Osuka and D. Kim, J. Am. Chem. Soc., 2006, 128, 1700.

308. D. Y. Kim, T. K. Ahn, J. H. Kwon, D. Kim, T. Ikeue, N. Aratani, A. Osuka, M. Shigeiwa and S. Maeda, J. Phys. Chem. A, 2005, 109, 2996.

309. Y. Inokuma, N. Ono, H. Uno, D. Y. Kim, S. B. Noh, D. Kim and A. Osuka, Chem. Commun., 2005, 3782.

310. S. Hiroto, K. Furukawa, H. Shinokubo and A. Osuka, J. Am. Chem. Soc., 2006, 128, 12380.

311. S. Cho, J. M. Lim, S. Hiroto, P. Kim, H. Shinokubo, A. Osuka and D. Kim, J. Am. Chem. Soc., 2009, 131, 6412.

312. M.-C. Yoon, S. B. Noh, A. Tsuda, Y. Nakamura, A. Osuka and D. Kim, J. Am. Chem. Soc., 2007, 129, 10080.

313. Y. Nakamura, S. Y. Jang, T. Tanaka, N. Aratani, J. M. Lim, K. S. Kim, D. Kim and A. Osuka, Chem. Eur. J., 2008, 14, 8279.

314. Y. Nakamura, N. Aratani, H. Shinokubo, A. Takagi, T. Kawai, T. Matsumoto, Z. S. Yoon, D. Y. Kim, T. K. Ahn, D. Kim, A. Muranaka, N. Kobayashi and A. Osuka, J. Am. Chem. Soc., 2006, 128, 4119.

315. M. Drobizhev, Y. Stepanenko, A. Rebane, C. J. Wilson, T. E. O. Screen and H. L. Anderson, J. Am. Chem. Soc., 2006, 128, 12432.

316. S. A. Odom, R. F. Kelley, S. Ohira, T. R. Ensley, C. Huang, L. A. Padilha, S. Webster, V. Coropceanu, S. Barlow, D. J. Hagan, E. W. Van Stryland, J.-L. Brédas, H. L. Anderson, M. R. Wasielewski and S. R. Marder, J. Phys. Chem. A, 2009, 113, 10826.

317. X. Huang, Q. Shi, W.-Q. Chen, C. Zhu, W. Zhou, Z. Zhao, X.M. Duan and X. Zhan, Macromolecules, 2010, 43, 9620.

318. W. Zhou, F. Jin, X. Huang, X.-M. Duan and X. Zhan, Macromolecules, 2012, 45, 7823.

319. J. M. Hales, M. Cozzuol, T. E. O. Screen, H. L. Anderson and J. W. Perry, Opt. Express, 2009, 17, 18478.

320. S. Webster, S. A. Odom, L. A. Padilha, O. V. Przhonska, D. Peceli, H. Hu, G. Nootz, A. D. Kachkovski, J. Matichak, S. Barlow, H. L. Anderson, S. R. Marder, D. J. Hagan and E. W. Van Stryland, J. Phys. Chem. B, 2009, 113, 14854.

321. K. J. Thorley, J. M. Hales, H. L. Anderson and J. W. Perry, Angew. Chem., 2008, 120, 7203.

322. M. Abe, Chem. Rev., 2013, 113, 7011.

323. M. Nakano, R. Kishi, S. Ohta, H. Takahashi, T. Kubo, K. Kamada, K. Ohta, E. Botek and B. Champagne, Phys. Rev. Lett., 2007, 99, 033001.

324. K. Kamada, K. Ohta, A. Shimizu, T. Kubo, R. Kishi, H. Takahashi, E. Botek, B. Champagne and M. Nakano, J. Phys. Chem. Lett., 2010, 1, 937.

325. M. Nakano and B. Champagne, WIREs Comput. Mol. Sci., 2016, 6, 198.

326. Z. Zeng, Y. M. Sung, N. Bao, D. Tan, R. Lee, J. L. Zafra, B. S. Lee, M. Ishida, J. Ding, J. T. López Navarrete, Y. Li, W. Zeng,
D. Kim, K.-W. Huang, R. D. Webster, J. Casado and J. Wu, J. Am. Chem. Soc., 2012, 134, 14513.

327. Y. Li, W.-K. Heng, B. S. Lee, N. Aratani, J. L. Zafra, N. Bao, R. Lee, Y. M. Sung, Z. Sun, K.-W. Huang, R. D. Webster, J. T. López Navarrete, D. Kim, A. Osuka, J. Casado, J. Ding and J. Wu, J. Am. Chem. Soc., 2012, 134, 14913.

328. Z. Sun, S. Lee, K. H. Park, X. Zhu, W. Zhang, B. Zheng, P. Hu, Z. Zeng, S. Das, Y. Li, C. Chi, R.-W. Li, K.-W. Huang, J. Ding, D. Kim and J. Wu, J. Am. Chem. Soc., 2013, 135, 18229.

329. Y.-C. Hsieh, H.-Y. Fang, Y.-T. Chen, R. Yang, C.-I. Yang, P.-T. Chou, M.-Y. Kuo and Y.-T. Wu, Angew. Chem. Int. Ed., 2015, 54, 3069.

330. A. Konishi, Y. Hirao, K. Matsumoto, H. Kurata, R. Kishi, Y. Shigeta, M. Nakano, K. Tokunaga, K. Kamada and T. Kubo, J. Am. Chem. Soc., 2013, 135, 1430.

331. X. Shi, P. M. Burrezo, S. Lee, W. Zhang, B. Zheng, G. Dai, J. Chang, J. T. López Navarrete, K.-W. Huang, D. Kim, J. Casado and C. Chi, Chem. Sci., 2014, 5, 4490.

332. Z. Zeng, M. Ishida, J. L. Zafra, X. Zhu, Y. M. Sung, N. Bao, R. D. Webster, B. S. Lee, R.-W. Li, W. Zeng, Y. Li, C. Chi, J. T. L. Navarrete, J. Ding, J. Casado, D. Kim and J. Wu, J. Am. Chem. Soc., 2013, 135, 6363.

333. Z. Zeng, S. Lee, M. Son, K. Fukuda, P. M. Burrezo, X. Zhu, Q. Qi, R.-W. Li, J. T. L. Navarrete, J. Ding, J. Casado, M. Nakano, D. Kim and J. Wu, J. Am. Chem. Soc., 2015, 137, 8572.

334. D. Schmidt, M. Son, J. M. Lim, M.-J. Lin, I. Krummenacher, H. Braunschweig, D. Kim and F. Würthner, Angew. Chem. Int. Ed., 2015, 54, 13980.

335. K. Kamada, S.-I. Fukuen, S. Minamide, K. Ohta, R. Kishi, M. Nakano, H. Matsuzaki, H. Okamoto, H. Higashikawa, K. Inoue, S. Kojima and Y. Yamamoto, J. Am. Chem. Soc., 2012, $135,232$.

336. Y. Ni, S. Lee, M. Son, N. Aratani, M. Ishida, A. Samanta, H. Yamada, Y.-T. Chang, H. Furuta, D. Kim and J. Wu, Angew. Chem. Int. Ed., 2016, 55, 2815.

337. W. Zeng, M. Ishida, S. Lee, Y. M. Sung, Z. Zeng, Y. Ni, C. Chi, D. Kim and J. Wu, Chem. Eur. J., 2013, 19, 16814.

338. H. Zhang, J. Kim, H. Phan, T. S. Herng, T. Y. Gopalakrishna, W. Zeng, J. Ding, D. Kim and J. Wu, J. Porphyrins Phthalocyanines, 2020, 24, 220.

339. J.-Y. Cho, S. Barlow, S. R. Marder, J. Fu, L. A. Padilha, E. W. Van Stryland, D. J. Hagan and M. Bishop, Opt. Lett., 2007, 32, 671 .

340. S. Rigaut, C. Olivier, K. Costuas, S. Choua, O. Fadhel, J. Massue, P. Turek, J.-Y. Saillard, P. H. Dixneuf and D. Touchard, J. Am. Chem. Soc., 2006, 128, 5859.

341. M. H. Smith, R. L. Fork and S. T. Cole, Opt. Express, 2001, 8, 537.

342. J. Bailey, A. Simpson and D. Crisp, Publ. Astron. Soc. Pac., 2007, 119, 228.

343. M. J. Miller, A. G. Mott and B. P. Ketchel, Proc. SPIE, 1998, 3472, 1.

344. D. Dini, M. J. Calvete and M. Hanack, Chem. Rev., 2016, 116, 13043.

345. Q. Zheng, G. S. He, C. Lu and P. N. Prasad, J. Mater. Chem., 2005, 15, 3488.

346. G. S. He, Z. Qingdong, L. Changgui and P. N. Prasad, IEEE J. Quantum Electron., 2005, 41, 1037.

347. Q. Zheng, G. S. He, A. Baev and P. N. Prasad, J. Phys. Chem. $B, 2006,110,14604$.

T.-C. Lin, G. S. He, Q. Zheng and P. N. Prasad, J. Mater. Chem., 2006, 16, 2490. 
349. C. Lu, W. Huang, J. Luan, Z. Lu, Y. Qian, B. Yun, G. Hu, Z. Wang and Y. Cui, Opt. Commun., 2008, 281, 4038.

350. T.-C. Lin, Q. Zheng, C.-Y. Chen, G. S. He, W.-J. Huang, A. I. Ryasnyanskiy and P. N. Prasad, Chem. Commun., 2008, 389.

351. G. S. He, Q. Zheng, K.-T. Yong, A. I. Ryasnyanskiy, P. N. Prasad and A. Urbas, Appl. Phys. Lett., 2007, 90, 181108.

352. J. W. Perry, K. Mansour, I.-Y. S. Lee, X.-L. Wu, P. V. Bedworth, C.-T. Chen, D. Ng, S. R. Marder, P. Miles, T. Wada, M. Tian and H. Sasabe, Science, 1996, 273, 1533.

353. R. Anemian, Y. Morel, P. L. Baldeck, B. Paci, K. Kretsch, J.M. Nunzi and C. Andraud, J. Mater. Chem., 2003, 13, 2157.

354. J. Kleinschmidt, S. Rentsch, W. Tottleben and B. Wilhelmi, Chem. Phys. Lett., 1974, 24, 133.

355. P.-A. Bouit, R. Westlund, P. Feneyrou, O. Maury, M. Malkoch, E. Malmstrom and C. Andraud, New J. Chem., 2009, 33, 964.

356. Q. Bellier, N. S. Makarov, P. A. Bouit, S. Rigaut, K. Kamada, P. Feneyrou, G. Berginc, O. Maury, J. W. Perry and C. Andraud, Phys. Chem. Chem. Phys., 2012, 14, 15299.

357. D. Chateau, Q. Bellier, F. Chaput, P. Feneyrou, G. Berginc, O. Maury, C. Andraud and S. Parola, J. Mater. Chem. C, 2014, 2, 5105.

358. S. David, D. Chateau, H.-J. Chang, L. H. Karlsson, M. V. Bondar, C. Lopes, B. Le Guennic, D. Jacquemin, G. Berginc, O. Maury, S. Parola and C. Andraud, J. Phys. Chem. C, 2020, 124, 24344.

359. H. Terasawa, F. Tan, O. Sugihara, A. Kawasaki, D. Inoue, T. Yamashita, M. Kagami, O. Maury, Y. Bretonnière and C. Andraud, Opt. Lett., 2017, 42, 2236.

360. F. Tan, H. Terasawa, O. Sugihara, A. Kawasaki, T. Yamashita, D. Inoue, M. Kagami and C. Andraud, J. Light. Technol., 2018, 36, 2478. 


\section{Authors' biographies}

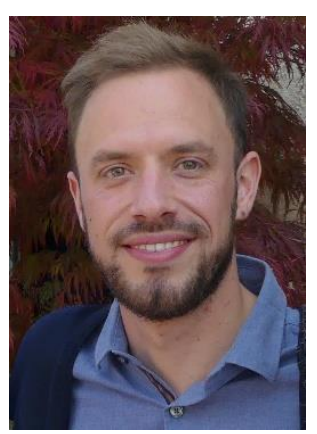

Simon Pascal studied molecular chemistry at the University of Rennes, and then obtained his PhD in 2014 at the Ecole Normale Supérieure in Lyon, developing polymethine dyes for nonlinear optics, under the direction of Drs C. Andraud and O. Maury. After a postdoctoral stay at the University of Geneva, investigating cationic helicenes with Prof. J. Lacour, he was appointed Chargé de Recherche CNRS in 2016 at the Interdisciplinary Centre of Nanoscience in Marseille (CINaM) in the team of Dr. O. Siri, where he is exploring the chemistry of colourful quinones and macrocycles.

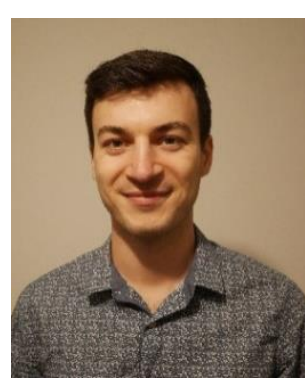

Sylvain David studied organic chemistry and chemical engineering at Ecole Centrale in Marseille and University Pierre et Marie Curie in Paris. He has then graduated from his $P h D$ in 2020 at Ecole Normale Supérieure de Lyon where he worked on an industrial project conducted by Thales LAS company under the supervision of Drs. C. Andraud and G. Berginc. His research project focused on the design of aza-bodipy based optical power limiting devices.

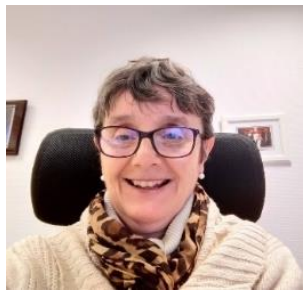

Chantal Andraud obtained a first PhD at the University of Clermont-Ferrand on spectroscopic properties of lanthanide fluorides in the KY3F1O matrix and a second one at Pierre and Marie Curie University in Paris on spectroscopic studies of lead defects in an unilamellar inorganic system, during which she was appointed as Chargée de Recherche in CNRS in 1983. She moved to the Laboratory of Chemistry of Ecole Normale Supérieure de Lyon in 1990, where she was appointed as Directeur de Recherche in CNRS, and where she created the team "Chemistry for Optics". She has been at the head of the Laboratory since ten years. She develops molecular engineering particularly in NIR, for different photoinduced different effects and particularly in the field on nonlinear optics such as multiphoton absorption, for various applications in telecommunications, defense and biology.

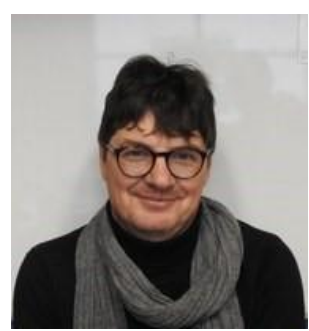

Olivier Maury was graduated from the Ecole Nationale Supérieure de Chimie de Paris in 1993 and obtained a master degree in inorganic and physicalchemistry. He completed his PhD in 1997 under the supervision of $M$. Ephritikhine in Paris on low-valent uranium organometallic chemistry. After a post-doctoral position with J.-M. Basset in Lyon in organometallic supported catalysis, he got a CNRS position as Chargé de Recherche in 1999 at the University of Rennes in the group of $\mathrm{H}$. Le Bozec where he started exploring the nonlinear optical properties of lanthanide complexes. In 2004 he moved to the Ecole Normale Supérieure de Lyon in the team of C. Andraud. His current research interests concern the design of lanthanides containing molecular materials and NIR chromophores with optimized spectroscopic properties towards optical limiting purposes, biological imaging, protein crystallization and photodynamic therapy applications. 